Florida International University FIU Digital Commons

6-28-2010

\title{
Sex-Specific Patterns of Movement and Space Use in the Strawberry Poison Frog, Oophaga pumilio
}

Seiichi Murasaki

Florida International University, smura002@fiu.edu

DOI: $10.25148 /$ etd.FI10080418

Follow this and additional works at: https://digitalcommons.fiu.edu/etd

\section{Recommended Citation}

Murasaki, Seiichi, "Sex-Specific Patterns of Movement and Space Use in the Strawberry Poison Frog, Oophaga pumilio" (2010). FIU Electronic Theses and Dissertations. 226.

https://digitalcommons.fiu.edu/etd/226 


\title{
FLORIDA INTERNATIONAL UNIVERSITY
}

Miami, Florida

\section{SEX-SPECIFIC PATTERNS OF MOVEMENT AND SPACE USE IN THE STRAWBERRY POISON FROG, OOPHAGA PUMILIO}

\author{
A thesis submitted in partial fulfillment of the \\ requirements for the degree of \\ MASTER OF SCIENCE \\ in \\ BIOLOGY \\ by
}

Seiichi Murasaki

2010 
To: Dean Kenneth Furton

College of Arts and Sciences

This thesis, written by Seiichi Murasaki, and entitled Sex-Specific Patterns of Movement and Space Use in the Strawberry Poison Frog, Oophaga pumilio, having been approved in respect to style and intellectual content, is referred to you for judgment.

We have read this thesis and recommend that it be approved.

Jennifer Gebelein

Philip Stoddard

Maureen Donnelly, Major Professor

Date of Defense: June 28, 2010

The thesis of Seiichi Murasaki is approved.

Dean Kenneth Furton
College of Arts and Sciences

Interim Dean Kevin O'Shea

University Graduate School

Florida International University, 2010 


\section{DEDICATION}

To Akiko 


\section{ACKNOWLEDGMENTS}

I would like to express my gratitude to those who supported me through the years that have (finally) brought me to this point. I thank both of my families: first, the family I mostly did not choose (but would never give up; especially my parents, Akiko, Ryo, Rina, and Maya) and then the family I did choose (at FIU). In particular, I thank Mo, who accepted me into her lab, provided me with the raw data, and (tirelessly) guided me through graduate school towards the prize. I thank Steve Oberbauer for his quiet encouragement over the years, and my academic siblings (Steven, Vivian, Justin, Kelsey, Monica, Paolo, and Lilly) for enriching my graduate school life. I would also like to thank Philip Stoddard and Jennifer Gebelein for their support and understanding as I prepared this thesis. 


\begin{abstract}
OF THE THESIS
SEX-SPECIFIC PATTERNS OF MOVEMENT AND SPACE USE IN THE

STRAWBERRY POISON FROG, OOPHAGA PUMILIO

by
\end{abstract}

Seiichi Murasaki

Florida International University, 2010

Miami, Florida

\title{
Professor Maureen Donnelly, Major Professor
}

The home range encompasses an animal's movements as it goes about its normal activity, and several home range estimators have been developed. I evaluated the performance of the Minimum Convex Polygon, Bivariate Normal, and several kernel home range estimators in a geographical information system environment using simulations and a large database of $O$. pumilio mark-recapture locations. A fixed $90 \%$ kernel estimator using Least-Square Cross-Validation (to select the bandwidth) outperformed other methods of estimating home range size and was effective with relatively few capture points. Home range size, core area size, intrasexual overlap, and movement rates among coordinates were higher in female frogs than in male frogs. These measures likely reflect behavioral differences related to territoriality (males only) and parental care (both sexes). The simple Biological Index of Vagility (BIV) generated movement values that scaled well with home range size while revealing more information than home range estimates alone. 


\section{TABLE OF CONTENTS}

CHAPTER

PAGE

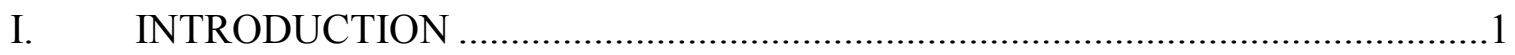

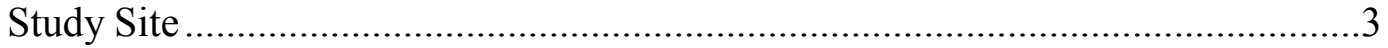

Experimental Design ..............................................................................

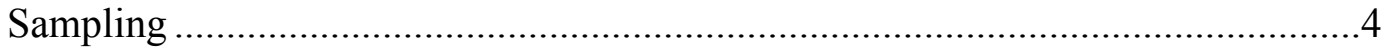

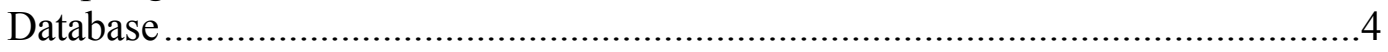

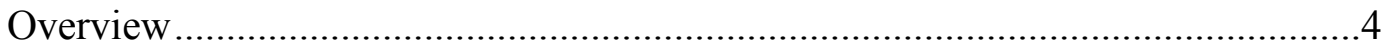

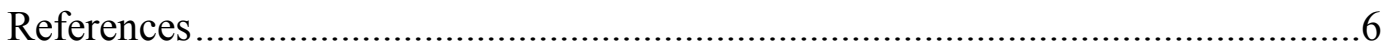

II. COMPARISON OF HOME RANGE ESTIMATORS AT SMALL SCALES .....12

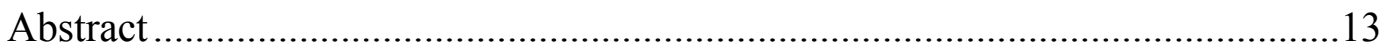

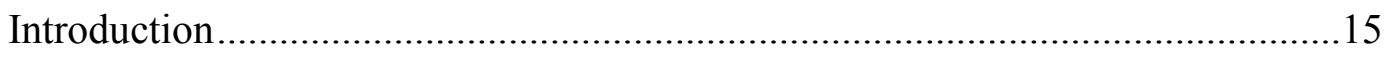

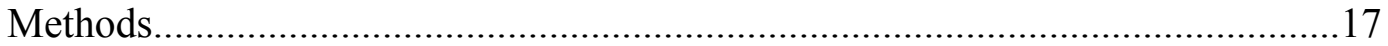

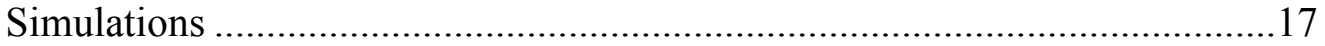

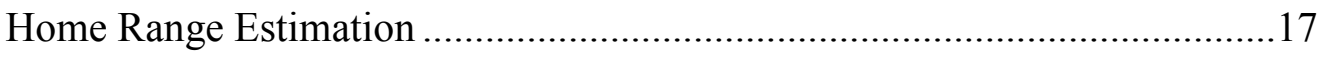

Minimum Convex Polygon............................................................................ 18

Bivariate Normal Ellipses .........................................................................18

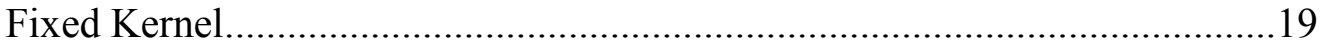

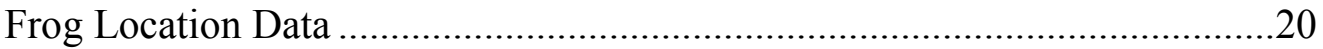

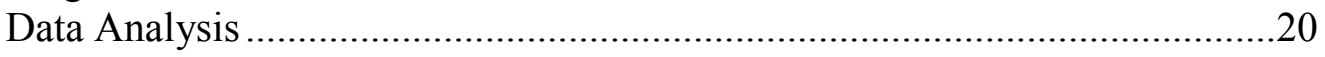

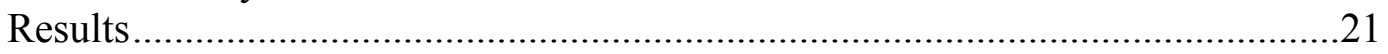

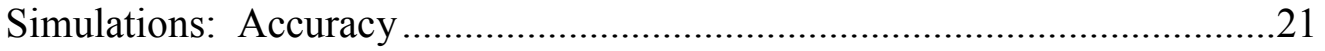

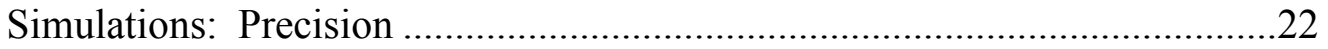

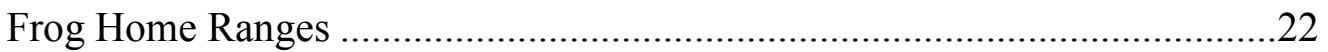

Comparison to the Population Utilization Distribution method ........................23

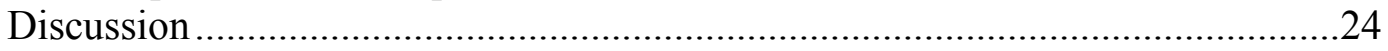

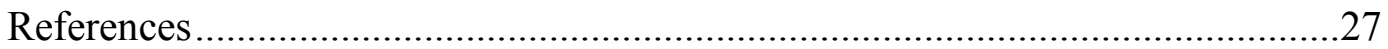

III. SEX-SPECIFIC PATTERNS OF MOVEMENT AND SPACE USE IN THE

STRAWBERRY POISON FROG, OOPHAGA PUMILIO ..................................50

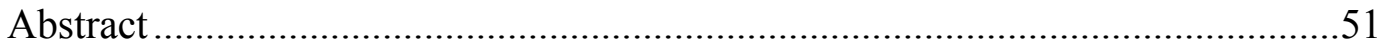

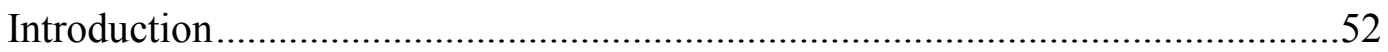

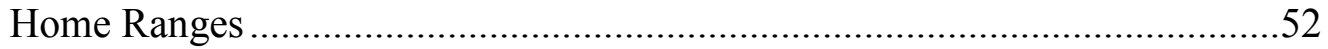

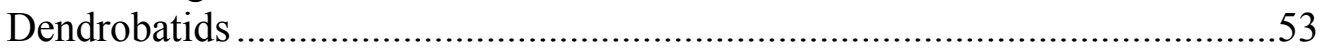

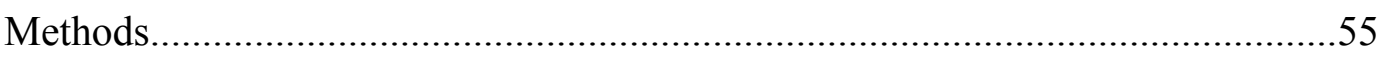

Home Range and Core Area Estimation .....................................................56

Overlap of Home Ranges and Core Areas ..................................................56

The Biological Index of Vagility .................................................................57

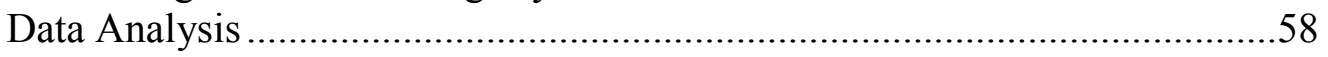

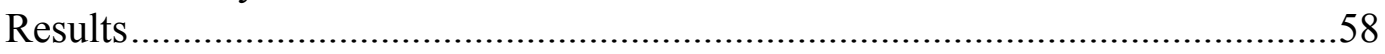

Home Ranges and Core Areas ..................................................................58

Overlap of Home Ranges and Core Areas .....................................................60 
The Biological Index of Vagility ............................................................60

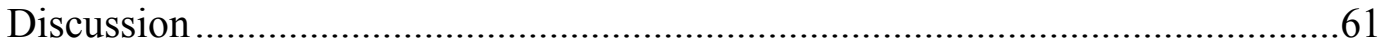

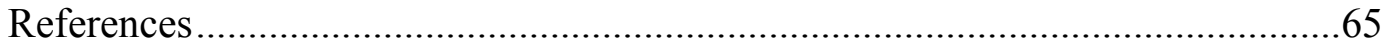

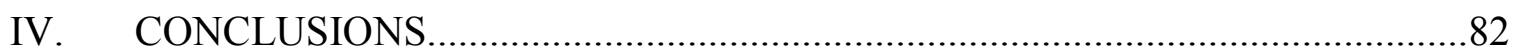

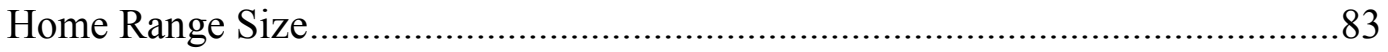

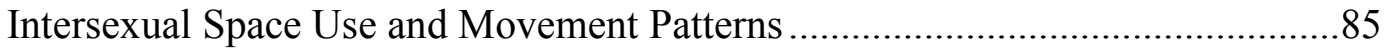

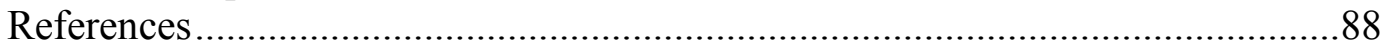




\section{LIST OF TABLES}

TABLE

PAGE

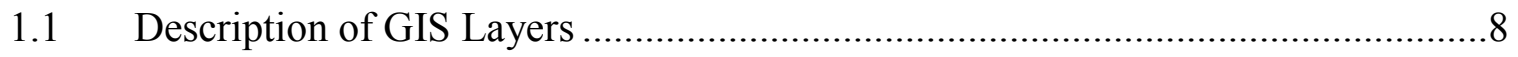

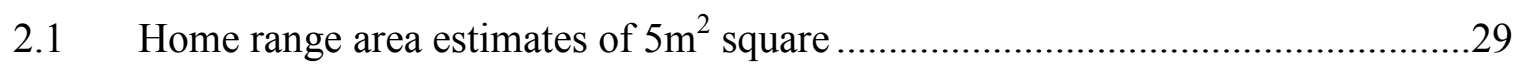

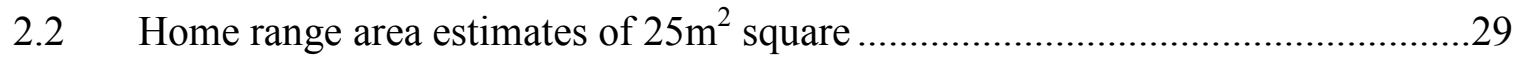

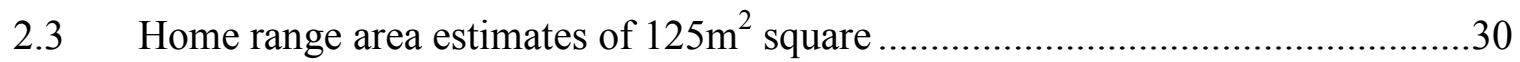

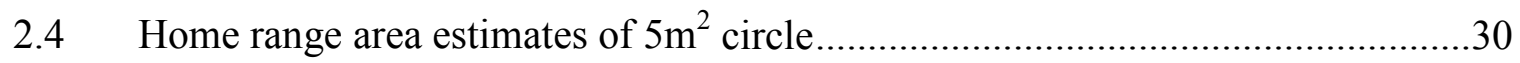

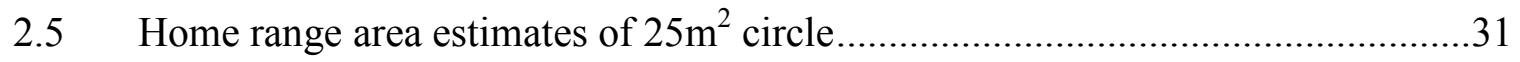

2.6 Home range area estimates of $125 \mathrm{~m}^{2}$ circle................................................... 31

2.7 Welch's t-tests values from square home ranges ........................................ 32

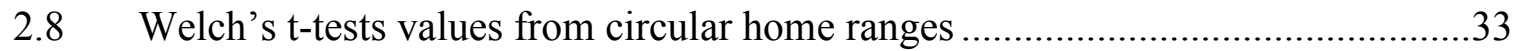

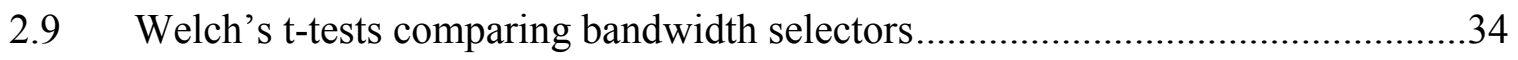

2.10 Home range area of adult Strawberry Poison Frogs ........................................35

2.11 Mann-Whitney $\mathrm{U}$ test results comparing estimates by method ..........................36

2.12 Home range estimates produced by the PUD method ......................................36

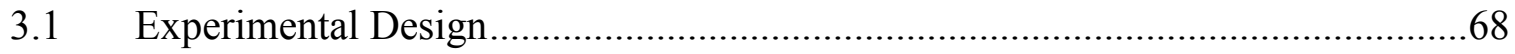

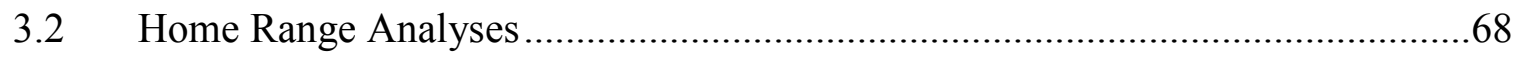

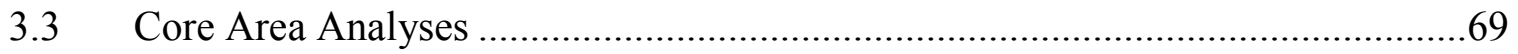

3.4 Home Range and Core Area Overlap .....................................................69

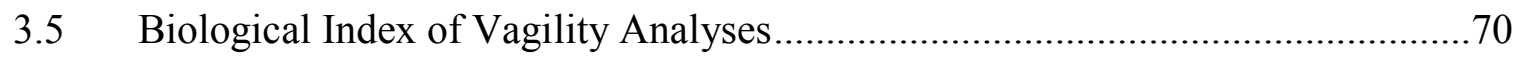




\section{LIST OF FIGURES}

FIGURE

PAGE

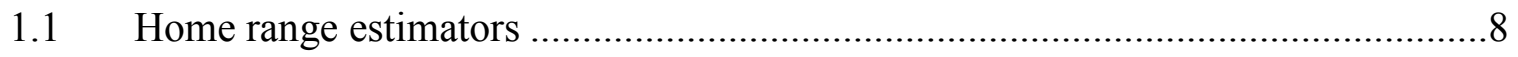

1.2 La Selva Biological Station, Costa Rica ...................................................

1.3 Twelve study plots with microhabitat and adult frog locations ..........................10

1.4 Detail of plot six with microhabitat and adult frog locations ............................11

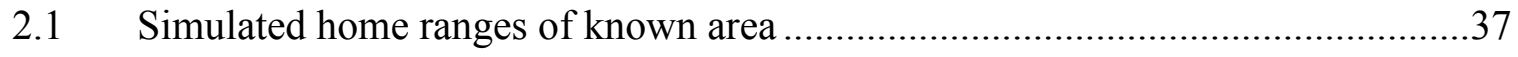

2.2 Randomly generated locations within simulated home ranges...............................

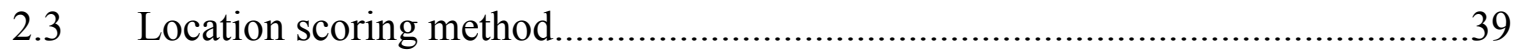

2.4 Examples of home range estimates from simulated square home range ..............40

2.5 Examples of home range estimates from simulated circle home range................41

2.6 Means of home range areas by method and sample size for the $5 \mathrm{~m}^{2}$ square........42

2.7 Means of home range areas by method and sample size for the $25 \mathrm{~m}^{2}$ square.......43

2.8 Means of home range areas by method and sample size for the $125 \mathrm{~m}^{2}$ square .....44

2.9 Means of home range areas by method and sample size for the $5 \mathrm{~m}^{2}$ circle .........45

2.10 Means of home range areas by method and sample size for the $5 \mathrm{~m}^{2}$ circle .........46

2.11 Means of home range areas by method and sample size for the $5 \mathrm{~m}^{2}$ circle .........47

2.12 Means of home range areas for all frogs by method .......................................48

2.13 Means of home range areas for frogs by method and sex...............................49

3.1 Example of the Biological Index of Vagility ............................................... 70

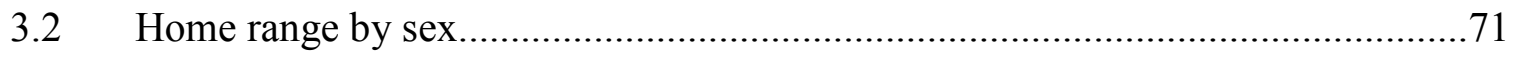

3.3 Home range by bromeliad treatment...................................................... 71

3.4 Home range by leaf litter treatment …........................................................ 72 
3.5 Home range by bromeliad and sex interactions ................................................72

3.6 Home range by leaf litter and sex interactions....................................................

3.7 Home range by bromeliad and leaf litter interactions.........................................73

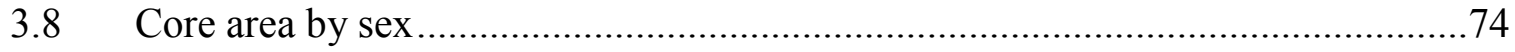

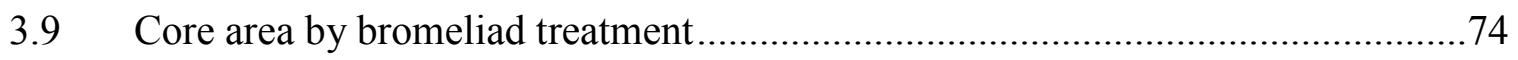

3.10 Core area by leaf litter treatment ……………...............................................75

3.11 Core area by bromeliad and sex interactions .......................................................75

3.12 Core area by leaf litter and sex interactions.......................................................

3.13 Core area by bromeliad and leaf litter interactions .............................................76

3.14 Home range overlap by sex interactions ...........................................................77

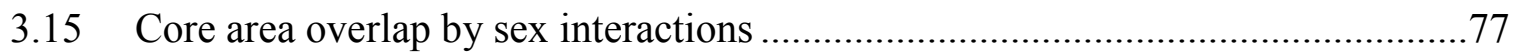

3.16 Biological Index of Vagility scores by sex ……………...................................

3.17 Biological Index of Vagility scores by bromeliad treatment ................................78

3.18 Biological Index of Vagility scores by leaf litter treatment.................................79

3.19 Biological Index of Vagility scores by bromeliad and sex interactions ................79

3.20 Biological Index of Vagility scores by leaf litter and sex interactions ...................80

3.21 Biological Index of Vagility scores by bromeliad and leaf litter interactions .......80

3.22 Biological Index of Vagility scores by home range size ………….......................81 


\section{CHAPTER I}

INTRODUCTION 
Animal movement and space use is directed by the interaction of environmental conditions (e.g., resource availability; Emlen \& Oring 1977, Guyer 1988, Donnelly 1989b), animal physiology (e.g., energetic needs; Perry \& Garland 2002), and animal behavior (e.g., territoriality; Adams 2001, Prö hl 2005). Determining the factors that drive variation in movement and space use is fundamental to understanding a variety of ecological dynamics. The first step in teasing out biologically relevant information is often to estimate the area that encompasses the movements of an animal. The area that contains the everyday movements of an animal is called the home range (Burt 1943).

Animal movement differs considerably among and within taxa, and because home ranges reflect variation in movement, home range features vary widely among animals and measuring home ranges can be problematic. Consequently, myriad methods to estimate home ranges have been developed (e.g., Minimum Convex Polygon method; Mohr 1947, Hayne 1949, Bivariate Normal method; Jennrich \& Turner 1969, and kernel density estimators; Worton 1989; Figure 1.1). Unfortunately, verifying the 'true' home range size is impossible (Schoener 1981), and although various studies have evaluated methods in relation to specific groups of animals (e.g., birds and mammals), few have investigated the utility of common home range estimators at the scale of very smallbodied animals (e.g., amphibians).

In comparisons with other vertebrates, amphibians generally have small home ranges (Wells 2007), which are likely associated with low rates of movement (Bowne \& Bowers 2004) or low metabolic demands (Pough 1980). Therefore, methods of estimating home ranges may perform differently for amphibians than for other vertebrate groups. 
My aim in the present study is to evaluate common estimators of home range size in relation to small animals with presumably small home range size. Additionally, I integrate the examination of methodology with an investigation of intraspecific differences in space utilization using empirical field data from a population of Strawberry Poison Frogs from northeastern Costa Rica. The study site, experimental design, and sampling methods for the field data have been described elsewhere (Donnelly 1989a, b) and are summarized here.

\section{Study Site}

Data collection was conducted at the La Selva Biological Reserve in northeastern Costa Rica (Figure 1.2). The site was an active cacao plantation transitional between lowland and premontane wet forest (Holdridge et al. 1971). Although trees were removed prior to planting, several large individuals were left standing to provide shade for cacao seedlings. The site was selected because replicate plots could be established in a homogenous environment.

\section{Experimental Design}

Twelve $15 \times 15 \mathrm{~m}$ plots, each separated by at least $10 \mathrm{~m}$, were established in April, 1982 (Figure 1.3). Each plot was defined by 16 stakes placed at $5 \mathrm{~m}$ intervals. The locations of all microhabitat features (trees, litter piles, bromeliads, fallen tree limbs, and fallen trees) were mapped on each plot (Figure 1.4). 


\section{Sampling}

Frogs were sampled with mark-recapture techniques beginning in May, 1982 (Donnelly 1989a). Censuses were conducted by walking in a zigzag pattern searching for active animals on the leaf litter, in litter piles, bromeliads, and litter accumulations at the bases of trees. A $1 \mathrm{~m}$ swath was covered on each sweep and all active individuals were captured. Each plot was traversed once per sample period. Snout-to-vent (SVL) length, capture site relative to the grid stakes, microhabitat association, and group size $(1,2, \ldots \mathrm{n}$ frogs) was recorded for each individual captured. For newly captured individuals, age and sex were noted and they were marked by clipping toes in unique combinations. Adults were distinguished from juveniles based on body size (adult SVL $>20 \mathrm{~mm}$ ) and males were distinguished from females based on color of the throat; adult males have brown throats (Donnelly 1989c).

\section{Database}

Using Donnelly’s dataset, I created Geographic Information System (GIS) layers using ArcMap 9.3.1 (ESRI 2009) including frog capture and microhabitat (e.g., trees, bromeliads, stakes, treefalls, leaf litter clumps) locations (Table 1.1).

\section{Overview}

In chapter two, I evaluate common methods of home range size estimation using simulations of small sample sizes at relatively small spatial scales to test for differences in home range estimation performance. I report results in accuracy and precision from three methods of estimating home range size at three sample size levels when compared 
to the known area of six simulated home ranges. To demonstrate area estimation trends in actual field data, I apply the tested methods to calculate home range areas for adult Strawberry Poison Frogs (Oophaga pumilio) from a large dataset of field-collected markrecapture locations.

In chapter three, I investigate intersexual variation in home range size, core area shape, differences in home range and core area overlap, and rates of movement in a Costa Rican population of $O$. pumilio. I also introduce a simple index to quantify movement of an animal within the home range in relation to moves among coordinates. I conclude the thesis in chapter four. 


\section{REFERENCES}

Adams, E.S. (2001) Approaches to the study of territory size and shape. Annual Review of Ecology and Systematics, 32, 277-303.

Bowne, D.R. \& Bowers, M.A. (2004) Interpatch movements in spatially structured populations: a literature review. Landscape Ecology, 19, 1-20.

Burt, W.H. (1943) Territoriality and home range concepts as applied to mammals. Journal of Mammalogy, 24, 346-352.

Donnelly, M.A. (1989a) Demographic effects of reproductive resource supplementation in a territorial frog, Dendrobates pumilio. Ecological Monographs, 59, 207-221.

Donnelly, M.A. (1989b) Effects of reproductive resource supplementation on space-use patterns in Dendrobates pumilio. Oecologia, 81, 212-218.

Donnelly, M.A. (1989c) Reproductive phenology and age structure of Dendrobates pumilio in northeastern Costa Rica. Journal of Herpetology, 23, 362-367.

Emlen S.T. \& Oring L.W. (1977) Ecology, sexual selection, and the evolution of mating systems. Science, 197, 215-223.

ESRI (2009) ArcMap GIS 9.3.1. Environmental Systems Research Institute. Redlands, CA.

Guyer, C. (1988) Food supplementation in a tropical mainland anole, Norops humilis: demographic effects. Ecology, 69, 350-361.

Hayne, D.W. (1949) Calculation of size of home range. Journal of Mammalogy, 30, 1-18.

Holdridge, L.R., Grenke, W.C., Hatheway, W.H., Liang, T. \& Tosi Jr, J.A. (1971) Forest environments in tropical life zones: a pilot study. Pergamon Press, Oxford.

Jennrich, R. \& Turner, F. (1969) Measurement of non-circular home range. Journal of Theoretical Biology, 22, 227-237.

Mohr, C.O. (1947) Table of equivalent populations of North American small mammals. American Midland Naturalist, 37, 223-249.

Perry, G. \& Garland, T., Jr. (2002) Lizard home ranges revisited: effects of sex, body size, diet, habitat, and phylogeny. Ecology, 83, 1870-1885.

Pough, F.H. (1980) The advantages of ectothermy for tetrapods. The American Naturalist, 115, 92-112. 
Pröhl, H. (2005) Territorial behavior in dendrobatid frogs. Journal of Herpetology, 39, 354-365.

Schoener, T.W. (1981) An empirically based estimate of home range. Theoretical Population Biology, 20, 281-325.

Wells, K.D. (2007) The ecology and behavior of amphibians. University of Chicago Press, Chicago, IL, USA.

Worton, B.J. (1989) Kernel methods for estimating the utilization distribution in homerange studies. Ecology, 70, 164-168. 


\begin{tabular}{|c|c|c|}
\hline Layer & Description & Format \\
\hline$\overline{\text { Stakes }}$ & Site number, $\mathrm{x}$-y coordinates (XY) & Point \\
\hline Trees & Species, base diameter, $\mathrm{XY}$ & Polygon \\
\hline Supplementary Bromeliads & XY & Point \\
\hline Supplementary Leaf Litter & $\mathrm{XY}$ & Points \\
\hline Leaf Litter Clumps & $\mathrm{XY}$ & Polygon \\
\hline Logs, Treefalls, Stumps & $\mathrm{XY}$ & Polygon \\
\hline Frog Captures $(\hat{\delta} \&$ ) & ID, sex, toeclip code, date, $X Y$, habitat & Point \\
\hline
\end{tabular}

Table 1.1 Description of GIS Layers

a. Animal Locations

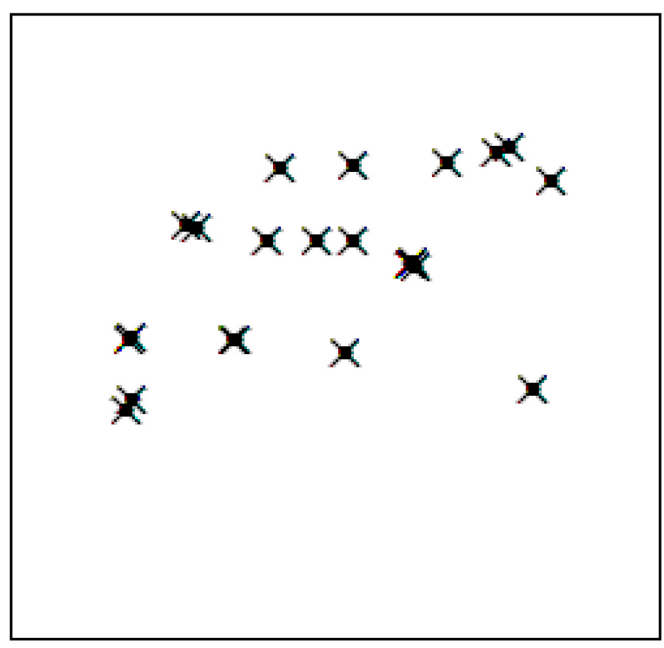

c. Bivariate Normal Ellipse

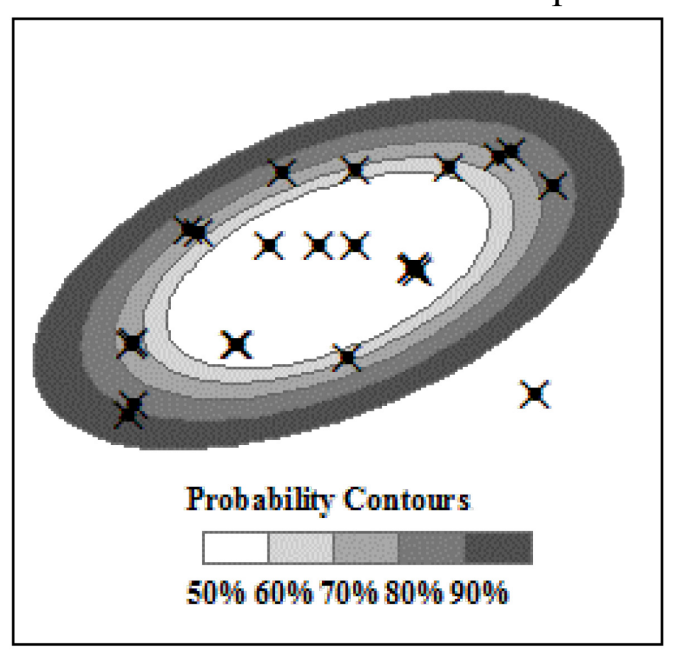

b. Minimum Convex Polygon

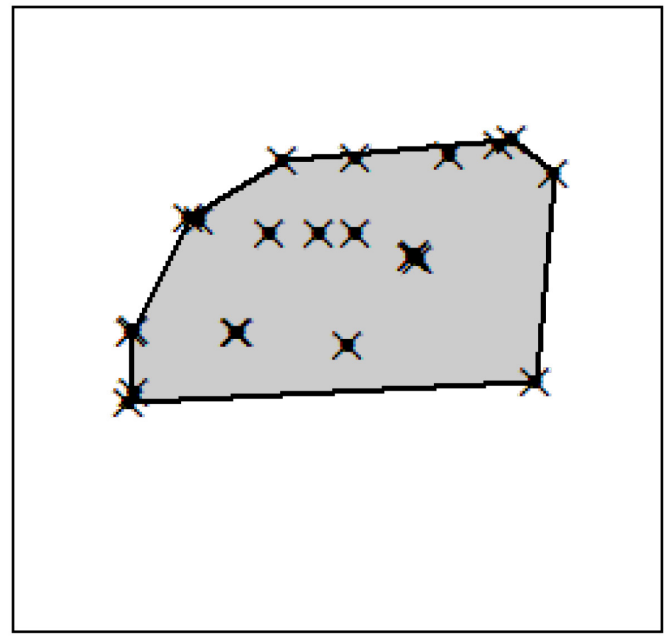

d. Kernel Density

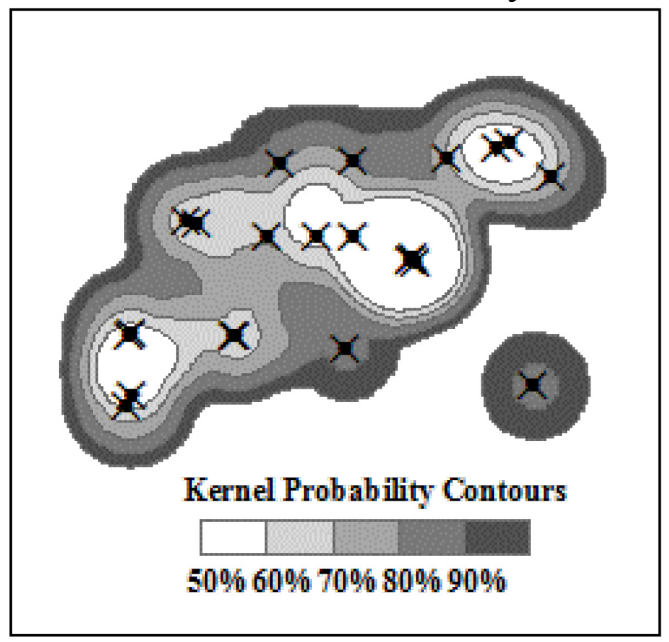

Figure 1.1 Home range estimators 


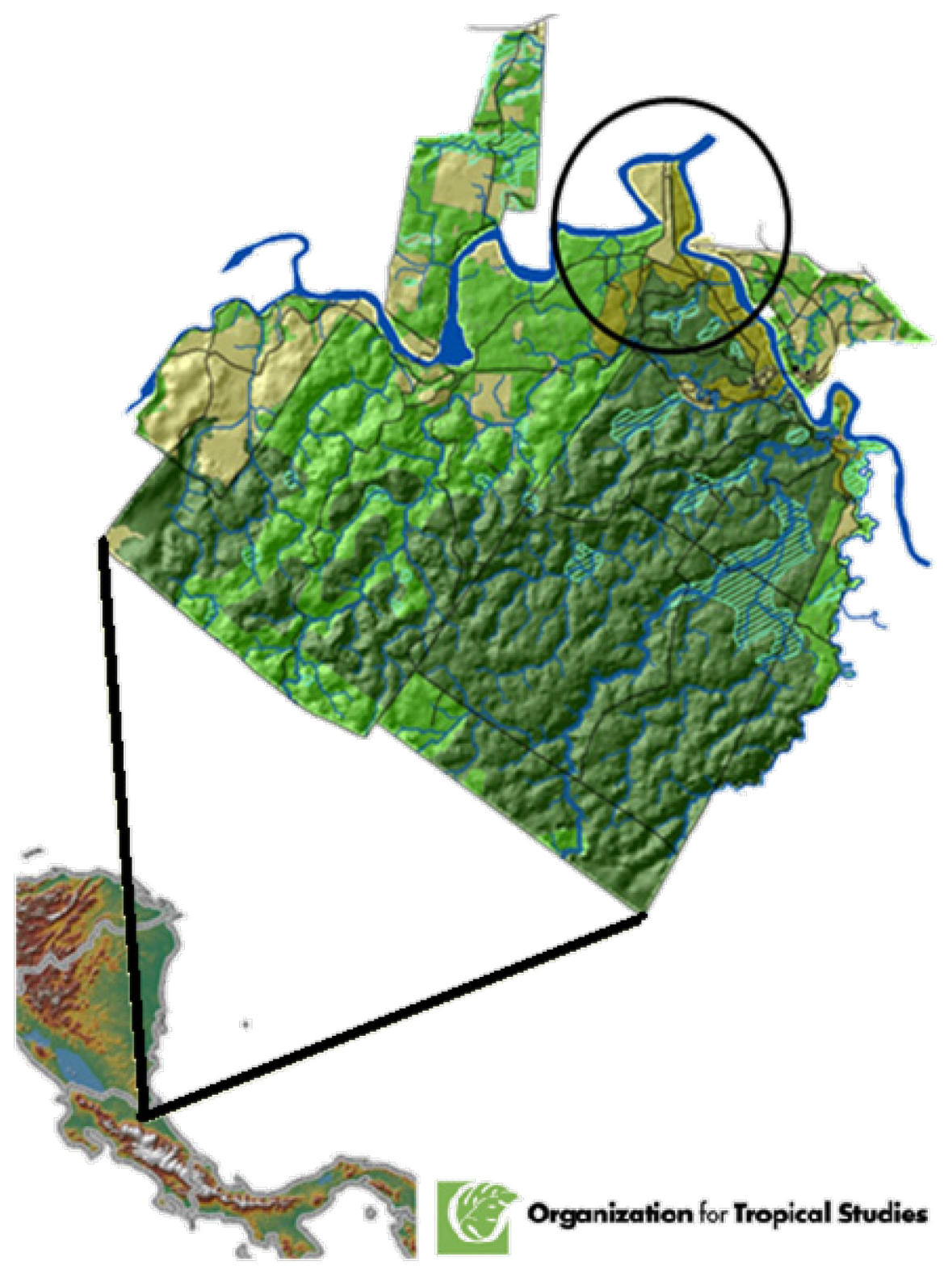

Circle indicates location of the Las Vegas Annex.

Figure 1.2 La Selva Biological Station, Costa Rica 
Plot 12

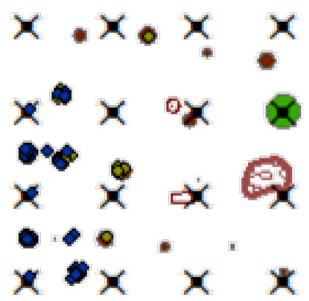

Plot 11

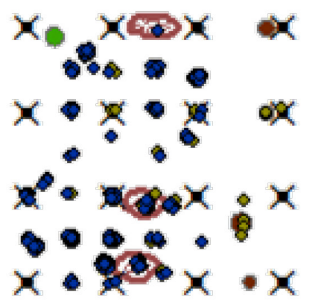

Plot 10

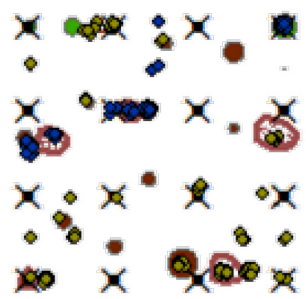

Plot 9
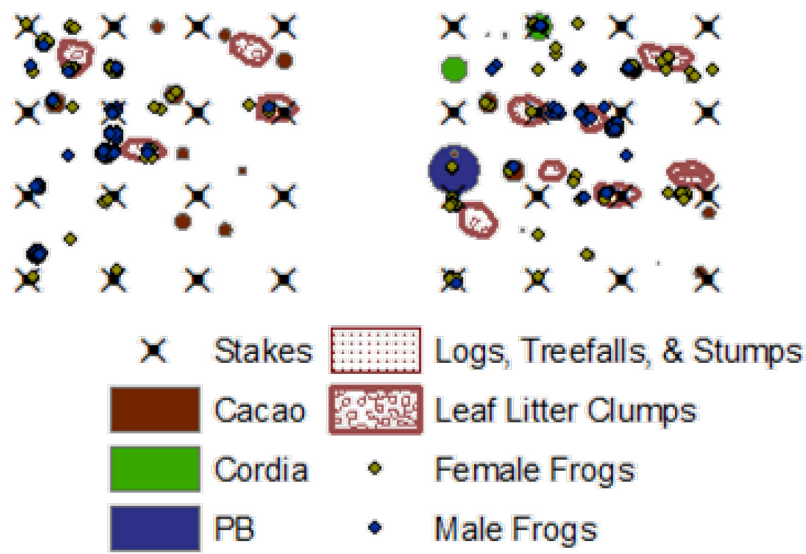

Plot 8

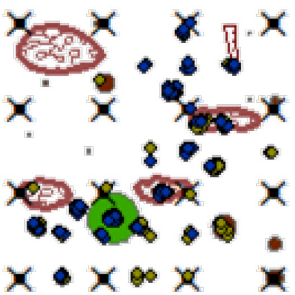

Plot 7

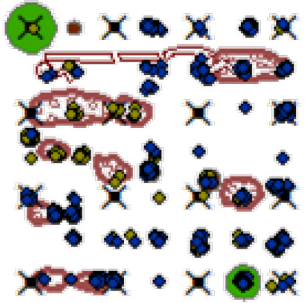

Plot 6

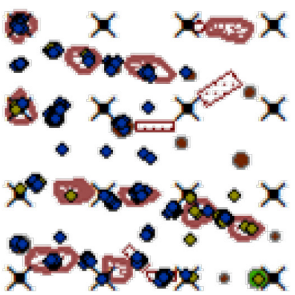

Plot 5

$x \ldots \circ x^{\circ} \times$ $x^{\circ} \cos x$

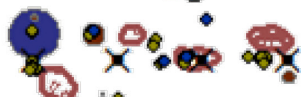

$x x^{\circ} x x$

$$
\text { Logs, Treefalls, \& Stumps }
$$

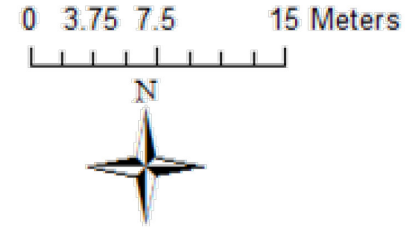

Figure 1.3 Twelve study plots with microhabitat and adult frog locations 


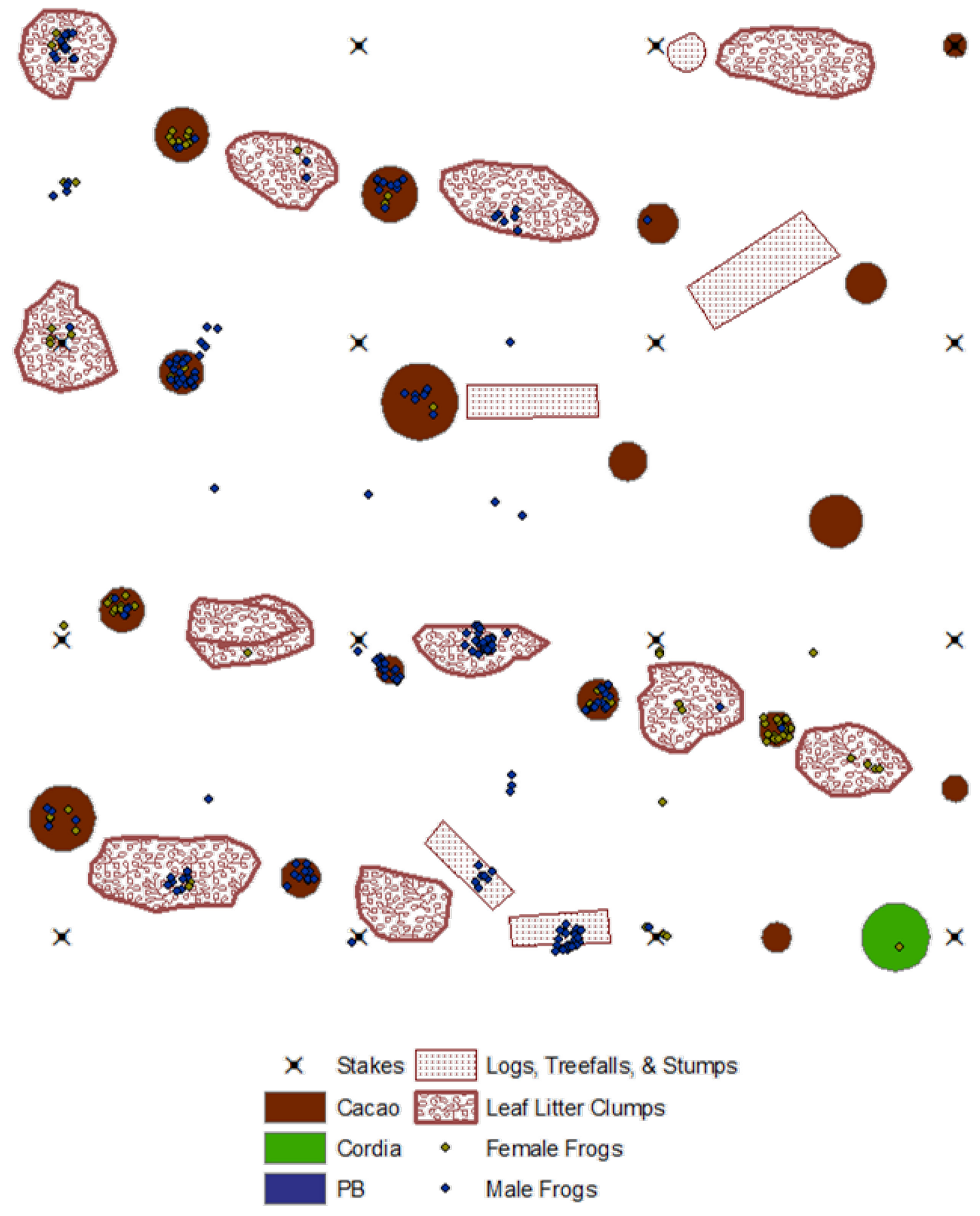

Figure 1.4 Detail of plot six with microhabitat and adult frog locations 
CHAPTER II

COMPARISON OF HOME RANGE ESTIMATORS AT SMALL SCALES 


\begin{abstract}
Home range is the area that encompasses the movements of an animal as it goes about its normal activity. Determining the home range size of animals is important in ecological and behavioral studies involved in, for example, territoriality, distribution and population density, habitat preference, resource use, and interactions with other animals. Various home range estimators have been developed to analyze the space use of animals and many home range studies focus on animals with relatively large home ranges. The objective of my study was to compare home range areas generated by current home range estimation methods -- Minimum Convex Polygon, Bivariate Normal Ellipse, and different versions of the Kernel Density Estimator at scales relevant to animals that maintain relatively small home ranges.

I used simulations of three different sample sizes at three spatial scales and two basic home range shapes to test for differences in home range estimation performance. In particular, I looked at accuracy and precision of estimates and compared them to the known home range area.
\end{abstract}

To demonstrate area estimation trends in actual field data, I applied the tested methods to calculate home range areas for 104 adult Strawberry Poison Frogs (Oophaga pumilio) from a large dataset of mark-recapture locations.

Analyses performed in the software environment $\mathrm{R}$ and a geographical information system (GIS) environment showed simulation home range area values calculated with the kernel estimator at a 90\% isopleths level were highly accurate even at low sample sizes when compared to estimates from other methods. Selection of kernel bandwidth with Least-Squares Cross-Validation resulted in similar, but more accurate 
estimates than the simpler ad hoc selection method. Home range estimates of actual field data demonstrated that kernel estimates had the lowest variance, indicating greater precision. The "ideal average individual" approach to calculating a utilization distribution used in the Population Utilization Distribution method may hide individual information in home range size and space use while providing an average value for the size of area utilized. 


\section{Introduction}

Most animals restrict their movements to part of the available environment. The area which contains the normal movements of an animal is called its home range (Burt 1943). Home ranges are shaped by animal movement and space use, which are, in turn, directed by the interaction among environmental conditions and physiological or behavioral processes. Researchers attempt to gain insights into these driving behavioral and ecological processes by estimating the size of the home range. Multiple home range estimators have been developed (see reviews by Worton 1987, Harris et al. 1990, Börger et al. 2008).

Using animal location data, basic home range estimators minimally produce a shape and size. The simplest estimator is the minimum convex polygon (MCP; Mohr 1947, Hayne 1949), in which the home range area is estimated by connecting the outermost animal locations to produce a convex polygon (all internal angles less than 180 degrees; Figure 1b). Determining the size, shape, and location of a home range provides only modest biologically relevant information (Powell 2000). To examine habitat preference, essential resources, and interactions with other animals, increasingly sophisticated home range models have been developed that incorporate animal movements and the intensity of space use within the home range.

Statistically based approaches such as the Bivariate Normal method (Jennrich \& Turner 1969; Figure 1c) and kernel methods (Worton 1989; Figure 1d) select home range parameters which best fit actual animal location data and then focus on estimating the most likely probability density function of a home range (Börger et al. 2008). In addition to providing an estimate of home range size, these methods produce a utilization 
distribution (UD), the probability of animal presence in a particular part of the home range (Jennrich \& Turner 1969, van Winkle 1975), which summarizes the frequency of space use (Katajisto \& Moilanen 2006).

Few studies have specifically tested the appropriateness of available methods for amphibians and reptiles (but see Row and Blouin-Demers 2006). Studies tracking amphibians and reptiles often suffer from low sample size because of difficulties in relocating the animals. Collecting animal locations is no longer a problem in most situations with large animals because of advances in radio and satellite telemetry. However, animal movement is seriously hampered when the lightest GPS tag weighs more than the study organism, such as with some poison frogs. In these cases, location data rely on mark-recapture methods. Furthermore, previous studies testing estimator accuracy have used simulated home ranges of proportions too large (e.g., $1 \mathrm{~km}^{2}$; Boulanger and White 1990, Worton 1995) to be relevant to animals that maintain home ranges on a smaller scale.

The purpose of the present study was to compare the accuracy and precision of three different methods of estimating home ranges using simulated home ranges and location sample sizes on a scale relevant to studies of small organisms (e.g., amphibians). Additionally, to demonstrate differences among estimators, I applied these three methods to calculate home ranges sizes of 104 adult strawberry poison frogs from a large markrecapture dataset. I also compared home range estimates using these three methods to estimates generated from the same dataset using another home range estimator, the Population Utilization Distribution (PUD) method of Ford and Krumme (1979). 


\section{Methods}

\section{Simulations}

I used simulated home ranges for testing the different home range estimation methods because, unlike actual animal home ranges, the true area value is known. Furthermore, replicates can be constructed to allow for more powerful statistical comparisons. I generated six home range types using two basic shapes (a square and a circle) of three different sizes relevant to studies of animals that maintain smaller home ranges $\left(5 \mathrm{~m}^{2}, 25 \mathrm{~m}^{2}\right.$, and $125 \mathrm{~m}^{2}$; Figure 2.1). I then created random location datasets from each of the six home range types. The random location sets represented a uniform distribution at three levels of sample size (25, 50, and 100 locations; Figure 2.2). Overall, there were 50 sets at each of the three sample size levels for each of the six home range types.

\section{Home Range Estimation}

I used the Animal Movement Extension version 2.0 (Hooge \& Eichenlaub 2000) in ArcView GIS 3.3 (ESRI 2002) to calculate all home range estimates. I calculated simulated home ranges using the 100\% Minimum Convex Polygon method, the Bivariate Normal Ellipse method, and four versions of the fixed kernel method. Following the recommendations of Börger et al. (2006) to use isopleths in the 50\%-90\% range to avoid bias; I calculated 90\% home range areas for Bivariate Normal and kernel estimates for the current comparisons of home range methods. To compare against previous studies, I also calculated home range areas using the historically common 95\% isopleths for kernel home ranges. Overall, I ran 5,400 estimates for the simulated home ranges. 


\section{Minimum Convex Polygons}

One of the simplest and therefore most commonly used home range estimators is the Minimum Convex Polygon (MCP; Mohr 1947). This non-parametric method relies on connecting the outer-most animal locations to form a polygon with internal angles of no more than 180 degrees. Home range values estimated using the MCP method can be over-estimates (i.e., MCPs are sensitive to outliers, and may include areas unused by the animal) or under-estimates (i.e., MCPs are sensitive to small sample sizes, and will increase with increased sampling). Traditionally, MCPs are calculated using all locations, these " $100 \%$ " MCPs often over-estimate home range size when outliers are

present. Although several methods exist to "peel" away outer points to reduce the effect of outliers, they are unnecessary since all locations in the simulated data were generated within the home range polygon. Therefore, one of the most serious weaknesses of the MCP method is avoided in these simulations.

\section{Bivariate Normal Ellipses}

Although it produces an unrealistic elliptical shape and depends on a bivariate normal distribution, the Bivariate Normal method (Jennrich \& Turner 1969) is another very simple technique to estimate the size of a home range that is said to be less sensitive to sample size than MCP. The Bivariate Normal method should perform well in the simulations because the random points were extracted from a normal distribution. Furthermore, given the simple circular shape of half of the home range types, the Bivariate Normal method is expected to generate relatively accurate estimates of home range size. 


\section{Fixed Kernel}

Kernel density estimators (Worton 1989) are more sophisticated than the previously mentioned estimators. Based on probability functions of animal presence, kernel estimators are currently considered a standard because they can be used to estimate the utilization distribution of an animal in addition to the home range size. Kernel estimators are also extremely flexible with numerous parameters that can be customized to the data. The parameter that most affects kernel estimates is the smoothing parameter or bandwidth. Automated methods of selecting the bandwidth have been developed and the most widely accepted is the least-squares cross-validation (LSCV) method (Gitzen \& Millspaugh 2003) which compares among bandwidth values and selects the bandwidth that minimizes error. Because "fixed" kernels (those that use a single bandwidth throughout) have been shown to be more accurate than "adaptive" kernels (those kernels which use varying bandwidths), I calculated fixed kernel home ranges using LSCV to determine the bandwidth that best reduced variance and bias. The LSCV method may fail to select a bandwidth when locations are clustered (Gitzen et al. 2006), which one would expect to find with animals that defend territories or have centers of activities. Because many amphibians and reptiles are known to demonstrate territoriality, I also calculated fixed kernel home ranges using the ad hoc bandwidth selection method to select bandwidth values, which, despite being dependent on a normal distribution of the kernel around each point, produces values that are often similar to LSCV values (Hooge et al. 1999). The ad hoc bandwidth selector, or reference method, is a rapid method that replaces the unknown density function with a 'reference' set from a normal distribution with the same variance. 
Frog Location Data

I compared the different home range estimators using Strawberry Poison Frog (Oophaga pumilio) location data collected at the La Selva Biological Reserve in northeastern Costa Rica (Donnelly 1989a, b). Mark-recapture data from frogs captured on twelve 15 x 15 m plots from May 1982 to September 1983 were compiled into a dataset consisting of 1720 frogs and 8984 captures. From this dataset, I excluded all juveniles and adult frogs with fewer than twenty captures. Because the location scoring method assigned all captures within the "window" of a coordinate the same values as the coordinate (Figure 2.3), home ranges were difficult to estimate for frogs with limited "unique sites" (e.g., home ranges for frogs captured multiple times near one coordinate were a single point). Therefore, I "jittered" the original coordinate values for all adult frogs with twenty or more captures (females, $n=47$, males, $n=57$ ) by adding random numbers ranging from -0.24 to 0.24 ( $<25$ centimeters in any direction). The smoothing parameter selector, LSCV experiences problems when location data are repeated. Thus, jittering was also necessary to prevent LSCV from failing to calculate a bandwidth for kernel densities.

\section{Data Analysis}

For the simulations, I used Welch's t-tests to compare home range estimates to actual area values to test for accuracy, and I calculated variances to examine precision of the estimates. Because estimates from the frog field data were not normally distributed, I used Mann-Whitney U tests to compare the home range estimates from each method to 
estimates from other methods and with previously reported home range values calculated using the PUD method. I performed statistical analyses in the R software environment (R Development Core Team 2010).

\section{Results}

\section{Simulations: Accuracy}

All home range estimators produced mean area values that were significantly different from the actual area value $(\mathrm{p}<0.01)$ except for the kernel estimators in some situations (see below). The Minimum Convex Polygon method underestimated home range in all simulations (Tables 2.1-2.6, Figures 2.4-2.11). Values generated by MCP were $34.15 \%$ smaller than the actual area in the datasets with 25 locations and 'improved' to $13.62 \%$ smaller in the datasets with 100 locations. Bivariate Normal Ellipses overestimated the home range area in all simulations (Tables 2.1-2.6, Figures 2.4-2.11). Increased sample size did not improve the accuracy of the home range size estimated by the Bivariate Normal method. In all but the circular home ranges with the smallest sample size, the kernel estimator generated mean home range area values greater than the actual area (Tables 2.1-2.6, Figures 2.4-2.11). Among the various kernel estimators, 95\% density estimates always overestimated the actual home range area by at least $10 \%$. Area values calculated at the $90 \%$ density were most accurate. In all of the datasets with 25 locations when the bandwidth was selected with LSCV, calculated value means were not significantly different from the actual area value $(\mathrm{p}=0.56,0.43,0.63,0.56,0.39,0.15$; Tables 2.7-2.8). Additionally, in all circular home ranges using datasets with 25 locations, kernel estimators using the ad hoc selected bandwidth calculated value means 
that were not significantly different from the actual area value $(p=0.45,0.66,0.23$; Table 2.9). Furthermore, mean estimates from kernel estimates with LSCV selected bandwidths and ad hoc selected bandwidths were not significantly different at each sample size level (Tables 2.9).

\section{Simulations: Precision}

Increases in sample size improved precision (i.e., decreased variance) in all simulations (Tables 2.1-2.6, Figures 2.4-2.11) except the mid-sized square when calculated with the LSCV bandwidth-selected 95\% kernel (Table 2.1). The MCP method consistently had the lowest variance, while variances for the Bivariate Normal and 95\% kernel methods were generally similarly greater than those for the $90 \%$ kernel.

\section{Frog Home Ranges}

The mean home range areas calculated for all adult frogs with 20 or more captures ranged from $17.29 \mathrm{~m}^{2}$ using the $90 \%$ kernel with LSCV to $42.43 \mathrm{~m}^{2}$ using the Bivariate Normal method (Table 2.10, Figure 2.12). The MCP method generated a mean home range area value of $27.96 \mathrm{~m}^{2}(2.15 \mathrm{SE})$ with values ranging from $0.18 \mathrm{~m}^{2}$ to $102.04 \mathrm{~m}^{2}$. The Bivariate Normal method generated home range sizes of $0.35 \mathrm{~m}^{2}$ to $161.91 \mathrm{~m}^{2}$. The fixed kernel with LSCV selected bandwidth generated an average 90\% kernel home range size of $17.29 \mathrm{~m}^{2}(1.95 \mathrm{SE})$ and an average $95 \%$ kernel home range size of $24.62 \mathrm{~m}^{2}$ (2.47 SE). Home range sizes for these isopleths ranged from $0.29 \mathrm{~m}^{2}$ to $149.90 \mathrm{~m}^{2}$ and $0.34 \mathrm{~m}^{2}$ to $173.03 \mathrm{~m}^{2}$, respectively. The average $90 \%$ kernel home range size when using the ad hoc selected bandwidth was $18.26 \mathrm{~m}^{2}(2.03 \mathrm{SE})$ with sizes ranging from $0.30 \mathrm{~m}^{2}$ to 
$154.56 \mathrm{~m}^{2}$. The average $95 \%$ kernel home range size when using the ad hoc selected bandwidth was $25.92 \mathrm{~m}^{2}(2.57 \mathrm{SE})$ with sizes ranging from $0.35 \mathrm{~m}^{2}$ to $178.76 \mathrm{~m}^{2}$. Among methods, the $90 \%$ kernel with LSCV exhibited the lowest variance, while the Bivariate Normal method produced the highest variance. Separating the dataset into single sex groups tightened male values (i.e., lower variance, range, etc.) (Table 2.10, Figure 2.13), and released female values (i.e., higher mean, variance, etc.) (Table 2.10). Home ranges calculated with kernel density estimators clustered at values lower than MCP and Bivariate Normal estimates. Because the values from different methods would require different transformations to normality (MCP and Bivariate Normal values could be square-root transformed, but kernel generated values required a natural log transformation), I chose to test for differences in estimate values by method using MannWhitney U (Wilcoxon) tests. Kernel density estimators at $90 \%$ were similar regardless of bandwidth selection choice $(\mathrm{p}=0.62)$. Kernel density estimators at $95 \%$ were also similar to each other $(\mathrm{p}=0.65)$. The MCP values and the $95 \%$ kernel values were not significantly different $(p=0.08$ for the LSCV and $p=0.18$ for the ad hoc). All other combinations were significantly different (Table 2.11).

\section{Comparison to the Population Utilization Distribution method}

Home range sizes calculated for Oophaga pumilio adults in this study spanned a much larger range than those reported by Donnelly (1989b) using the PUD method. Home range size for male frogs ranged from a minimum value of $0.18 \mathrm{~m}^{2}(\mathrm{MCP})$ to a maximum of $131.86 \mathrm{~m}^{2}$ (Bivariate Normal). In contrast, the PUD method estimated male frog home sizes to range from $2.26 \mathrm{~m}^{2}$ to $15.07 \mathrm{~m}^{2}$ (Table 2.12). Home range size for 
female frogs ranged from a minimum of $2.03 \mathrm{~m}^{2}$ (MCP) to a maximum of $178.76 \mathrm{~m}^{2}$ ( $95 \%$ Kernel with ad hoc selected bandwidth). Home range size for female frogs estimated by the PUD method ranged from $5.72 \mathrm{~m}^{2}$ to $15.11 \mathrm{~m}^{2}$. Home range estimates in the present study display much greater variance than estimates using the "ideal average individual" approach of the PUD method.

\section{Discussion}

Tests of home range size estimators using simulated home ranges and sample sizes relevant to studies of small animals showed LSCV-selected bandwidth kernels at the $90 \%$ isopleth level returned the most accurate estimates of home range size at all home range sizes and sample sizes. Kernel estimates using ad hoc calculations to select the bandwidth returned less accurate but similar results, indicating the computationally less expensive method of selecting bandwidths using ad hoc calculations can be substituted for rapid comparisons or when LSCV fails to select a bandwidth (i.e., because of clustering of locations at identical coordinates). Kernel estimators at the traditionally popular 95\% isopleths level performed poorly, overestimating the home range size in 95\% of the simulations (1709 times out of 1800 runs). The Bivariate Normal Ellipse method of calculating home range size was least affected by sample size, but returned overestimates of home range size in $92 \%$ of the simulations, even among the circular simulated home ranges where I expected this method to perform well. The lack of outliers in the simulations protected the Minimum Convex Polygon method from the major problem of overestimation; however estimates from the MCP method were strongly negatively biased, even among the largest sample sizes and smallest home 
ranges, where, intuitively, the method should perform well. Although the MCP method had lower variance, indicating greater precision, the need for a much larger sample size to generate accurate estimates makes it less suitable than the $90 \%$ kernel, which performed surprisingly well at even the lowest sample sizes.

Applying the methods to a large dataset of mark-recapture locations of small poison frogs, kernel estimators at the $90 \%$ isopleth level performed best (i.e., results had the lowest variance). As expected following the simulations, the Bivariate Normal method produced large home range estimates. Bivariate Normal ellipses also showed the most variance, indicating the Bivariate Normal method is inappropriate for determining home range sizes for this frog. Home range estimates generated with the MCP method were larger with a relatively high variance. Higher estimates may be a result of overestimation because of the presence of outliers (i.e., forays outside the home range) in field data. Findings in the present study that the kernel estimator produces home range estimates with higher accuracy (in the simulations) and smaller variance (using actual field data) than estimates produced with the MCP method are in contrast to findings in recent studies of herptofauna (e.g., Row and Blouin-Demers 2006).

The "idealized individual" approach to calculating a utilization distribution used in the Population Utilization Distribution (PUD) method produced mean home range sizes significantly smaller than those in the present study. The much smaller variance in estimates from the PUD method may indicate that combining frog locations camouflages individual variance in home range size and space use while providing an average value.

The results of the present study indicate that traditional methods of estimating home range size (e.g., Minimum Convex Polygon, Bivariate Normal, and the 95\% kernel 
methods) may generate erroneous estimates in similar situations. Because the $90 \%$ contour of the kernel density estimator using LSCV to select the bandwidth produced the most accurate estimates in simulations and demonstrated the lowest variance using empirical data, I recommend their use for studies involving small vertebrates and/or limited location data. 


\section{REFERENCES}

Bö rger, L., Franconi, N., de Michele, G., Gantz, A., Meschi, F., Manica, A., Lovari, S., \& Coulson, T. (2006) Effects of sampling regime on the mean and variance of home range size estimates. Journal of Animal Ecology, 75, 1393-1405.

Börger, L., Dalziel, B.D. \& Fryxell, J.M. (2008) Are there general mechanisms of animal home range behaviour? A review and prospects for future research. Ecology letters, $11,637-650$.

Boulanger, J.G. \& White, G.C. (1990) A comparison of home-range estimators using Monte Carlo simulation. Journal of Wildlife Management, 54, 310-315.

Burt, W.H. (1943) Territoriality and home range concepts as applied to mammals. Journal of Mammalogy, 24, 346-352.

Donnelly, M.A. (1987) Territoriality in the poison-dart frog Dendrobates pumilio (Anura: Dendrobatidae). Ph.D. dissertation, University of Miami.

Donnelly, M.A. (1989a) Demographic effects of reproductive resource supplementation in a territorial frog, Dendrobates pumilio. Ecological Monographs, 59, 207-221.

Donnelly, M.A. (1989b) Effects of reproductive resource supplementation on space-use patterns in Dendrobates pumilio. Oecologia, 81, 212-218.

ESRI (2002) ArcView GIS 3.3. Environmental Systems Research Institute. Redlands, CA, USA.

Ford, R.G. \& Krumme, D.W. (1979) The analysis of space use patterns. Journal of theoretical biology, 76, 125-155.

Gitzen, R.A., Millspaugh, J.J. (2003) Comparison of least-squares cross-validation bandwidth options for kernel home-range estimation. Wildlife Society Bulletin, 31, 823-831.

Gitzen, R.A., Millspaugh, J.J., Kernohan, B.J. (2006) Bandwidth selection for fixedkernel analysis of animal utilization distributions. The Journal of Wildlife Management, 70, 1334-1344.

Harris, S., Cresswell, W.J., Forde, P.G., Trewhella, W.J., Woolard, T. \& Wray, S. (1990) Home-range analysis using radio-tracking data-a review of problems and techniques particularly as applied to the study of mammals. Mammal Review, 20, 97-123.

Hayne, D.W. (1949) Calculation of size of home range. Journal of Mammalogy, 30, 1-18. 
Hooge, P.N. \& Eichenlaub, W.M. (2000) Animal Movement extension to Arcview verison 2.0. Alaska Science Center - Biological Science Office, U.S. Geological Survey, Anchorage, AK, USA.

Hooge, P.N., Eichenlaub, W.M. \& Solomon, E.K. (1999) Using GIS to analyze animal movements in the marine environment. and Management of Marine Populations. Alaska Sea.

Jennrich, R. \& Turner, F. (1969) Measurement of non-circular home range. Journal of Theoretical Biology, 22, 227-237.

Katajisto, J. \& Moilanen, A. (2006) Kernel-based home range method for data with irregular sampling intervals. Ecological Modelling, 194, 405-413.

Mohr, C.O. (1947) Table of equivalent populations of North American small mammals. American Midland Naturalist, 37, 223-249.

Powell, R.A. (2000) Animal home ranges and territories and home range estimators. Research techniques in animal ecology: controversies and consequences. Boitani, L. \& Fuller, T.K.),pp. 65-110. Columbia University Press, New York.

R Development Core Team (2010). R: A language and environment for statistical computing. R Foundation for Statistical Computing, Vienna, Austria.

Row, J. \& Blouin-Demers, G. (2006) Kernels are not accurate estimators of home-range size for herpetofauna. Copeia, 2006, 797-802.

van Winkle, W. (1975) Comparison of several probabilistic home-range models. The Journal of Wildlife Management, 39, 118 - 123.

Worton, B.J. (1987) A review of models of home range for animal movement. Ecological Modelling, 38, 277-298.

Worton, B.J. (1989) Kernel methods for estimating the utilization distribution in homerange studies. Ecology, 70, 164-168.

Worton, B.J. (1995) Using Monte Carlo simulation to evaluate kernel-based home range estimators. Journal of Wildlife Management, 59, 794-800. 


\begin{tabular}{lrrrrrrrrr}
\hline & $\mathrm{n}$ & Mean $\left(\mathrm{m}^{2}\right)$ & SD & SE & Variance & Range & Max & Min \\
\hline \hline MCP & 25 & 3.34 & 0.35 & 0.05 & 0.12 & 1.74 & 4.22 & 2.48 \\
& 50 & 3.98 & 0.29 & 0.04 & 0.08 & 1.34 & 4.59 & 3.25 \\
& 100 & 4.38 & 0.15 & 0.02 & 0.02 & 0.62 & 4.68 & 4.07 \\
Bivariate Normal & 25 & 5.83 & 0.69 & 0.10 & 0.47 & 3.27 & 7.47 & 4.20 \\
& 50 & 5.93 & 0.60 & 0.09 & 0.36 & 2.46 & 7.03 & 4.57 \\
Kernel 90 (LSCV) & 100 & 6.00 & 0.36 & 0.05 & 0.13 & 1.47 & 6.62 & 5.15 \\
& 25 & 5.05 & 0.58 & 0.08 & 0.34 & 2.42 & 6.15 & 3.73 \\
& 50 & 5.51 & 0.50 & 0.07 & 0.25 & 2.01 & 6.57 & 4.56 \\
Kernel 95 (LSCV) & 100 & 5.69 & 0.28 & 0.04 & 0.08 & 1.25 & 6.33 & 5.07 \\
& 25 & 5.72 & 0.60 & 0.08 & 0.36 & 2.70 & 7.04 & 4.33 \\
Kernel 90 (ad hoc) & 50 & 6.16 & 0.49 & 0.07 & 0.24 & 2.01 & 7.23 & 5.22 \\
& 100 & 6.28 & 0.26 & 0.04 & 0.07 & 1.21 & 6.86 & 5.65 \\
& 25 & 5.18 & 0.59 & 0.08 & 0.35 & 2.50 & 6.30 & 3.80 \\
Kernel 95 (ad hoc) & 50 & 5.60 & 0.51 & 0.07 & 0.26 & 2.03 & 6.68 & 4.65 \\
& 100 & 5.77 & 0.28 & 0.04 & 0.08 & 1.25 & 6.39 & 5.14 \\
& 25 & 5.87 & 0.62 & 0.09 & 0.38 & 2.83 & 7.24 & 4.42 \\
& 50 & 6.28 & 0.49 & 0.07 & 0.24 & 2.04 & 7.36 & 5.33 \\
& 100 & 6.37 & 0.26 & 0.04 & 0.07 & 1.20 & 6.94 & 5.74 \\
\hline
\end{tabular}

Table 2.1 Home range area estimates of $5 \mathrm{~m}^{2}$ square

\begin{tabular}{lrrrrrrrr}
\hline & $\mathrm{n}$ & Mean $\left(\mathrm{m}^{2}\right)$ & SD & SE & Variance & Range & Max & Min \\
\hline \hline MCP & 25 & 17.12 & 1.84 & 0.26 & 3.39 & 7.81 & 20.91 & 13.10 \\
& 50 & 20.14 & 1.31 & 0.19 & 1.72 & 4.77 & 22.25 & 17.48 \\
& 100 & 21.96 & 0.82 & 0.12 & 0.67 & 4.13 & 23.89 & 19.76 \\
Bivariate Normal & 25 & 29.70 & 4.16 & 0.59 & 17.28 & 18.29 & 39.19 & 20.90 \\
& 50 & 29.24 & 2.38 & 0.34 & 5.66 & 11.11 & 35.83 & 24.72 \\
& 100 & 29.90 & 1.70 & 0.24 & 2.90 & 7.34 & 33.57 & 26.24 \\
Kernel 90 (LSCV) & 25 & 25.52 & 4.26 & 0.60 & 18.18 & 18.67 & 36.16 & 17.49 \\
& 50 & 27.30 & 2.32 & 0.33 & 5.36 & 12.39 & 33.74 & 21.36 \\
Kernel 95 (LSCV) & 100 & 28.67 & 1.35 & 0.19 & 1.83 & 6.26 & 31.88 & 25.62 \\
& 25 & 29.21 & 4.24 & 0.60 & 17.96 & 18.45 & 39.63 & 21.18 \\
& 50 & 30.16 & 4.86 & 0.69 & 23.62 & 37.00 & 37.21 & 0.20 \\
Kernel 90 (ad hoc) & 100 & 30.99 & 4.66 & 0.66 & 21.74 & 34.58 & 34.59 & 0.01 \\
& 25 & 26.36 & 4.33 & 0.61 & 18.71 & 19.02 & 37.01 & 17.99 \\
& 50 & 27.83 & 2.35 & 0.33 & 5.53 & 12.63 & 34.50 & 21.87 \\
Kernel 95 (ad hoc) & 100 & 29.06 & 1.35 & 0.19 & 1.83 & 6.40 & 32.37 & 25.97 \\
& 25 & 30.06 & 4.27 & 0.60 & 18.21 & 18.87 & 40.57 & 21.70 \\
& 50 & 31.36 & 2.25 & 0.32 & 5.06 & 10.98 & 37.92 & 26.93 \\
& 100 & 32.03 & 1.38 & 0.20 & 1.91 & 6.51 & 35.13 & 28.62 \\
\hline
\end{tabular}

Table 2.2 Home range area estimates of $25 \mathrm{~m}^{2}$ square 


\begin{tabular}{lrrrrrrrr}
\hline & $\mathrm{n}$ & Mean $\left(\mathrm{m}^{2}\right)$ & \multicolumn{1}{c}{ SD } & SE & Variance & Range & Max & \multicolumn{1}{c}{ Min } \\
\hline \hline MCP & 25 & 84.60 & 10.45 & 1.48 & 109.11 & 43.41 & 103.33 & 59.92 \\
& 50 & 100.39 & 6.08 & 0.86 & 36.97 & 27.45 & 111.80 & 84.35 \\
& 100 & 110.05 & 4.59 & 0.65 & 21.05 & 19.35 & 118.34 & 98.99 \\
Bivariate Normal & 25 & 147.48 & 23.22 & 3.28 & 539.37 & 97.51 & 194.84 & 97.33 \\
& 50 & 149.50 & 15.20 & 2.15 & 231.09 & 66.01 & 183.12 & 117.11 \\
& 100 & 148.79 & 10.30 & 1.46 & 106.12 & 43.79 & 170.92 & 127.12 \\
Kernel 90 (LSCV) & 25 & 129.05 & 19.52 & 2.76 & 380.99 & 86.85 & 166.55 & 79.70 \\
& 50 & 136.42 & 13.13 & 1.88 & 172.34 & 49.96 & 158.73 & 108.77 \\
Kernel 95 (LSCV) & 100 & 143.07 & 7.64 & 1.08 & 58.30 & 32.32 & 157.59 & 125.27 \\
& 25 & 146.05 & 20.31 & 2.87 & 412.30 & 92.27 & 183.66 & 91.39 \\
& 50 & 153.62 & 12.82 & 1.81 & 164.23 & 51.14 & 176.32 & 125.18 \\
Kernel 90 (ad hoc) & 100 & 157.55 & 7.37 & 1.04 & 54.28 & 32.33 & 172.07 & 139.75 \\
& 25 & 132.74 & 19.74 & 2.79 & 389.64 & 88.79 & 170.54 & 81.75 \\
& 50 & 138.71 & 13.55 & 1.92 & 183.57 & 50.41 & 161.25 & 110.85 \\
Kernel 95 (ad hoc) & 100 & 144.97 & 7.70 & 1.09 & 59.33 & 32.77 & 159.55 & 126.78 \\
& 25 & 149.83 & 20.70 & 2.93 & 428.52 & 93.96 & 188.00 & 94.05 \\
& 50 & 156.74 & 12.93 & 1.83 & 167.26 & 51.83 & 179.44 & 127.61 \\
& 100 & 159.77 & 7.47 & 1.06 & 55.87 & 32.58 & 174.32 & 141.74 \\
\hline
\end{tabular}

Table 2.3 Home range area estimates of $125 \mathrm{~m}^{2}$ square

\begin{tabular}{lrrrrrrrr}
\hline & $\mathrm{n}$ & Mean $\left(\mathrm{m}^{2}\right)$ & SD & SE & Variance & Range & Max & Min \\
\hline MCP & 25 & 3.22 & 0.37 & 0.05 & 0.14 & 1.66 & 3.96 & 2.30 \\
& 50 & 3.83 & 0.24 & 0.03 & 0.06 & 1.29 & 4.23 & 2.93 \\
& 100 & 4.21 & 0.14 & 0.02 & 0.02 & 0.54 & 4.45 & 3.91 \\
Bivariate Normal & 25 & 5.61 & 0.72 & 0.10 & 0.52 & 3.31 & 7.63 & 4.31 \\
& 50 & 5.58 & 0.50 & 0.07 & 0.25 & 2.16 & 6.48 & 4.33 \\
& 100 & 5.68 & 0.31 & 0.04 & 0.10 & 1.37 & 6.35 & 4.98 \\
Kernel 90 (LSCV) & 25 & 4.93 & 0.80 & 0.11 & 0.64 & 3.10 & 6.80 & 3.70 \\
& 50 & 5.31 & 0.48 & 0.07 & 0.23 & 2.44 & 6.28 & 3.84 \\
& 100 & 5.60 & 0.28 & 0.04 & 0.08 & 1.15 & 6.20 & 5.05 \\
Kernel 95 (LSCV) & 25 & 5.52 & 1.11 & 0.16 & 1.23 & 7.36 & 7.37 & 0.02 \\
& 50 & 5.93 & 0.49 & 0.07 & 0.24 & 2.48 & 6.80 & 4.32 \\
& 100 & 6.12 & 0.26 & 0.04 & 0.07 & 1.10 & 6.65 & 5.55 \\
Kernel 90 (ad hoc) & 25 & 5.09 & 0.81 & 0.11 & 0.65 & 3.12 & 6.93 & 3.81 \\
& 50 & 5.41 & 0.50 & 0.07 & 0.25 & 2.47 & 6.37 & 3.91 \\
& 100 & 5.67 & 0.28 & 0.04 & 0.08 & 1.16 & 6.28 & 5.12 \\
Kernel 95 (ad hoc) & 25 & 5.77 & 0.79 & 0.11 & 0.62 & 2.95 & 7.53 & 4.57 \\
& 50 & 6.04 & 0.49 & 0.07 & 0.24 & 2.53 & 6.92 & 4.39 \\
& 100 & 6.21 & 0.26 & 0.04 & 0.07 & 1.13 & 6.75 & 5.62 \\
\hline
\end{tabular}

Table 2.4 Home range area estimates of $5 \mathrm{~m}^{2}$ circle 


\begin{tabular}{lrrrrrrrr}
\hline & $\mathrm{n}$ & Mean $\left(\mathrm{m}^{2}\right)$ & SD & SE & Variance & Range & Max & Min \\
\hline \hline MCP & 25 & 15.72 & 1.69 & 0.24 & 2.87 & 7.67 & 19.31 & 11.64 \\
& 50 & 19.39 & 1.05 & 0.15 & 1.11 & 4.24 & 21.62 & 17.37 \\
& 100 & 21.28 & 0.60 & 0.09 & 0.37 & 2.87 & 22.42 & 19.55 \\
Bivariate Normal & 25 & 27.67 & 3.54 & 0.50 & 12.56 & 15.23 & 34.72 & 19.49 \\
& 50 & 28.73 & 2.30 & 0.33 & 5.31 & 9.91 & 33.55 & 23.64 \\
& 100 & 28.82 & 1.67 & 0.24 & 2.77 & 8.87 & 32.45 & 23.57 \\
Kernel 90 (LSCV) & 25 & 24.59 & 3.57 & 0.51 & 12.76 & 18.94 & 33.19 & 14.25 \\
& 50 & 26.96 & 2.06 & 0.29 & 4.25 & 9.19 & 31.34 & 22.15 \\
Kernel 95 (LSCV) & 25 & 27.66 & 3.59 & 0.51 & 12.86 & 18.86 & 35.91 & 17.05 \\
& 50 & 30.16 & 2.04 & 0.29 & 4.17 & 8.92 & 34.11 & 25.18 \\
& 100 & 28.27 & 1.50 & 0.21 & 2.26 & 8.39 & 30.99 & 22.60 \\
Kernel 90 (ad hoc) & 25 & 25.22 & 3.62 & 0.51 & 13.08 & 19.23 & 33.87 & 14.64 \\
& 50 & 27.53 & 2.06 & 0.29 & 4.26 & 9.04 & 31.77 & 22.73 \\
& 100 & 28.62 & 1.50 & 0.21 & 2.26 & 8.34 & 31.34 & 23.00 \\
Kernel 95 (ad hoc) & 25 & 28.37 & 3.62 & 0.51 & 13.10 & 19.17 & 36.71 & 17.54 \\
& 50 & 30.72 & 2.04 & 0.29 & 4.18 & 8.86 & 34.67 & 25.80 \\
& 100 & 31.36 & 1.31 & 0.19 & 1.73 & 7.26 & 33.93 & 26.67 \\
\hline
\end{tabular}

Table 2.5 Home range area estimates of $25 \mathrm{~m}^{2}$ circle

\begin{tabular}{lrrrrrrrr}
\hline & \multicolumn{1}{c}{$\mathrm{n}$} & Mean $\left(\mathrm{m}^{2}\right)$ & \multicolumn{1}{c}{ SD } & SE & Variance & Range & \multicolumn{1}{l}{ Max } & \multicolumn{1}{c}{ Min } \\
\hline MCP & 25 & 81.08 & 7.51 & 1.06 & 56.41 & 32.41 & 95.83 & 63.42 \\
& 50 & 96.74 & 4.71 & 0.67 & 22.17 & 24.33 & 104.25 & 79.92 \\
& 100 & 106.58 & 3.57 & 0.51 & 12.77 & 16.52 & 112.77 & 96.25 \\
Bivariate Normal & 25 & 138.12 & 14.37 & 2.03 & 206.64 & 57.02 & 166.33 & 109.32 \\
& 50 & 145.34 & 12.02 & 1.70 & 144.36 & 51.16 & 172.16 & 121.00 \\
& 100 & 143.39 & 8.54 & 1.21 & 73.01 & 34.41 & 157.50 & 123.09 \\
Kernel 90 (LSCV) & 25 & 124.04 & 14.07 & 1.99 & 197.90 & 56.37 & 151.12 & 94.74 \\
& 50 & 137.07 & 11.91 & 1.68 & 141.92 & 48.54 & 157.57 & 109.03 \\
& 100 & 141.18 & 7.66 & 1.08 & 58.75 & 34.75 & 154.45 & 119.70 \\
Kernel 95 (LSCV) & 25 & 139.99 & 14.56 & 2.06 & 212.09 & 57.91 & 167.95 & 110.04 \\
& 50 & 152.13 & 10.92 & 1.54 & 119.16 & 45.01 & 171.22 & 126.21 \\
Kernel 90 (ad hoc) & 100 & 154.56 & 6.97 & 0.99 & 48.54 & 34.31 & 167.13 & 132.82 \\
& 25 & 127.51 & 14.46 & 2.04 & 208.99 & 56.85 & 154.12 & 97.26 \\
& 50 & 139.47 & 11.94 & 1.69 & 142.59 & 48.93 & 160.11 & 111.18 \\
Kernel 95 (ad hoc) & 100 & 143.01 & 7.77 & 1.10 & 60.35 & 36.32 & 157.18 & 120.86 \\
& 25 & 143.73 & 14.82 & 2.10 & 219.62 & 57.49 & 171.07 & 113.59 \\
& 50 & 154.86 & 11.05 & 1.56 & 122.05 & 45.57 & 174.24 & 128.67 \\
& 100 & 156.70 & 7.05 & 1.00 & 49.77 & 35.22 & 169.67 & 134.44 \\
\hline
\end{tabular}

Table 2.6 Home range area estimates of $125 \mathrm{~m}^{2}$ circle 


\begin{tabular}{|c|c|c|c|c|c|c|c|}
\hline \multirow[b]{2}{*}{ Method } & \multirow[b]{2}{*}{$\mathrm{n}$} & \multicolumn{2}{|c|}{$5 \mathrm{~m}^{2}$ square } & \multicolumn{2}{|c|}{$25 \mathrm{~m}^{2}$ square } & \multicolumn{2}{|c|}{$125 \mathrm{~m}^{2}$ square } \\
\hline & & $\mathrm{t}$ & $\mathrm{p}$ & $\mathrm{t}$ & $\mathrm{p}$ & $\mathrm{t}$ & $\mathrm{p}$ \\
\hline Minimum Convex Polygon & 25 & 33.70 & $<0.001$ & 30.27 & $<0.001$ & 27.35 & $<0.001$ \\
\hline Minimum Convex Polygon & 50 & 24.74 & $<0.001$ & 26.23 & $<0.001$ & 28.62 & $<0.001$ \\
\hline Minimum Convex Polygon & 100 & 28.29 & $<0.001$ & 26.25 & $<0.001$ & 23.05 & $<0.001$ \\
\hline Bivariate Normal & 25 & -8.55 & $<0.001$ & -7.99 & $<0.001$ & -6.85 & $<0.001$ \\
\hline Bivariate Normal & 50 & -10.84 & $<0.001$ & -12.59 & $<0.001$ & -11.40 & $<0.001$ \\
\hline Bivariate Normal & 100 & -19.63 & $<0.001$ & -20.35 & $<0.001$ & -16.33 & $<0.001$ \\
\hline Kernel 90 (LSCV) & 25 & -0.59 & 0.559 & -0.87 & 0.391 & -1.47 & 0.149 \\
\hline Kernel 90 (LSCV) & 50 & -7.17 & $<0.001$ & -7.03 & $<0.001$ & -6.09 & $<0.001$ \\
\hline Kernel 90 (LSCV) & 100 & -17.53 & $<0.001$ & -19.16 & $<0.001$ & -16.74 & $<0.001$ \\
\hline Kernel 95 (LSCV) & 25 & -8.55 & $<0.001$ & -7.03 & $<0.001$ & -7.33 & $<0.001$ \\
\hline Kernel 95 (LSCV) & 50 & -16.82 & $<0.001$ & -7.50 & $<0.001$ & -15.79 & $<0.001$ \\
\hline Kernel 95 (LSCV) & 100 & -35.30 & $<0.001$ & -9.09 & $<0.001$ & -31.24 & $<0.001$ \\
\hline Kernel 90 (ad hoc) & 25 & -2.16 & 0.0361 & -2.22 & 0.031 & -2.77 & $<0.01$ \\
\hline Kernel 90 (ad hoc) & 50 & -8.39 & $<0.001$ & -8.50 & $<0.001$ & -7.16 & $<0.001$ \\
\hline Kernel 90 (ad hoc) & 100 & -19.55 & $<0.001$ & -21.20 & $<0.001$ & -18.34 & $<0.001$ \\
\hline Kernel 95 (ad hoc) & 25 & -9.61 & $<0.001$ & -8.39 & $<0.001$ & -8.48 & $<0.001$ \\
\hline Kernel 95 (ad hoc) & 50 & -18.29 & $<0.001$ & -20.00 & $<0.001$ & -17.36 & $<0.001$ \\
\hline Kernel 95 (ad hoc) & 100 & -37.40 & $<0.001$ & -35.96 & $<0.001$ & -32.90 & $<0.001$ \\
\hline
\end{tabular}

Table 2.7 Welch's t-tests values from square home ranges 


\begin{tabular}{lrrrrrrrr}
\hline & & \multicolumn{1}{c}{$5 \mathrm{~m}^{2}$ circle } & \multicolumn{2}{c}{$25 \mathrm{~m}^{2}$ circle } & \multicolumn{1}{c}{$125 \mathrm{~m}^{2}$} & circle \\
\hline \hline \multicolumn{1}{c}{ Method } & $\mathrm{n}$ & $\mathrm{t}$ & $\mathrm{p}$ & $\mathrm{t}$ & $\mathrm{p}$ & $\mathrm{t}$ & $\mathrm{p}$ \\
Minimum Convex Polygon & 25 & 33.75 & $<0.001$ & 38.73 & $<0.001$ & 41.34 & $<0.001$ \\
Minimum Convex Polygon & 50 & 35.30 & $<0.001$ & 37.66 & $<0.001$ & 42.44 & $<0.001$ \\
Minimum Convex Polygon & 100 & 40.06 & $<0.001$ & 43.49 & $<0.001$ & 36.45 & $<0.001$ \\
Bivariate Normal & 25 & -5.98 & $<0.001$ & -5.33 & $<0.001$ & -6.46 & $<0.001$ \\
Bivariate Normal & 50 & -8.12 & $<0.001$ & -11.45 & $<0.001$ & -11.97 & $<0.001$ \\
Bivariate Normal & 100 & -15.57 & $<0.001$ & -16.24 & $<0.001$ & -15.22 & $<0.001$ \\
Kernel 90 (LSCV) & 25 & 0.58 & 0.563 & 0.80 & 0.425 & 0.48 & 0.633 \\
Kernel 90 (LSCV) & 50 & -4.55 & $<0.001$ & -6.73 & $<0.001$ & -7.16 & $<0.001$ \\
Kernel 90 (LSCV) & 100 & -15.37 & $<0.001$ & -15.35 & $<0.001$ & -14.92 & $<0.001$ \\
Kernel 95 (LSCV) & 25 & -3.31 & $<0.01$ & -5.25 & $<0.001$ & -7.28 & $<0.001$ \\
Kernel 95 (LSCV) & 50 & -13.43 & $<0.001$ & -17.86 & $<0.001$ & -17.58 & $<0.001$ \\
Kernel 95 (LSCV) & 100 & -30.57 & $<0.001$ & -31.51 & $<0.001$ & -30.00 & $<0.001$ \\
Kernel 90 (ad hoc) & 25 & -0.77 & 0.446 & -0.44 & 0.663 & -1.23 & 0.225 \\
Kernel 90 (ad hoc) & 50 & -5.91 & $<0.001$ & -8.67 & $<0.001$ & -8.57 & $<0.001$ \\
Kernel 90 (ad hoc) & 100 & -17.03 & $<0.001$ & -17.03 & $<0.001$ & -16.40 & $<0.001$ \\
Kernel 95 (ad hoc) & 25 & -6.89 & $<0.001$ & -6.59 & $<0.001$ & -8.94 & $<0.001$ \\
Kernel 95 (ad hoc) & 50 & -15.05 & $<0.001$ & -19.81 & $<0.001$ & -19.11 & $<0.001$ \\
Kernel 95 (ad hoc) & 100 & -32.27 & $<0.001$ & -34.19 & $<0.001$ & -31.77 & $<0.001$ \\
\hline
\end{tabular}

Table 2.8 Welch's t-tests values from circular home ranges 


\begin{tabular}{|c|c|c|c|c|c|c|c|c|}
\hline \multirow{8}{*}{$\begin{array}{l}\text { Square } \\
\text { home } \\
\text { ranges }\end{array}$} & \multicolumn{4}{|c|}{$5 \mathrm{~m}^{2}$ square } & \multicolumn{2}{|c|}{$25 \mathrm{~m}^{2}$ square } & \multicolumn{2}{|c|}{$125 \mathrm{~m}^{2}$ square } \\
\hline & Kernel & $\mathrm{n}$ & $\mathrm{t}$ & $\mathrm{p}$ & $\mathrm{t}$ & $\mathrm{p}$ & $\mathrm{t}$ & $\mathrm{p}$ \\
\hline & $90 \%$ & 25 & -1.12 & 0.27 & -0.97 & 0.33 & -0.94 & 0.35 \\
\hline & $90 \%$ & 50 & -0.95 & 0.35 & -1.12 & 0.27 & -0.86 & 0.39 \\
\hline & $90 \%$ & 100 & -1.39 & 0.17 & -1.45 & 0.15 & -1.24 & 0.22 \\
\hline & $95 \%$ & 25 & -1.12 & 0.26 & -1.00 & 0.32 & -0.92 & 0.36 \\
\hline & $95 \%$ & 50 & -1.20 & 0.23 & -1.59 & 0.12 & -1.21 & 0.23 \\
\hline & $95 \%$ & 100 & -1.76 & 0.08 & -1.51 & 0.14 & -1.50 & 0.14 \\
\hline
\end{tabular}

\begin{tabular}{llrllllllr} 
& \multicolumn{4}{c}{$5 \mathrm{~m}^{2}$ circle } & \multicolumn{2}{c}{$25 \mathrm{~m}^{2}$ circle } & \multicolumn{2}{c}{$125 \mathrm{~m}^{2}$ circle } \\
\cline { 2 - 9 } & \multicolumn{1}{c}{ Kernel } & \multicolumn{1}{c}{$\mathrm{n}$} & $\mathrm{t}$ & $\mathrm{p}$ & $\mathrm{t}$ & $\mathrm{p}$ & $\mathrm{t}$ & $\mathrm{p}$ \\
Circular & $90 \%$ & 25 & -0.96 & 0.34 & -0.88 & 0.38 & -1.22 & 0.23 \\
home & $90 \%$ & 50 & -1.05 & 0.30 & -1.38 & 0.17 & -1.01 & 0.32 \\
ranges & $90 \%$ & 100 & -1.27 & 0.21 & -1.17 & 0.24 & -1.19 & 0.24 \\
& $95 \%$ & 25 & -1.30 & 0.20 & -0.99 & 0.33 & -1.27 & 0.21 \\
& $95 \%$ & 50 & -1.14 & 0.26 & -1.38 & 0.17 & -1.24 & 0.22 \\
& $95 \%$ & 100 & -1.61 & 0.11 & -1.62 & 0.11 & -1.52 & 0.13 \\
\hline
\end{tabular}

Table 2.9 Welch's t-tests comparing bandwidth selectors 


\begin{tabular}{llllllllll} 
& \multicolumn{1}{c}{$\mathrm{n}$} & Mean $\left(\mathrm{m}^{2}\right)$ & SD & SE & Variance & Range & Max & Min \\
\cline { 2 - 9 } & MCP & 104 & 27.96 & 21.95 & 2.15 & 481.64 & 101.86 & 102.04 & 0.18 \\
All & Bivariate Normal & 104 & 42.43 & 32.60 & 3.20 & 1062.87 & 161.55 & 161.91 & 0.35 \\
frogs & Kernel 90 (LSCV) & 104 & 17.29 & 19.94 & 1.95 & 397.48 & 149.61 & 149.90 & 0.29 \\
& Kernel 95 (LSCV) & 104 & 24.62 & 25.16 & 2.47 & 632.92 & 172.68 & 173.03 & 0.34 \\
& Kernel 90 (ad hoc) & 104 & 18.26 & 20.75 & 2.03 & 430.49 & 154.26 & 154.56 & 0.30 \\
& Kernel 95 (ad hoc) & 104 & 25.92 & 26.23 & 2.57 & 687.95 & 178.41 & 178.76 & 0.35 \\
\hline
\end{tabular}

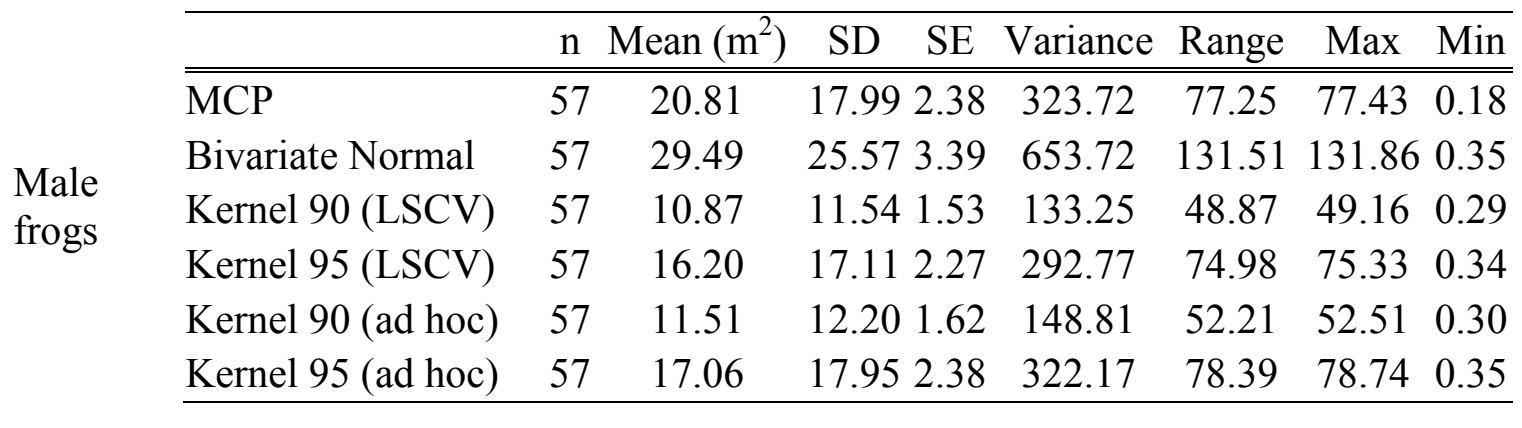

\begin{tabular}{llcccccccc} 
& \multicolumn{1}{c}{$\mathrm{n}$} & Mean $(\mathrm{m} 2)$ & SD & SE & Variance & Range & Max & Min \\
\cline { 2 - 9 } & MCP & 47 & 36.62 & 23.33 & 3.40 & 544.46 & 100.01 & 102.04 & 2.03 \\
Female & Bivariate Normal & 47 & 58.12 & 33.54 & 4.89 & 1124.83 & 157.82 & 161.91 & 4.08 \\
frogs & Kernel 90 (LSCV) & 47 & 25.08 & 24.79 & 3.62 & 614.70 & 147.17 & 149.90 & 2.73 \\
& Kernel 95 (LSCV) & 47 & 34.84 & 29.43 & 4.29 & 866.38 & 168.98 & 173.03 & 4.05 \\
& Kernel 90 (ad hoc) & 47 & 26.45 & 25.65 & 3.74 & 657.86 & 151.66 & 154.56 & 2.90 \\
& Kernel 95 (ad hoc) & 47 & 36.67 & 30.54 & 4.46 & 932.90 & 174.48 & 178.76 & 4.28 \\
\hline
\end{tabular}

Table 2.10 Home range area of adult Strawberry Poison Frogs 


\begin{tabular}{llccc}
\hline \multicolumn{1}{c}{ Method Type 1 } & \multicolumn{1}{c}{ Method Type 2 } & U & P & \\
\hline \hline Minimum Convex Polygon & Bivariate Normal & 3936 & $6.98 \mathrm{E}-04$ & $* * *$ \\
Minimum Convex Polygon & $90 \%$ Kernel (LSCV) & 7301 & $1.30 \mathrm{E}-05$ & $* * *$ \\
Minimum Convex Polygon & $95 \%$ Kernel (LSCV) & 6173 & $7.82 \mathrm{E}-02$ &. \\
Minimum Convex Polygon & $90 \%$ Kernel (ad hoc) & 7154 & $5.78 \mathrm{E}-05$ & $* * *$ \\
Minimum Convex Polygon & $95 \%$ Kernel (ad hoc) & 5987 & 0.183 & \\
Bivariate Normal & $90 \%$ Kernel (LSCV) & 8451 & $2.38 \mathrm{E}-12$ & $* * *$ \\
Bivariate Normal & $95 \%$ Kernel (LSCV) & 7438 & $2.93 \mathrm{E}-06$ & $* * *$ \\
Bivariate Normal & $90 \%$ Kernel (ad hoc) & 8299 & $2.74 \mathrm{E}-11$ & $* * *$ \\
Bivariate Normal & $95 \%$ Kernel (ad hoc) & 7298 & $1.34 \mathrm{E}-05$ & $* * *$ \\
90\% Kernel (LSCV) & $95 \%$ Kernel (LSCV) & 4284 & $9.64 \mathrm{E}-03$ & $* * *$ \\
90\% Kernel (LSCV) & $90 \%$ Kernel (ad hoc) & 5194 & 0.623 & \\
$90 \%$ Kernel (LSCV) & $95 \%$ Kernel (ad hoc) & 4146 & $3.66 \mathrm{E}-03$ & $* *$ \\
95\% Kernel (LSCV) & $90 \%$ Kernel (ad hoc) & 6374 & $2.61 \mathrm{E}-02$ & $*$ \\
$95 \%$ Kernel (LSCV) & $95 \%$ Kernel (ad hoc) & 5209 & 0.647 & \\
$90 \%$ Kernel (ad hoc) & $95 \%$ Kernel (ad hoc) & 4289 & $9.97 \mathrm{E}-03$ & $* *$ \\
\hline
\end{tabular}

Table 2.11 Mann-Whitney U test results comparing estimates by method

\begin{tabular}{lcccccccc}
\hline & $\mathrm{n}$ & Mean $\left(\mathrm{m}^{2}\right)$ & $\mathrm{SD}$ & $\mathrm{SE}$ & Variance & Range & Max & Min \\
\hline \hline PUD (All frogs) & 42 & 8.91 & 3.44 & 0.53 & 11.81 & 12.85 & 15.11 & 2.26 \\
PUD (Males) & 24 & 7.82 & 3.52 & 0.72 & 12.39 & 12.81 & 15.07 & 2.26 \\
PUD (Females) & 18 & 10.36 & 2.79 & 0.66 & 7.80 & 9.39 & 15.11 & 5.72 \\
\hline
\end{tabular}

Table 2.12 Home range estimates produced by the PUD method 


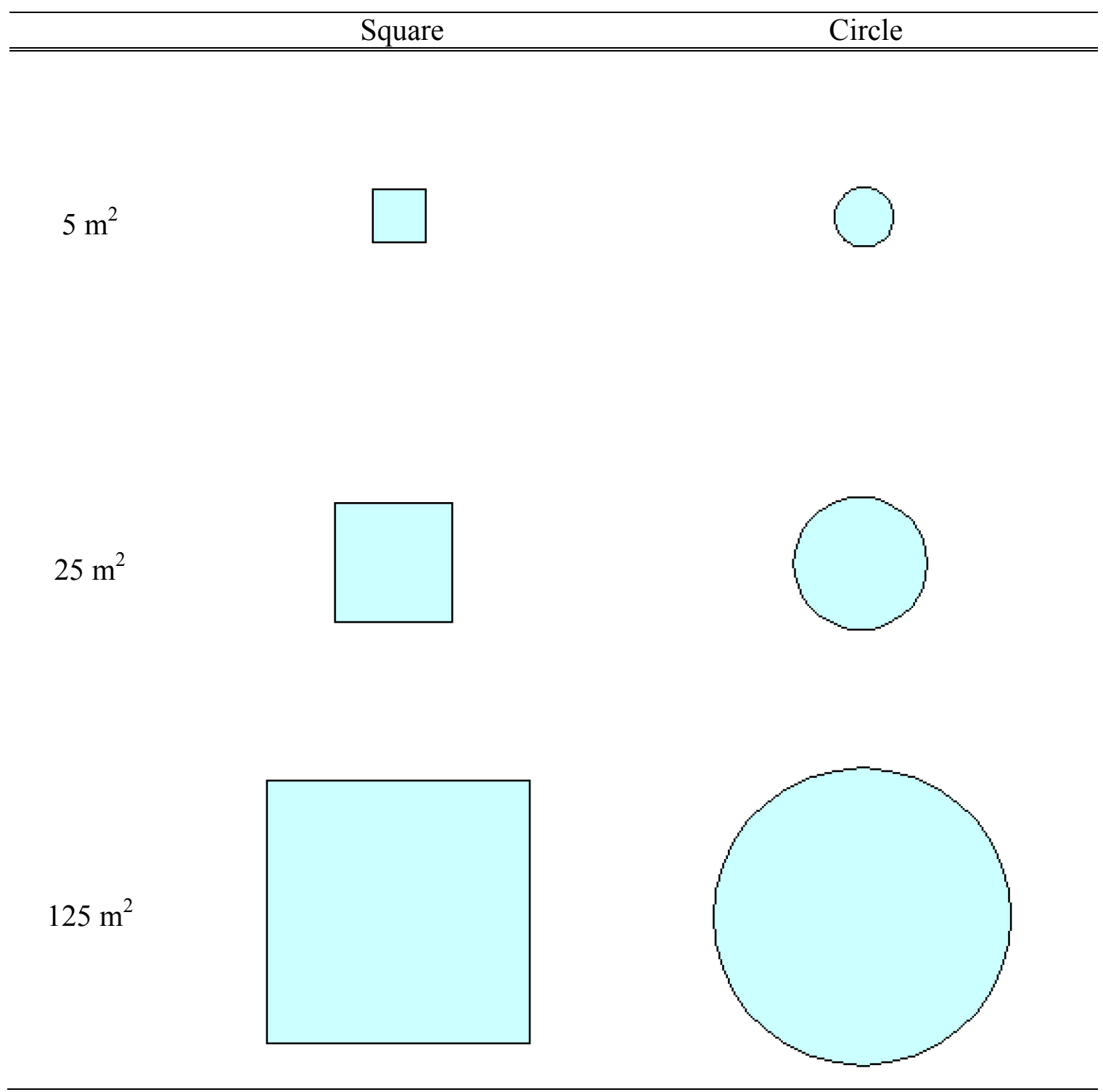

Figure 2.1 Simulated home ranges of known area 


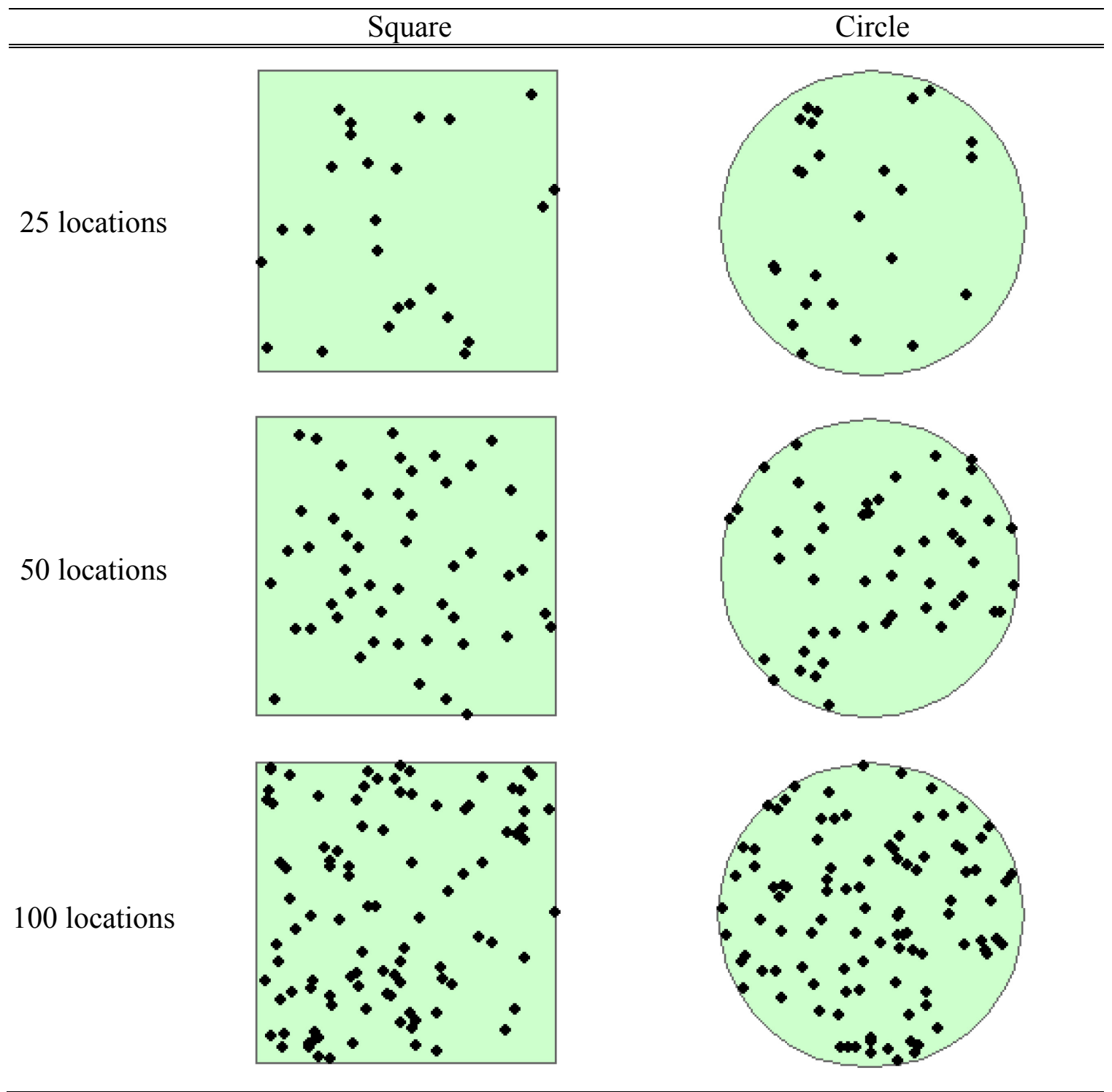

Figure 2.2 Randomly generated locations within simulated home ranges 


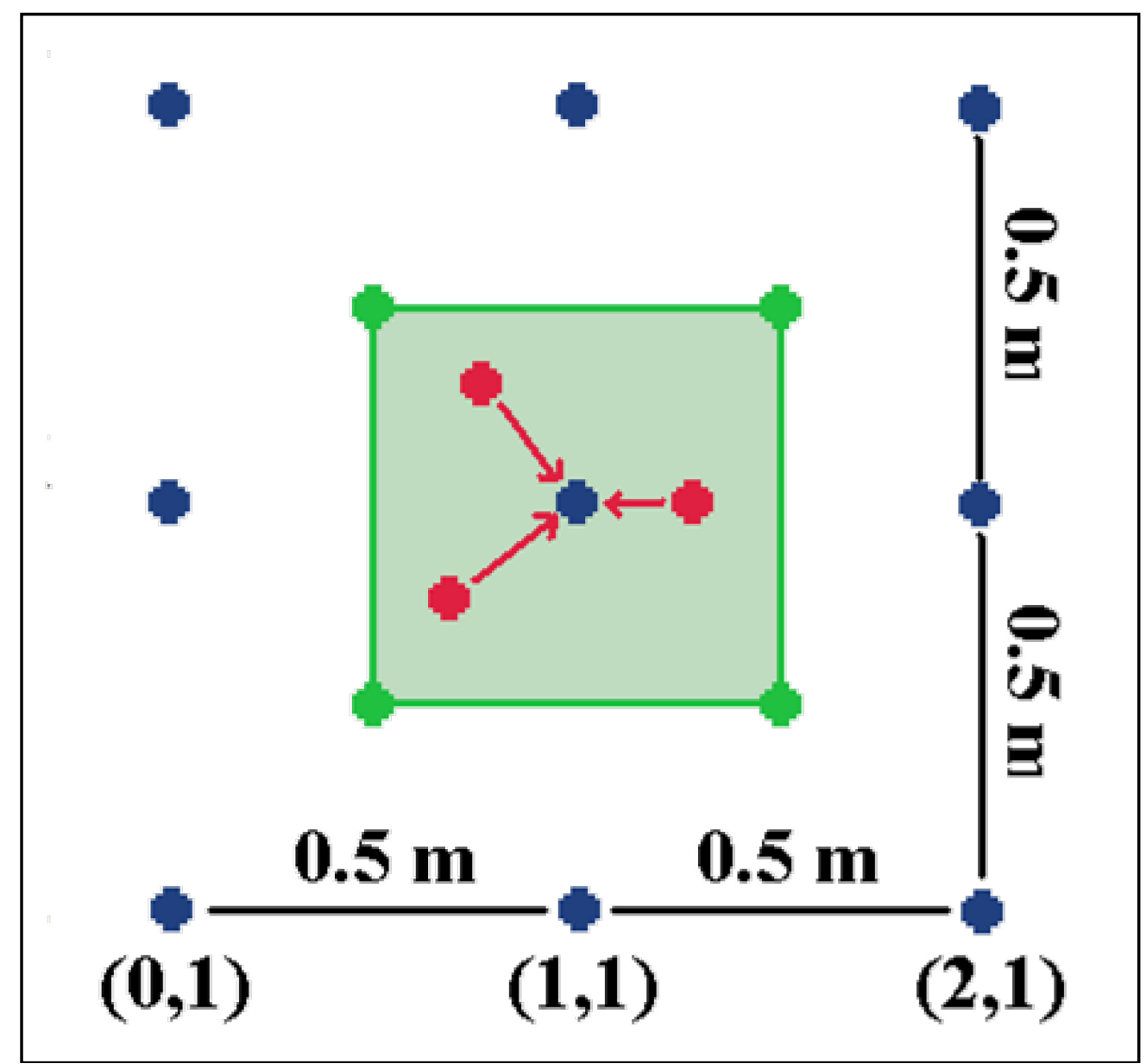

All captures within the "window" of a coordinate were assigned the same coordinate value (in this case, $x=1$ and $y=2$, for all three capture points).

Figure 2.3 Location scoring method 


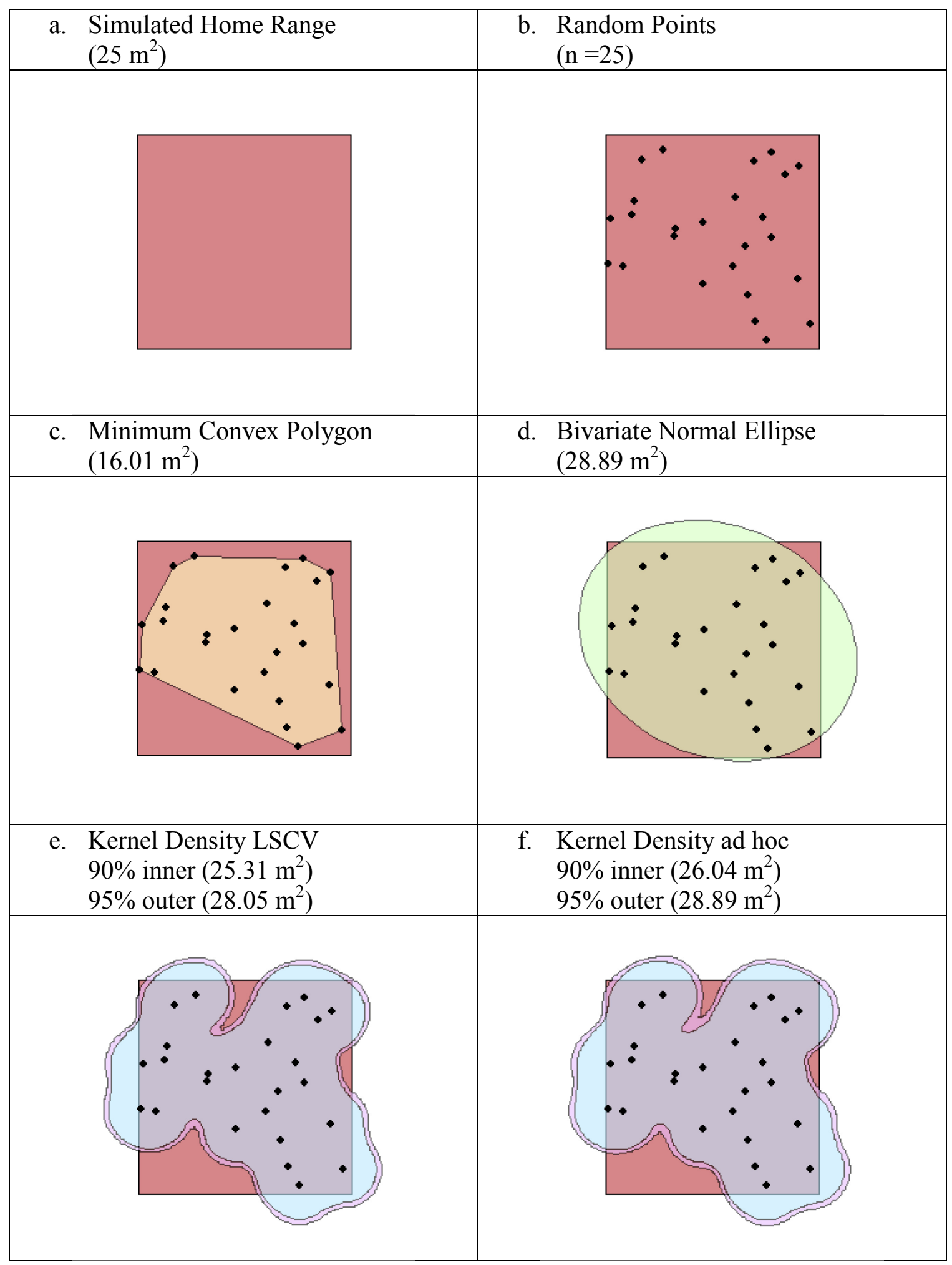

Figure 2.4 Examples of home range estimates from simulated square home range 


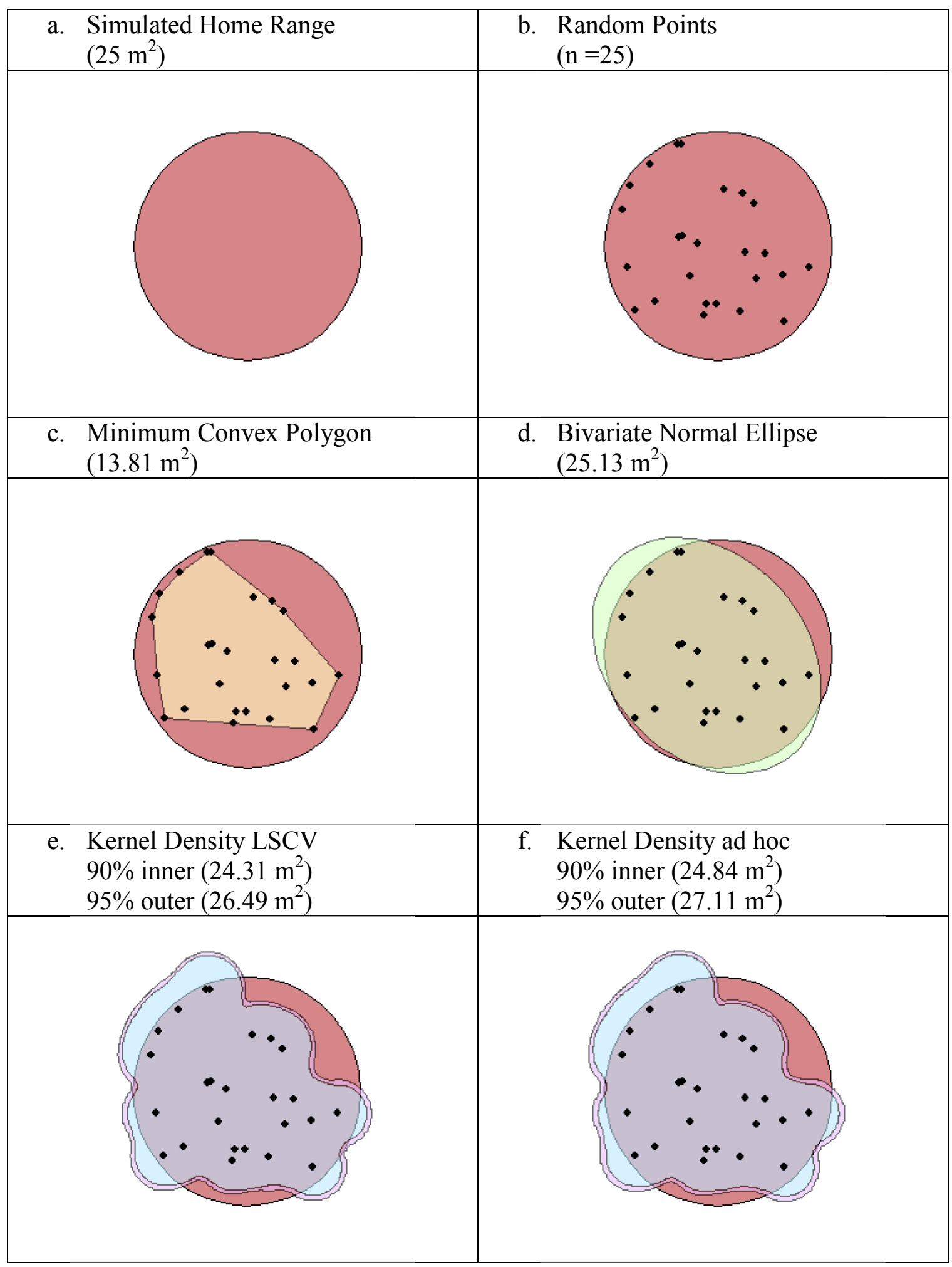

Figure 2.5 Examples of home range estimates from simulated circle home range 


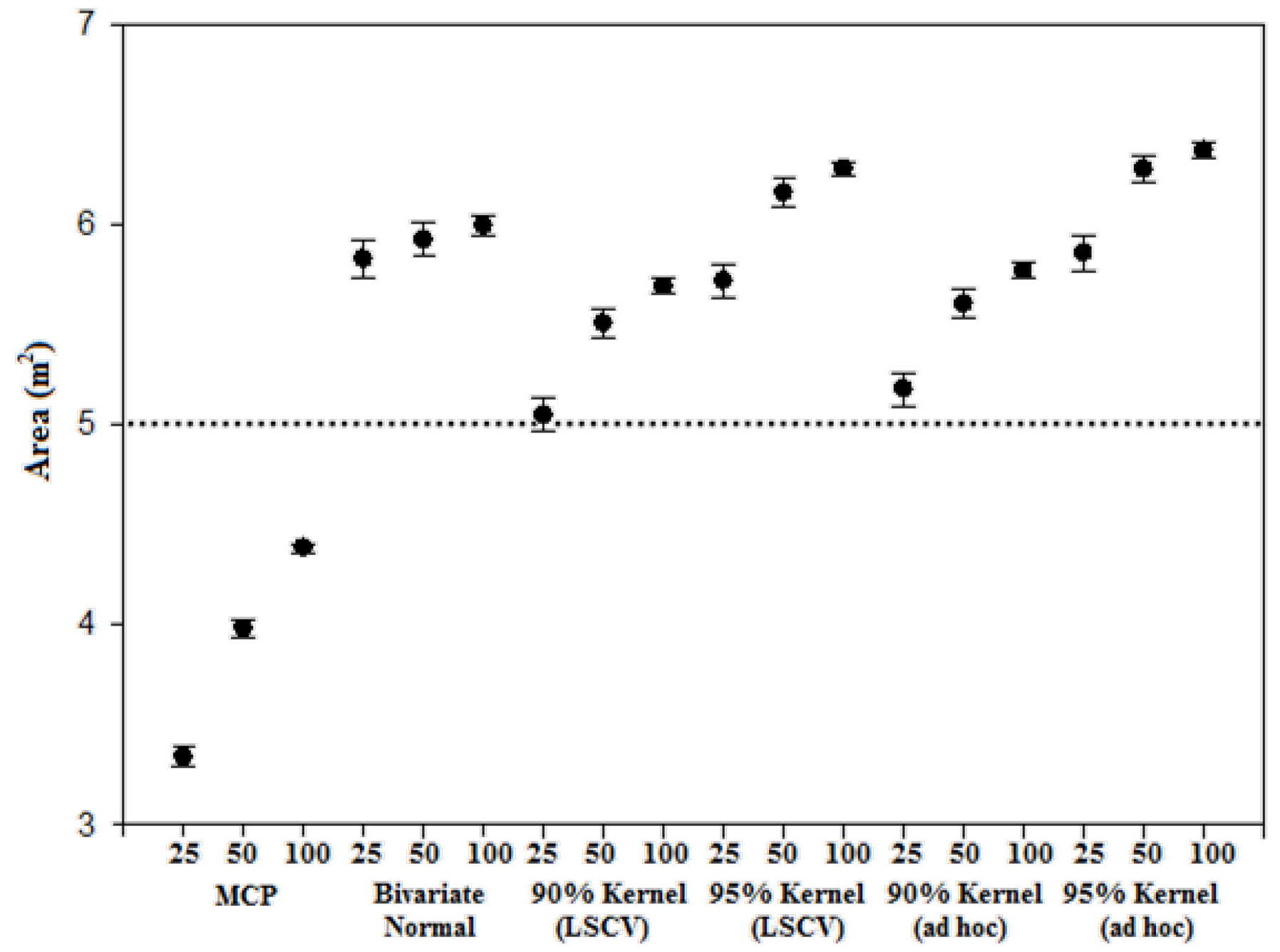

Dotted line marks the actual area of the simulated home range and bars represent standard error.

Figure 2.6 Means of home range areas by method and sample size for the $5 \mathrm{~m}^{2}$ square 


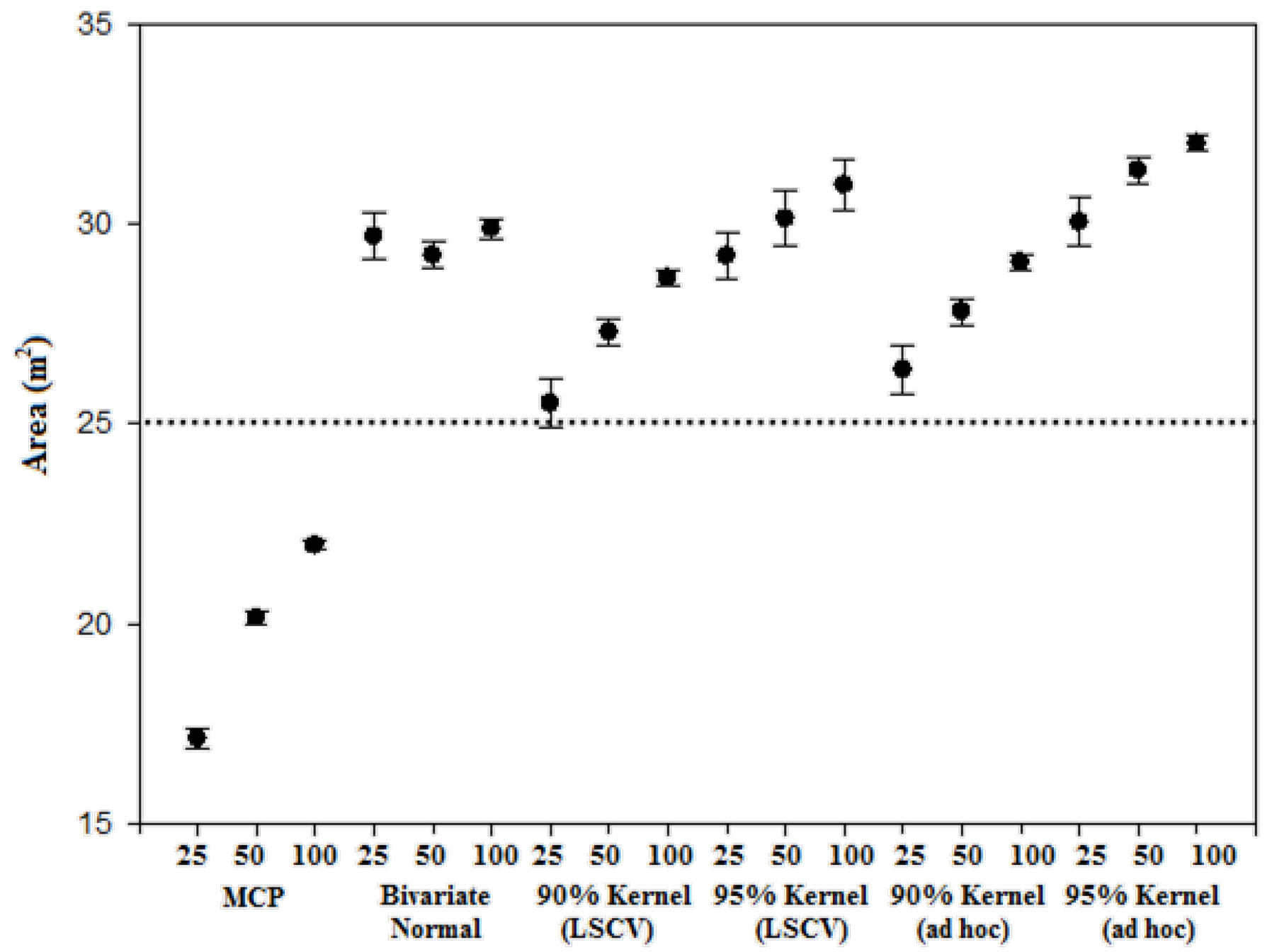

Dotted line marks the actual area of the simulated home range and bars represent standard error.

Figure 2.7 Means of home range areas by method and sample size for the $25 \mathrm{~m}^{2}$ square 


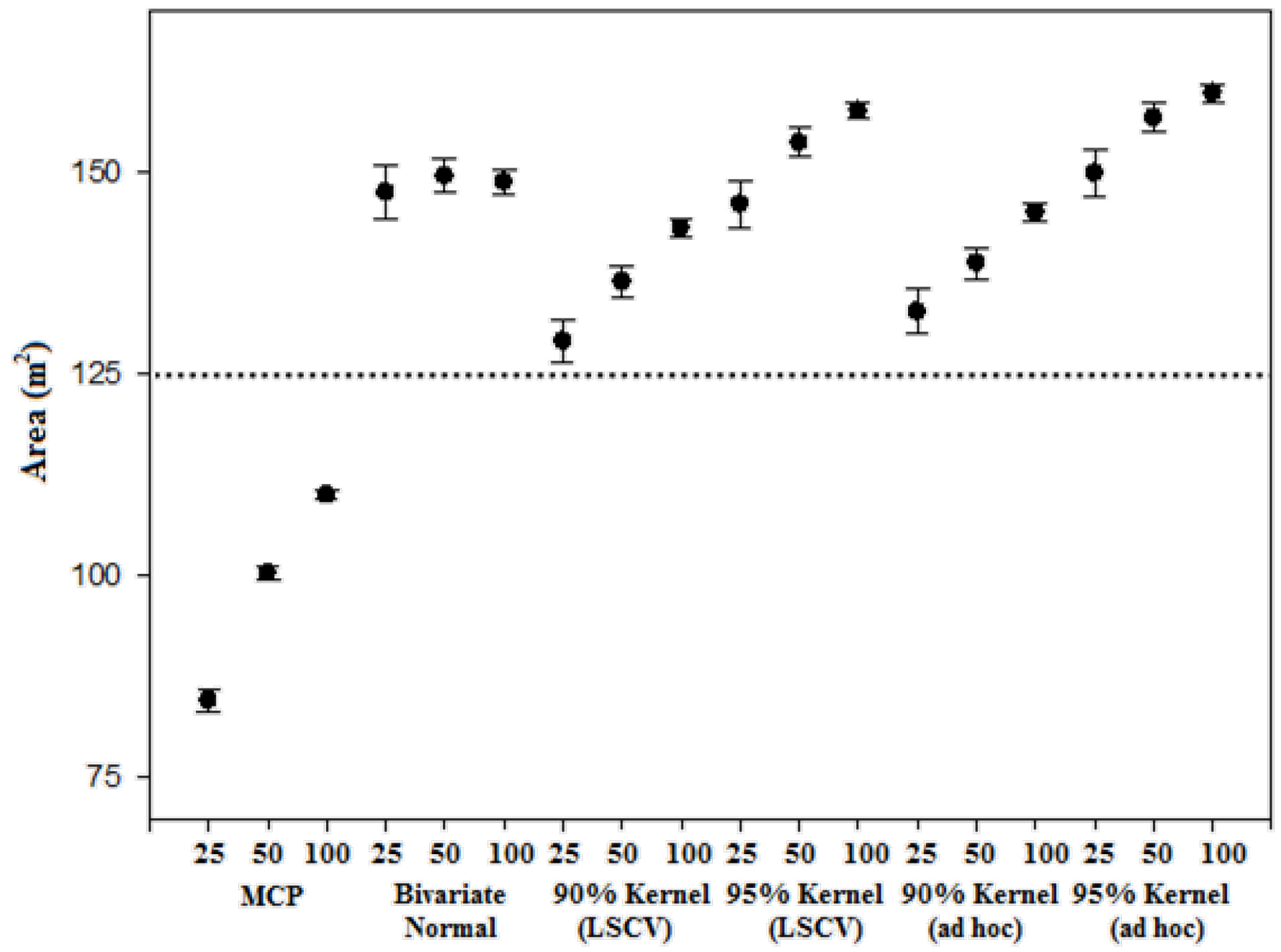

Dotted line marks the actual area of the simulated home range and bars represent standard error. igure 2.8 Means of home range areas by method and sample size for the $125 \mathrm{~m}^{2}$ square 


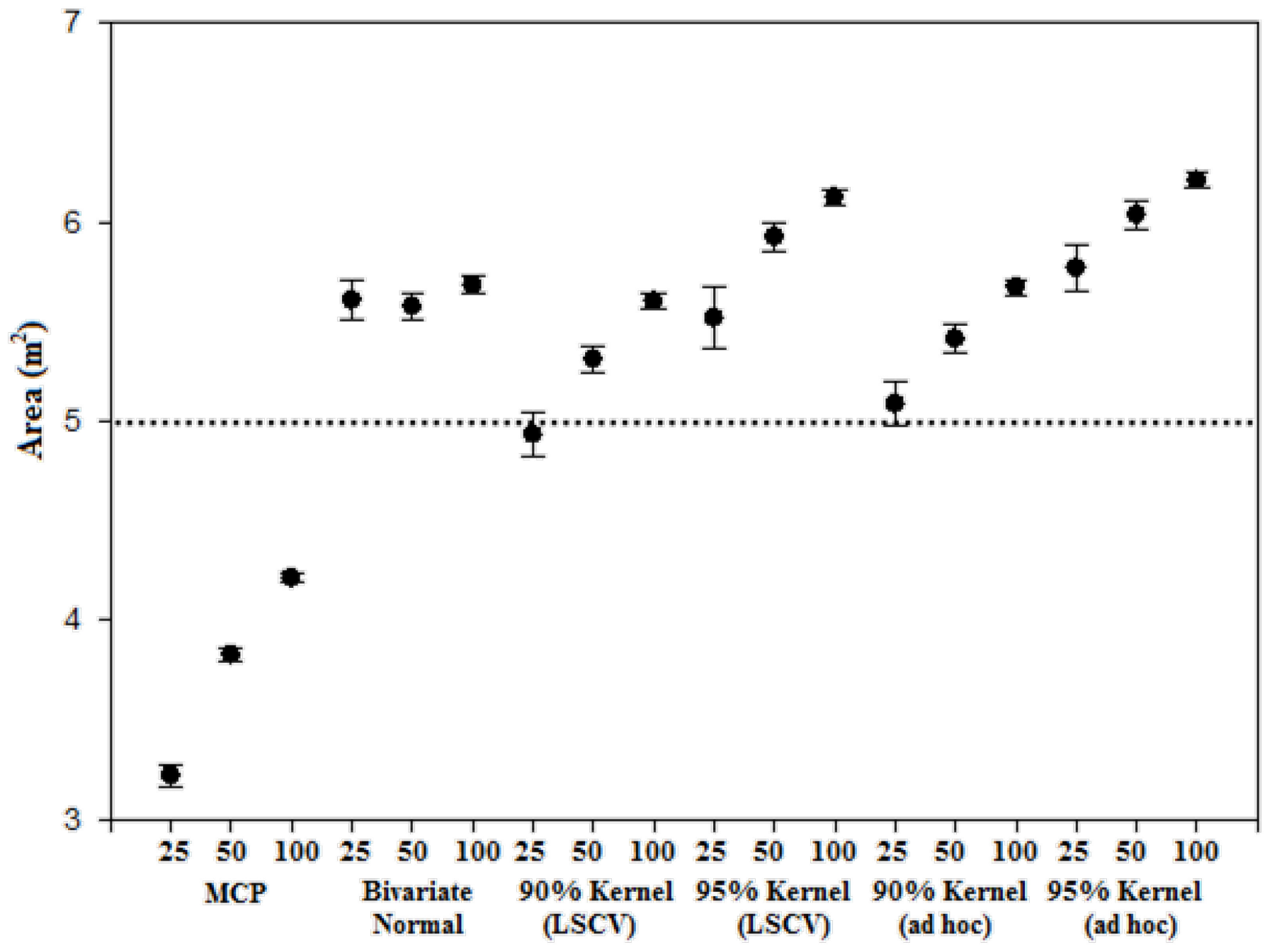

Dotted line marks the actual area of the simulated home range and bars represent standard error.

Figure 2.9 Means of home range areas by method and sample size for the $5 \mathrm{~m}^{2}$ circle 


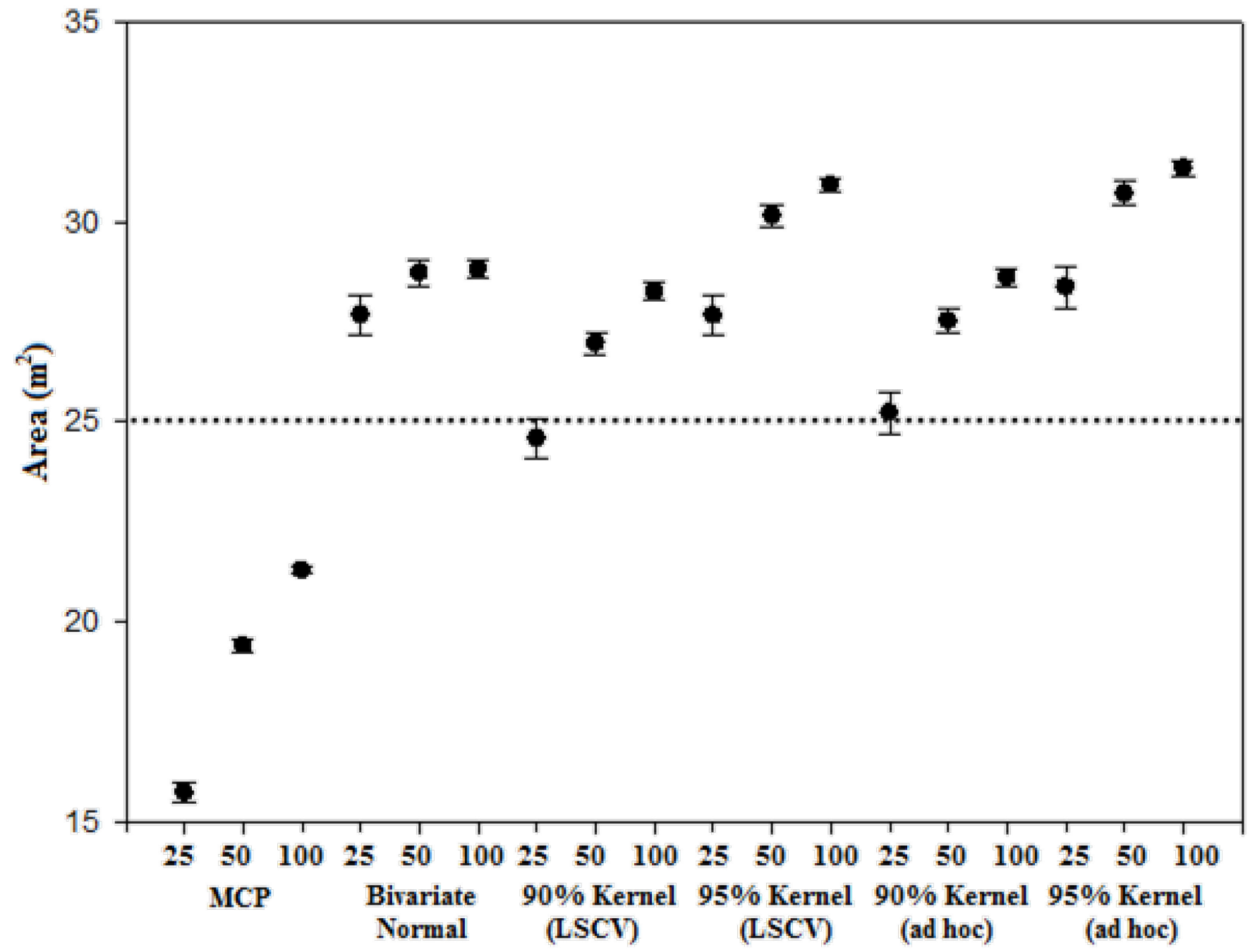

Dotted line marks the actual area of the simulated home range and bars represent standard error.

Figure 2.10 Means of home range areas by method and sample size for the $25 \mathrm{~m}^{2}$ circle 


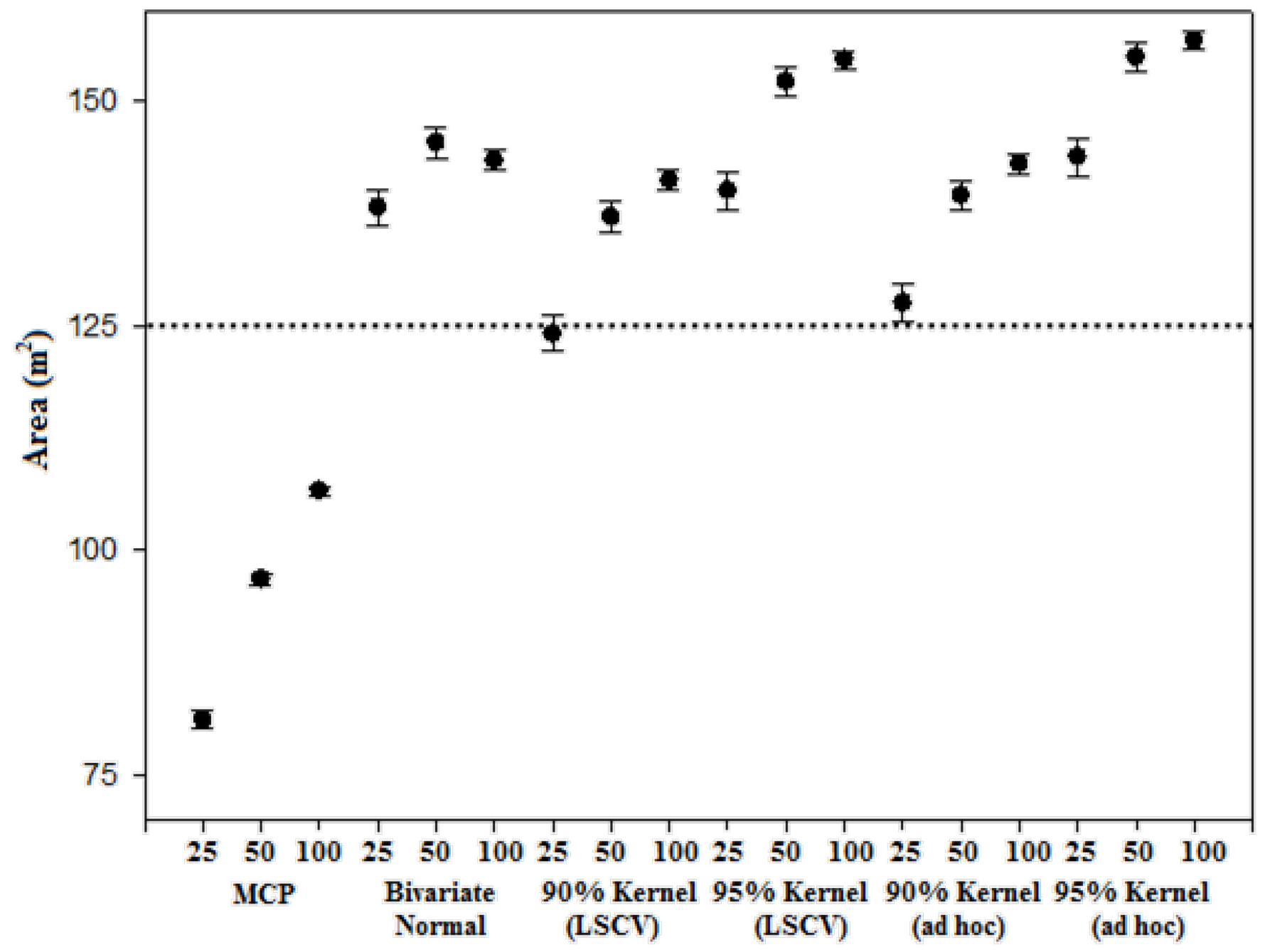

Dotted line marks the actual area of the simulated home range and bars represent standard error.

Figure 2.11 Means of home range areas by method and sample size for the $125 \mathrm{~m}^{2}$ circle 


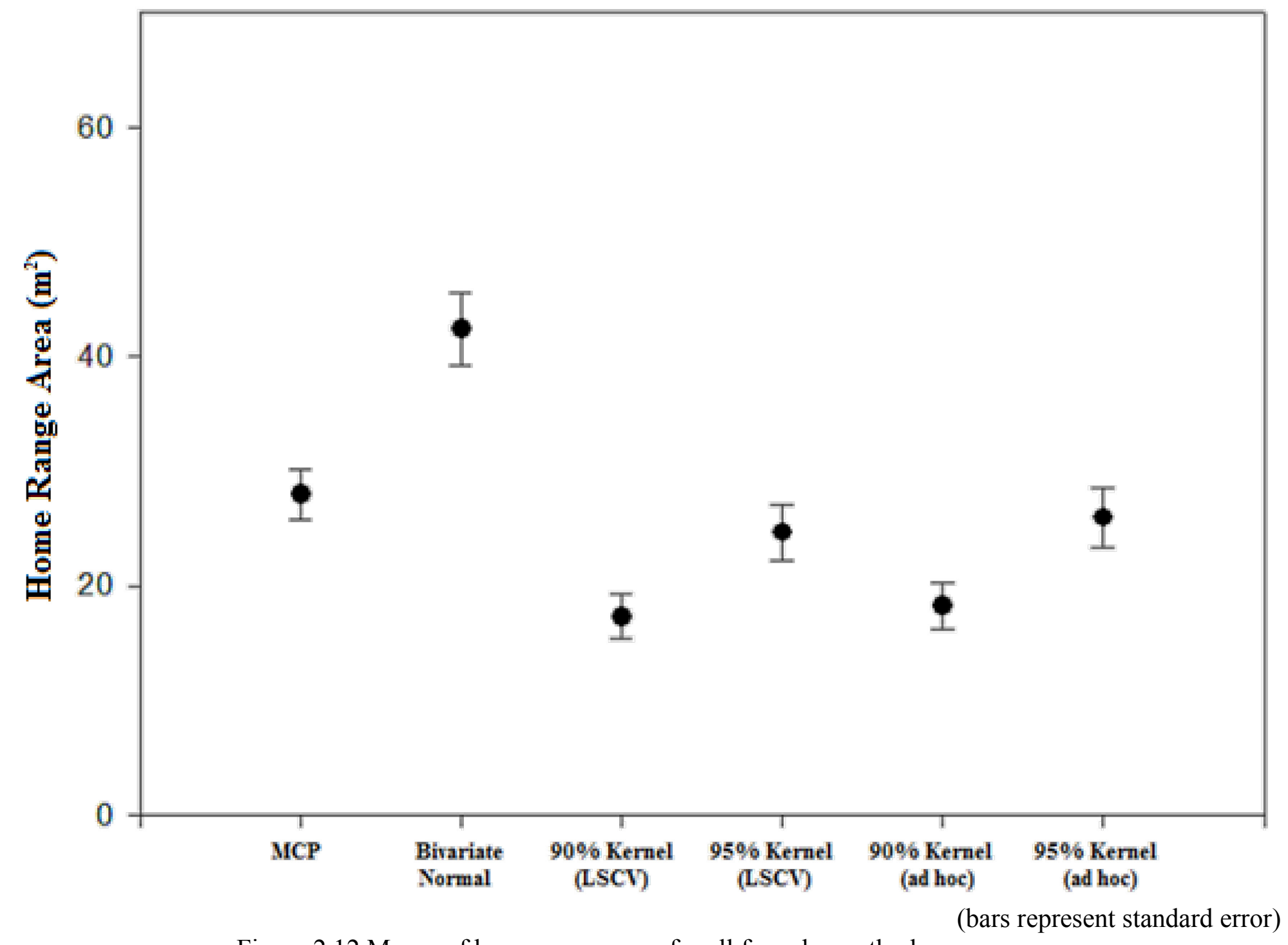

Figure 2.12 Means of home range areas for all frogs by method 


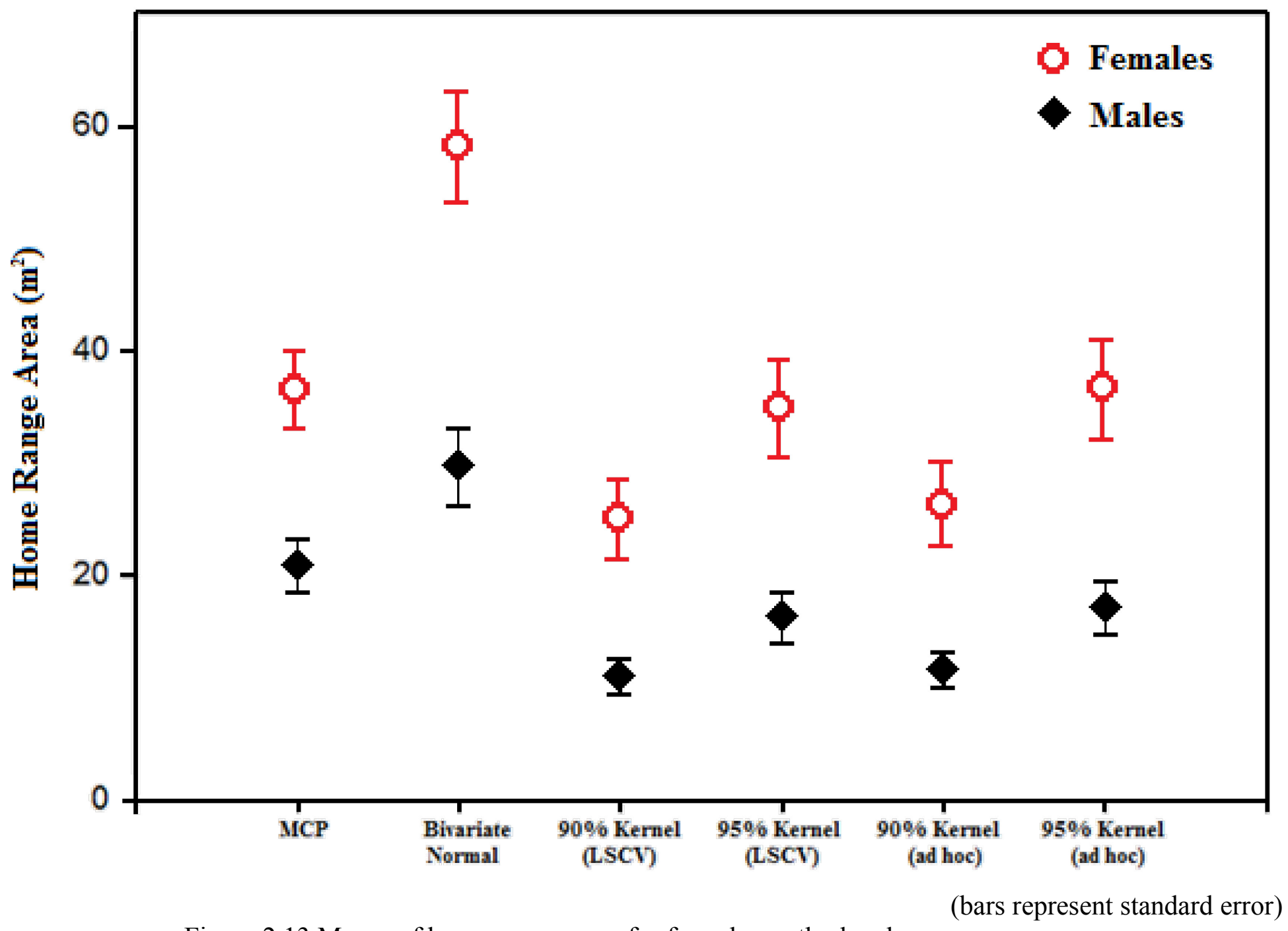

Figure 2.13 Means of home range areas for frogs by method and sex 
CHAPTER III

\section{SEX-SPECIFIC PATTERNS OF MOVEMENT AND SPACE USE IN THE}

STRAWBERRY POISON FROG, OOPHAGA PUMILIO 


\begin{abstract}
Measurements of space use and movement patterns may conceal ecologically or behaviorally important information if groups within a population are not identified and analyzed separately. In the present study, I compared the location data of 104 adult male and female Oophaga pumilio to identify differences in space use and movement.

I mapped animal locations in a Geographic Information System (GIS), where I calculated home ranges using a 90\% fixed kernel density estimator, and core areas using a 50\% fixed kernel estimator. I identified and measured overlapping home ranges and core areas and compared overlap percentage among intersexual and intrasexual pairs. Finally, I used a simple index to quantify and compare movement patterns within home ranges.
\end{abstract}

Intersexual variation was apparent in all measurements of space use and animal movement. Female frogs maintained larger home ranges with larger core areas than male frogs. Intersexual overlap of space use was higher than intrasexual overlap. The overlap of home ranges and core areas among females was greater in quantity and intensity than overlap among males. Female frogs moved more frequently among coordinates within their home ranges than did males.

Sexes also responded differently to two different resource supplementation treatments. Female home range size decreased with the addition of bromeliads while male home range size increased. In response to leaf litter additions, rates of movement among males increased. 


\section{Introduction}

\section{Home Ranges}

In addition to determining the size and shape of a home range, examining the space use intensity within home ranges by incorporating statistically based approaches such as the kernel density estimator (Worton 1989, 1995), can provide more biologically relevant information than standard methods (Powell 2000). The kernel density estimator produces a utilization distribution (UD) (Jennrich \& Turner 1969, van Winkle 1975), which summarizes the frequency of space use (Katajisto \& Moilanen 2006). When analyzed, the UD reveals that many animals use certain parts of their home range disproportionately.

Areas within a home range that are used at a greater frequency are often labeled core areas (Samuel et al. 1985). Core areas can be approximated using the kernel density estimator to select the area within the $50 \%$ isopleth. The $50 \%$ isopleth generally contains the most intensely used parts of a home range and will account for less than $50 \%$ of the total home range in a true core area (i.e., exceeds a uniform use pattern). Analysis of core areas may aid in the identification of ecological processes leading to uneven use of home ranges.

The factors resulting in disproportionate space use can be both environmental and behavior related. Territoriality (Adams 2001), resource location and availability (Moorcroft \& Barnett 2008), and the location of conspecifics (Pimm \& Rosenzweig 1981) are among factors that affect the dispersion of animals. Home range size and utilization also differ by sex (Safi et al. 2007). 


\section{Dendrobatids}

Members of the Neotropical frog family Dendrobatidae are ideal candidates for evaluating sex-specific differences of space use. Relatively long-lived and conspicuously colored, dendrobatids have been studied throughout their range using mark-recapture methods. Previous home range studies and studies involving displacement and homing demonstrate that dendrobatids restrict activities to a home range and can return to the home range when displaced (McVey et al. 1981). All species studied to date are known to be territorial (Pröhl 2005). Most of these territories have a reproductive function with frogs defending a limited reproductive resource (Donnelly 1989a,b, Summers \& McKeon 2004, Pröhl 2005). Space use is likely affected by the distribution of these critical resources. Additionally, complex parental care behavior, where parent frogs (=nurse frogs) transport tadpoles from terrestrial clutches to individual aquatic rearing sites, requires many of these species to possess detailed spatial cognition (Weygoldt 1987, Summers \& McKeon 2004). Furthermore, species in the genus Oophaga regularly return to tadpole deposition sites to feed tadpoles nutritive eggs as they develop (Weygoldt 1980).

Oophaga pumilio (=Dendrobates pumilio; Grant et al. 2006) is an aposematic poison frog (Saporito et al. 2007) which ranges from Nicaragua through Costa Rica to Panama (Savage 2002). In Costa Rica, these frogs are generally reddish-orange with blue-black appendages (Guyer \& Donnelly 2005). Home range sizes, space use and movement patterns in this frog likely vary inter-sexually (Donnelly 1989a, b).

Differences might be explained by different metabolic needs resulting from mating and breeding strategies and uneven parental care. 
Male O. pumilio defend territories within their home range (Donnelly 1989a, b) and have been observed attending terrestrial clutches in captivity (Weygoldt 1984). The home range shape of male frogs should reflect territoriality with reasonably small (i.e., defendable) core areas. Furthermore, O. pumilio males should have minimally overlapping home ranges and core areas. Selection of a territory may be influenced by the presence of female frogs as well as an absence of competing males. Once a territory is acquired, males may hold the space because the costs associated with moving may exceed the benefits gained from the move.

Females may be more mobile than males if they engage in mate selection. Moreover, O. pumilio females function as nurse frogs and are responsible for transporting tadpoles to the water-filled axils of bromeliads and other plants and returning regularly to feed offspring nutritive eggs (Limerick 1980, Brust 1993, Stynoski 2009). Female home ranges may include access to multiple males in addition to tadpole-rearing sites. The numerous tasks for which female frogs are responsible likely lead to the establishment of home ranges and core areas that are multimodal (i.e., multiple centers of activity).

Using the population utilization distribution (PUD) method (Ford \& Krumme 1979) to pool the relocation distances of multiple animals to estimate the home range of an "ideal, average individual," Donnelly (1989b) found that females of a Costa Rican population of $O$. pumilio had larger home ranges than males, females occurred more often with both males and other females while males co-occurred less often, and that tadpole-rearing sites appeared to be a limiting reproductive resource. These results established a size value and borders, but did not explore the detailed space use within the home range. 
I incorporated the robust dataset of frog locations from Donnelly's study into a GIS to identify and describe differences between sexes of $O$. pumilio by examining movement and space use patterns. I also developed an index of vagility to quantify the tendency for animals to move within the home range.

\section{Methods}

The original experiment was a fully crossed design with two reproductive resource addition treatments (bromeliads and leaf litter) at two levels for each treatment (Table 3.1). There was no significant difference in home range size associated with the treatments when home ranges were estimated using the "ideal average animal" approach of the Population Utilization Distribution method. Furthermore, I expect the sevenmonth treatment period was too short in these long-lived animals (Donnelly, pers. comm.) for any treatment effects to emerge. However, Donnelly (1989b) found that females had larger home range sizes than males. By including the sex of the animals as a third factor (Table 3.1); I investigated space-use patterns between the sexes. Using a three-factor ANOVA, I tested significance for each of the three main effects, each of the three two-way interactions, and the three-way interaction. I suspected that other measures of home range size and space use (e.g., core area size and overlap) would also differ between males and females.

In addition to a difference in home range size, I expected territoriality in males would lead to smaller core areas and less home range and core area overlap than females. I also expected that mate selection and parental care in females would result in larger home ranges and core areas as they traveled among male territories and tadpole 
deposition sites. Increased space use should also lead to a high prevalence of home range and core area overlap among female frogs.

\section{Home Range and Core Area Estimation}

I used the Animal Movement Extension version 2.0 (Hooge \& Eichenlaub 2000) in ArcView GIS 3.3 (ESRI 2002) to calculate home range and core area estimates of 104 adult frogs ( 57 males, 47 females) with 20 or more captures. Because the commonly used Minimum Convex Polygon (Mohr 1947) and Bivariate Normal (Jennrich and Turner 1969) methods generate largely inaccurate estimates of home range size and the fixed kernel density estimator performs well even at smaller sample sizes when working at relatively small scales (see Chapter two), I used the $90 \%$ kernel density isopleth to estimate home range and 50\% isopleths to define core areas. I used the Least-Squares Cross-Validation (LSCV) method to select the smoothing parameter for the kernel estimates since I found estimates generated using LSCV selected bandwidths were more accurate than estimates produced using bandwidths selected with the ad hoc bandwidth selector (see Chapter two).

\section{Overlap of Home Ranges and Core Areas}

I investigated male-male, male-female, and female-female overlap in both home ranges and core areas. I used the Intersect tool in ArcMap 9.3.1 (ESRI 2009) to identify overlapping home ranges and core areas and calculated the overlapping areas and the percentage of overlap in relation to the home ranges and core areas for each overlapping pair. 
The Biological Index of Vagility (BIV)

One way to examine how an animal uses its home range is to determine how it moves among coordinates in the home range. Calculating the total distance traveled or the number of moves made between coordinates returns values that are difficult to compare when the number of captures among individual animals are uneven. The Biological Index of Vagility (BIV) is a simple index that compares the number of moves among coordinates to the total number of captures minus one (Equation 3.1). Subtracting one from the total number of captures forces the index values to vary between zero and one.

$$
\mathrm{BIV}=\frac{\text { Number of movements }}{\text { Number of captures }-1}
$$

Equation 3.1

Sedentary animals will have a BIV approaching zero, while highly vagile animals will have a BIV approaching one. This index thus allows for the comparison of animals with an unequal number of captures. Additionally, the index will provide more space use information than a home range area value alone.

To illustrate this, imagine two animals each captured three times at the same four coordinates (for a total of twelve captures per animal). Because the four points cover the same area and the usage is even, all home range values for these two animals would be equal, regardless of the method used. The first animal is more sedentary and moves only three times (sequentially among the four points). The second animal is very vagile and moves eleven times among the sites. The BIV for the first animal would equal 0.273 and 
the BIV for the second animal would equal 1 (Figure 3.1), revealing the difference that a home range estimator alone is unable to show.

I defined capture locations greater than 25 centimeters apart as a movement and, using the three factor design above, calculated BIV scores and compared values with a three way ANOVA. I did not expect any treatment effect, but did expect frog vagility to relate to home range size, with larger BIV values associated with larger home range sizes. I predicted that females will be more vagile than males. Female frogs, having larger home ranges (and because of extensive travel involved in parental care) would have higher BIV values than males.

\section{Data Analysis}

I used log transformations on home range and core area values and square transformations on Biological Index of Vagility values to approximate a normal distribution before analyses. I analyzed home range, core area, and BIV values using three-factor ANOVA's and general linear models. I compared home range and core area overlaps using Mann-Whitney U tests because overlap values were not normally distributed. I performed all statistical analyses in the $\mathrm{R}$ software environment $(\mathrm{R}$ Development Core Team 2010).

\section{Results}

Home Range and Core Areas

Home range size, estimated using a 90\% kernel estimator with LSCV-selected bandwidths ranged from $0.29 \mathrm{~m}^{2}$ to $49.16 \mathrm{~m}^{2}$ in males (mean $=10.87 \mathrm{~m}^{2}$; Table 2.10 ) and 
$2.73 \mathrm{~m}^{2}$ to $149.90 \mathrm{~m}^{2}$ in females (mean $=25.08 \mathrm{~m}^{2}$; Table 2.10). Analysis of variance indicated there was a highly significant effect of $\operatorname{sex}(\mathrm{P}<0.001)$, a significant effect of bromeliad additions ( $(\mathrm{P}=0.030)$, and a significant interaction between the effects of sex and bromeliad additions $(\mathrm{P}=0.038)$ on home range size (Table 3.2). Home range size in females was significantly larger than home range size in males (Figure 3.2). Home ranges on bromeliad addition plots were significantly smaller than on plots without bromeliad treatment (Figure 3.3). Litter addition did not affect home range size (Figure 3.4). Home ranges of females were significantly smaller on bromeliad addition plots than on plots without bromeliad addition (Figure 3.5 ). The home range size was not greatly affected by leaf litter additions (Figure 3.6). Home range sizes on bromeliad addition plots were significantly smaller than on plots without bromeliad addition regardless of the litter treatment (Figure 3.7).

Core area size, estimated using a 50\% kernel estimator with LSCV-selected bandwidths averaged $2.28 \mathrm{~m}^{2}$ (ranging from $0.07 \mathrm{~m}^{2}$ to $11.01 \mathrm{~m}^{2}$ ) in males, and $5.18 \mathrm{~m}^{2}$ (ranging from $0.89 \mathrm{~m}^{2}$ to $26.81 \mathrm{~m}^{2}$ ) in females. Core areas demonstrated similar trends to home ranges. Analysis of variance indicated there was a highly significant effect of sex $(\mathrm{P}<0.001$; Figure 3.8), a significant effect of bromeliad additions ( $\mathrm{P}=0.010$; Figure 3.9), and a significant effect of the interaction between sex and bromeliads $(\mathrm{P}=0.013$; Figure 3.11) on core area size (Table 3.3). Males had significantly smaller core areas than females (Figure 3.8). Core areas on bromeliad addition plots were significantly smaller than core areas on plots without bromeliad additions (Figure 3.9). Leaf litter supplementation had little effect on core area sizes (Figure 3.10). Female core areas were smaller and male core areas were larger on bromeliad addition plots when compared to 
plots without bromeliad additions (Figure 3.11). Leaf litter additions did not affect the core area size of either sex significantly (Figure 3.12). Core areas on plots with bromeliad additions were smaller than on plots without bromeliad additions regardless of litter treatment (Figure 3.13).

\section{Overlap of Home Ranges and Core Areas}

Frog home range overlap ranged from $0.1 \%$ to $100 \%$ (Table 3.4 ). Overlap was greatest between male and female frogs at an average of $45.3 \%$ and a total of 113 pairings. The overlap between the home ranges of male and female frogs was significantly greater than the overlap between same-sex pairs (Figure 3.14). Femalefemale home range overlap (mean $=32.5 \% ; 53$ pairs) was significantly higher than malemale home range overlap $($ mean $=26.2 \% ; 49$ pairs $)$.

Core area overlap ranged from $0.1 \%$ to $100 \%$ (Table 3.4 ) and was significantly higher in opposite-sex pairs at $61.5 \%$ among 46 pairs. The difference between same-sex pair overlap percentage was not significant (mean female-female overlap $=38.0 \%$ and mean male-male overlap $=34.0 \%$; Figure 3.15 ). However, there was a greater frequency of core area overlap between females (28 pairs) than between males (12 pairs).

\section{The Biological Index of Vagility}

Movement patterns as calculated by the Biological Index of Vagility (BIV) and analyzed with a three-factor ANOVA showed a strong sex effect $(P=0.0076)$ and a borderline significant $(\mathrm{P}=0.078)$ effect of the interaction between leaf litter and sex (Table 3.5). Female frogs demonstrated a much greater rate of movement than male 
frogs (Figure 3.16). Frogs moved less frequently on bromeliad addition plots (Figure 3.17). Rates of movement as measured with BIV were also lower on leaf litter addition plots than on plots without litter additions, although the difference was not significant for females (Figure 3.18). Sexes responded differently with bromeliad and leaf litter additions (Figures 3.19-3.20). Males moved more often on bromeliad addition plots than on plots without bromeliad supplementation. In contrast, females moved less on bromeliad addition plots than on plots without bromeliad additions. These trends were reversed by leaf litter addition, with males moving considerably less and females moving more on leaf litter addition plots than on plots without the treatment. Overall, frog movement was lower on bromeliad addition plots when (compared to plots without bromeliad addition, regardless of the leaf litter treatment (Figure 3.21). As expected, BIV scores for both sexes were highly correlated with home range size (Figure 3.22).

\section{Discussion}

Movement rates and space use requirements are important for understanding the biology of an animal. However, these measurements may reflect large variation within a population resulting from intraspecific differences of space use and movement patterns. Information may be obscured when data from different intraspecific groups are analyzed together. In the present study, I focused on identifying differences between the sex classes of adult Oophaga pumilio. Once isolated as independent groups, significant intersexual differences in space use and movement were revealed. Female frogs use more space (when comparing both home range and core area size) and move more often (as measured with an index of vagility) than male frogs. Home range and core area overlap 
patterns differ among sex pairs. Furthermore, sexes respond differently to different resource supplementation treatments.

Home range and core area sizes of female frogs were larger and showed higher variation than home range and core area sizes of males. The variation among home range and core area sizes of female frogs may reflect differences in reproductive status. Haase and Pröhl (2002) found that tadpole-rearing female frogs maintain smaller home ranges (presumably engaged primarily in parental care) than sexually receptive, non-rearing female frogs (which may be exploring mate or resource options). More accurate measurements of space use needs will require future studies to distinguish among different groups based not only on sex, but perhaps on reproductive status as well.

The Biological Index of Vagility revealed that female frogs moved more frequently among coordinates within their home range, while males remained highly sedentary. Movement patterns scaled well with home range size; increased vagility correlating with increased home range size in both sexes. In most cases, changes in vagility as a response to resource treatments intuitively mirrored changes in home range size in response to resource treatments; increases/decreases in home range size corresponded with increases/decreases in vagility (but see below).

Home range and core area overlap between opposite-sex pairs was greater than between same-sex pairs in both quantity and intensity (i.e., percent overlap). Furthermore, among intersexual pairs, in 43 pairings over $80 \%$ of the core area of a male frog was contained within the home range of a female frog, whereas the opposite (greater than $80 \%$ of the core area of a female contained within the home range of a male) occurred in only seven pairs. The high prevalence of female space use overlapping 
multiple male home ranges provided strong evidence that females of this species may select mates. Overlap among males, if analyzed temporally, may indicate territory disputes or takeovers.

Although leaf litter supplementation did not affect the home range or core area size of either sex, bromeliad addition had a significant effect on home range and core area size. Male and female frogs responded differently to bromeliad additions. The home range and core area sizes of male frogs were larger on plots with additional bromeliads than on plots without bromeliad additions, while the home range and core area sizes of female frogs were smaller on bromeliad-addition plots than on plots that did not receive the supplementation. The "increase" seen in the home ranges of male frogs may indicate an adjustment of territory size to compensate for recalculations of the costs and benefits of defending additional resources following an increase in the density of the limiting reproductive resource (Adams 2001). The "decrease" in home range size seen in female frogs on bromeliad addition plots may reflect a reduced need to locate unique tadpoledeposition sites. Reduced home range size with bromeliad addition suggests that bromeliads are the limiting reproductive resource. Additionally, it may provide evidence for territorial behavior in tadpole-rearing female frogs (Haase and Pröhl 2002).

One surprising result from the present study was the large difference in male vagility scores in response to leaf litter supplementation. This difference was not seen in female frogs. Although home range and core area size was unaffected, male movement decreased significantly on leaf litter addition plots. The arthropod prey items of $O$. pumilio reside in leaf litter (Levings \& Windsor 1985) and an increase in leaf litter may 
have led to an increase in prey abundance. Female frogs, presumably occupied with rearing young, would need to feed "on the run," and reduced movement in male frogs could, therefore, correspond to a reduction in the need to actively search for prey, especially given the possibility of a "sit-and-eat" mode of foraging in O. pumilio (Donnelly 1991). 


\section{REFERENCES}

Adams, E.S. (2001) Approaches to the study of territory size and shape. Annual Review of Ecology and Systematics, 32, 277-303.

Brust, D. (1993) Maternal brood care by Dendrobates pumilio: a frog that feeds its young. Journal of Herpetology, 27, 96-98.

Donnelly, M.A. (1989a) Demographic effects of reproductive resource supplementation in a territorial frog, Dendrobates pumilio. Ecological Monographs, 59, 207-221.

Donnelly, M.A. (1989b) Effects of reproductive resource supplementation on space-use patterns in Dendrobates pumilio. Oecologia, 81, 212-218.

Donnelly, M.A. (1991) Feeding Patterns of the Strawberry Poison Frog, Dendrobates pumilio (Anura: Dendrobatidae). Copeia, 1991, 723-730.

ESRI (2002) ArcView GIS 3.3. Environmental Systems Research Institute. Redlands, CA, USA.

ESRI (2009) ArcMap GIS 9.3.1. Environmental Systems Research Institute. Redlands, CA, USA.

Ford, R.G. \& Krumme, D.W. (1979) The analysis of space use patterns. Journal of theoretical biology, 76, 125-155.

Grant, T., Frost, D.R., Caldwell, J.P., Gagliardo, R., Haddad, C.F., Kok, P.J., Means, D.B., Noonan, B.P., Schargel, W.E. \& Wheeler, W.C. (2006) Phylogenetic systematics of dart-poison frogs and their relatives (Amphibia: Athesphatanura: Dendrobatidae). Bulletin of the American Museum of Natural History, 299, 1-262.

Guyer, C. \& Donnelly, M.A. (2005) Amphibians and reptiles of La Selva, Costa Rica, and the Caribbean Slope: A comprehensive guide. University of California Press, Berkeley and Los Angeles.

Haase, A., \& Pröhl, H. (2002) Female activity patterns and aggressiveness in the strawberry poison frog Dendrobates pumilio (Anura: Dendrobatidae). AmphibiaReptilia, 23, 129-140.

Hooge, P.N. \& Eichenlaub, W.M. (2000) Animal Movement extension to Arcview verison 2.0. Alaska Science Center - Biological Science Office, U.S. Geological Survey, Anchorage, AK, USA.

Jennrich, R. \& Turner, F. (1969) Measurement of non-circular home range. Journal of Theoretical Biology, 22, 227-237. 
Katajisto, J. \& Moilanen, A. (2006) Kernel-based home range method for data with irregular sampling intervals. Ecological Modelling, 194, 405-413.

Levings S.C., \& Windsor, D.M. (1985) Litter arthropod populations in a tropical deciduous forest: relationships between years and arthropod groups. Journal of Animal Ecology, 54, 61-69.

Limerick, S. (1980) Courtship behavior and oviposition of the poison-arrow frog Dendrobates pumilio. Herpetologica, 36, 69-71.

McVey, M.E., Zahary, R., Perry, D. \& MacDougal, J. (1981) Territoriality and homing behavior in the poison dart frog (Dendrobates pumilio). Copeia, 1981, 1-8.

Mohr, C.O. (1947) Table of equivalent populations of North American small mammals. American Midland Naturalist, 37, 223-249.

Moorcroft, P.R. \& Barnett, A. (2008) Mechanistic home range models and resource selection analysis: a reconciliation and unification. Ecology, 89, 1112-1119.

Pimm, S.L. \& Rosenzweig, M.L. (1981) Competitors and habitat use. Oikos, 37, 1 - 6.

Powell, R.A. (2000) Animal home ranges and territories and home range estimators. Research techniques in animal ecology: controversies and consequences. Boitani, L. \& Fuller, T.K.),pp. 65-110. Columbia University Press, New York.

Pröhl, H. (2005) Territorial behavior in dendrobatid frogs. Journal of Herpetology, 39, 354-365.

R Development Core Team (2010) R: A language and environment for statistical computing. R Foundation for Statistical Computing, Vienna, Austria.

Safi, K., Konig, B. \& Kerth, G. (2007) Sex differences in population genetics, home range size and habitat use of the parti-colored bat (Vespertilio murinus, Linnaeus 1758) in Switzerland and their consequences for conservation. Biological Conservation, 137, 28-36.

Samuel, M.D., Pierce, D.J., \& Garton, E.O. (1985) Identifying areas of concentrated use within the home range. Journal of Animal Ecology, 54, 711-719.

Saporito, R.A., Zuercher, R., Roberts, M., Gerow, K. \& Donnelly, M.A. (2007) Experimental evidence for aposematism in the dendrobatid poison frog Oophaga pumilio. Copeia, 2007, 1006-1011.

Savage, J.M. (2002) The amphibians and reptiles of Costa Rica: a herpetofauna between two continents, between two seas. University of Chicago Press, Chicago. 
Stynoski, J.L. (2009) Discrimination of offspring by indirect recognition in an eggfeeding dendrobatids frog, Oophaga pumilio. Animal Behaviour, 78, 1351-1356.

Summers, K. \& McKeon, C. (2004) The evolutionary ecology of phytotelmata use in Neotropical poison frogs. Ecology and evolution of phytotelm-breeding anurans.Lehtinen, R.M.),pp. 55-73. Miscellaneous Publications of the Museum of Zoology University of Michigan, Ann Arbor.

van Winkle, W. (1975) Comparison of several probabilistic home-range models. The Journal of Wildlife Management, 39, 118 - 123.

Weygoldt, P. (1980) Complex brood care and reproductive behaviour in captive poisonarrow frogs, Dendrobates pumilio O. Schmidt. Behavioral Ecology and Sociobiology, 7, 329-332.

Weygoldt, P. (1984) Contribution to the reproductive biology of captive Dendrobates pumilio Schmidt, 1857 (Salientia: Dendrobatidae). Salamandra, 20, 112-120.

Weygoldt, P. (1987) Evolution of parental care in dart poison frogs (Amphibia: Anura: Dendrobatidae). Journal of Zoological Systematics and Evolutionary Research, 25, 5167.

Worton, B.J. (1989) Kernel methods for estimating the utilization distribution in homerange studies. Ecology, 70, 164-168.

Worton, B.J. (1995) Using Monte Carlo simulation to evaluate kernel-based home range estimators. Journal of Wildlife Management, 59, 794-800. 
Original Design:

$2^{2}$ Full Factorial

\begin{tabular}{lcc}
\hline \multicolumn{1}{c}{ Factor } & Bromeliad & Leaf Litter \\
\hline \hline Bromeliads (B) & + & - \\
Leaf Litter (L) & - & + \\
BL & + & + \\
Control (C) & - & - \\
\hline
\end{tabular}

Sex included as Factor:

$2^{3}$ Full Factorial

\begin{tabular}{|c|c|c|c|}
\hline Factor & Bromeliad & Leaf Litter & Sex \\
\hline $\mathrm{B}$ + & + & - & $q$ \\
\hline $\mathrm{B}{ }^{\top}$ & + & - & $\hat{0}$ \\
\hline Lㅇ & - & + & q \\
\hline $\mathrm{L} \sigma^{\lambda}$ & - & + & $\hat{O}$ \\
\hline BLㅇ & + & + & $q$ \\
\hline $\mathrm{BL} \hat{\sigma}$ & + & + & $\hat{\sigma}$ \\
\hline $\mathrm{C} q$ & - & - & $q$ \\
\hline $\mathrm{C}{ }^{\lambda}$ & - & - & $\hat{0}$ \\
\hline
\end{tabular}

Table 3.1 Experimental Design

\begin{tabular}{lccccl}
\hline & Sum of Squares & df & F & P & \\
\hline \hline Bromeliad (B) & 4.508 & 1 & 4.8404 & 0.03020 & $*$ \\
Leaf Litter (L) & 1.252 & 1 & 1.3445 & 0.24911 & \\
Sex & 24.925 & 1 & 26.7625 & $1.26 \mathrm{E}-06$ & $* * *$ \\
B:L & 0.121 & 1 & 0.1300 & 0.71926 & \\
B:Sex & 4.136 & 1 & 4.4415 & 0.03768 & $*$ \\
L:Sex & 0.530 & 1 & 0.5690 & 0.45251 & \\
B:L:Sex & 0.012 & 1 & 0.0128 & 0.91006 & \\
Residuals & 89.408 & 96 & & & \\
\hline
\end{tabular}

(natural log transformed 90\% Kernel Density)

\begin{tabular}{rlccccc} 
& & Estimate & $\mathrm{SE}$ & $\mathrm{T}$ & $\mathrm{P}$ & \\
\cline { 2 - 6 } GLM & (Intercept) & 3.40 & 0.22 & 15.49 & $<2 \mathrm{E}-16$ & $* * *$ \\
& $\mathrm{~B}$ & -0.87 & 0.28 & -3.08 & $2.70 \mathrm{E}-03$ & $* *$ \\
& Sex & -1.56 & 0.32 & -4.90 & $3.70 \mathrm{E}-06$ & $* * *$ \\
& $\mathrm{~B}:$ Sex & 0.92 & 0.40 & 2.32 & 0.02 & $*$ \\
\hline
\end{tabular}

Table 3.2 Home Range Analyses 


\begin{tabular}{llccccc} 
& & Sum of Squares & df & F & P & \\
\cline { 2 - 7 } ANOVA & 5.008 & 1 & 6.8599 & 0.01025 & $*$ \\
& Bromeliad (B) & 0.809 & 1 & 1.1077 & 0.29522 & \\
& Leaf Litter (L) & 20.902 & 1 & 28.6303 & $5.95 \mathrm{E}-07$ & $* * *$ \\
& Sex & 0.012 & 1 & 0.0161 & 0.89920 & \\
& B:L & 4.655 & 1 & 6.3758 & 0.01321 & $*$ \\
& B:Sex & 0.807 & 1 & 1.1055 & 0.29570 & \\
L:Sex & 0.011 & 1 & 0.0147 & 0.90390 & \\
B:L:Sex & 70.086 & 96 & & & \\
Residuals & (natural log transformed 50\% Kernel Density)
\end{tabular}

\begin{tabular}{rlccccc} 
& & Estimate & SE & T & P & \\
\cline { 2 - 7 } GLM & 1.89 & 0.19 & 9.72 & $4.11 \mathrm{E}-16$ & $* * *$ \\
& B & -0.92 & 0.25 & -3.67 & $3.87 \mathrm{E}-04$ & $* * *$ \\
& Sex & -1.52 & 0.28 & -5.37 & $5.11 \mathrm{E}-07$ & $* * *$ \\
& B:Sex & 0.97 & 0.35 & 2.75 & $7.07 \mathrm{E}-03$ & $* *$ \\
\hline
\end{tabular}

Table 3.3 Core Area Analyses

\begin{tabular}{llccc}
\cline { 3 - 5 } & \multicolumn{1}{c}{ Home Range } & Male-Female & Female-Female & Male-Male \\
\cline { 2 - 5 } Overlapping Pairs & 113 & 53 & 49 \\
Home & Mean Overlap & $45.3 \%$ & $32.5 \%$ & $26.2 \%$ \\
Range & Standard Deviation & $35.6 \%$ & $27.0 \%$ & $28.2 \%$ \\
& Standard Error & $0.3 \%$ & $0.3 \%$ & $0.3 \%$ \\
& Variance & $12.7 \%$ & $7.3 \%$ & $8.0 \%$ \\
& Range & $5.1 \%-100 \%$ & $8.7 \%-100 \%$ & $0.1 \%-100 \%$ \\
\hline
\end{tabular}

\begin{tabular}{llccc} 
& \multicolumn{1}{c}{ Core Area } & Male-Female & Female-Female & Male-Male \\
\cline { 2 - 5 } & Overlapping Pairs & 46 & 28 & 12 \\
Core & Mean Overlap & $61.5 \%$ & $38.0 \%$ & $34.0 \%$ \\
Area & Standard Deviation & $35.9 \%$ & $26.0 \%$ & $28.3 \%$ \\
& Standard Error & $7.8 \%$ & $4.6 \%$ & $1.2 \%$ \\
& Variance & $12.9 \%$ & $6.8 \%$ & $8.0 \%$ \\
& Range & $2.1 \%-100 \%$ & $1.8 \%-100 \%$ & $0.1 \%-100 \%$ \\
\hline
\end{tabular}

Table 3.4 Home Range and Core Area Overlap 


\begin{tabular}{|c|c|c|c|c|c|c|c|}
\hline \multirow{10}{*}{ ANOVA } & & \multicolumn{2}{|c|}{ Sum of Squares } & $\mathrm{df}$ & $\mathrm{F}$ & \multicolumn{2}{|l|}{$\mathrm{P}$} \\
\hline & Bromeliad (B) & \multicolumn{2}{|c|}{0.0399} & 1 & 1.0307 & 0.312549 & \\
\hline & Leaf Litter (L) & \multicolumn{2}{|c|}{0.1067} & 1 & 2.7533 & 0.100319 & \\
\hline & Sex & \multicolumn{2}{|c|}{0.2884} & 1 & 7.4443 & 0.007569 & $* *$ \\
\hline & $\mathrm{B}: \mathrm{L}$ & \multicolumn{2}{|c|}{0.0171} & 1 & 0.4426 & 0.507487 & \\
\hline & B:Sex & \multicolumn{2}{|c|}{0.0864} & 1 & 2.2290 & 0.138720 & \\
\hline & L:Sex & \multicolumn{2}{|c|}{0.1231} & 1 & 3.1771 & 0.077837 & . \\
\hline & B:L:Sex & \multicolumn{2}{|c|}{0.0031} & 1 & 0.0808 & 0.776865 & \\
\hline & Residuals & \multicolumn{2}{|c|}{3.7198} & 96 & & & \\
\hline & & \multicolumn{6}{|c|}{ (square-transformed) } \\
\hline & & Estimate & $\mathrm{SE}$ & & $\Gamma$ & $\mathrm{P}$ & \\
\hline & (Intercept) & 0.42 & 0.04 & & 85 & $<2 \mathrm{E}-16$ & $* * *$ \\
\hline \multirow[t]{3}{*}{ GLM } & Sex & -0.03 & 0.06 & & 54 & 0.59 & \\
\hline & $\mathrm{L}$ & 0.02 & 0.06 & & 32 & 0.75 & \\
\hline & $\mathrm{L}: \mathrm{Sex}$ & -0.15 & 0.08 & & 97 & 0.05 & . \\
\hline
\end{tabular}

Table 3.5 Biological Index of Vagility Analyses

\begin{tabular}{|c|c|}
\hline Animal 1 & Animal 2 \\
\hline 3 & $\mathrm{BIV}=3 /(12-1)=0.273$
\end{tabular}

Figure 3.1 Example of the Biological Index of Vagility 


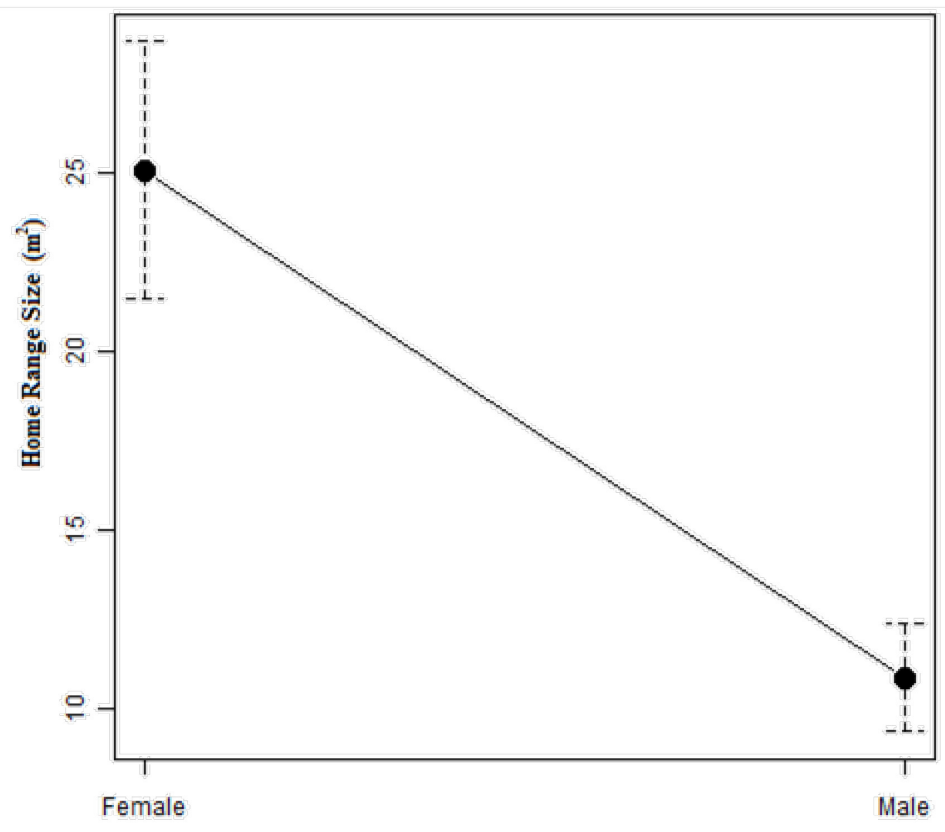

Group means of kernel estimated home range size by sex of frog (bars indicate standard error). Home range size of female frogs was significantly larger than home range size of male frogs.

Figure 3.2 Home range by sex

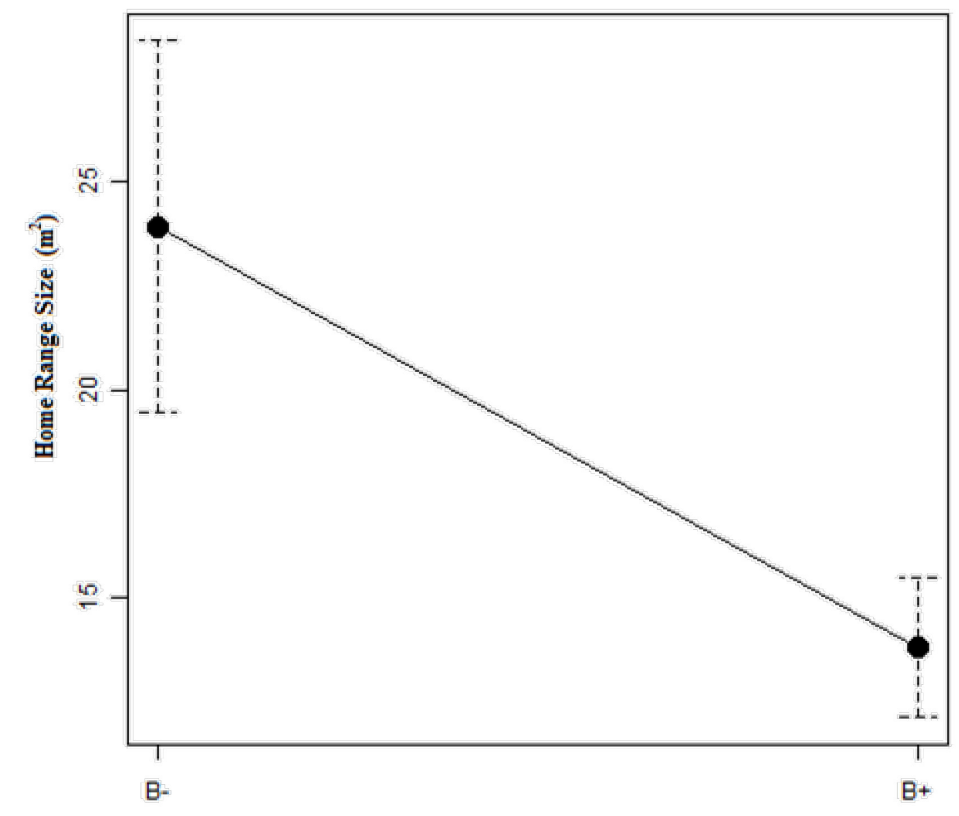

Group means of kernel estimated home range size by bromeliad treatment (bars indicate standard error). Home range size decreased significantly with bromeliad addition.

Figure 3.3 Home range by bromeliad treatment 


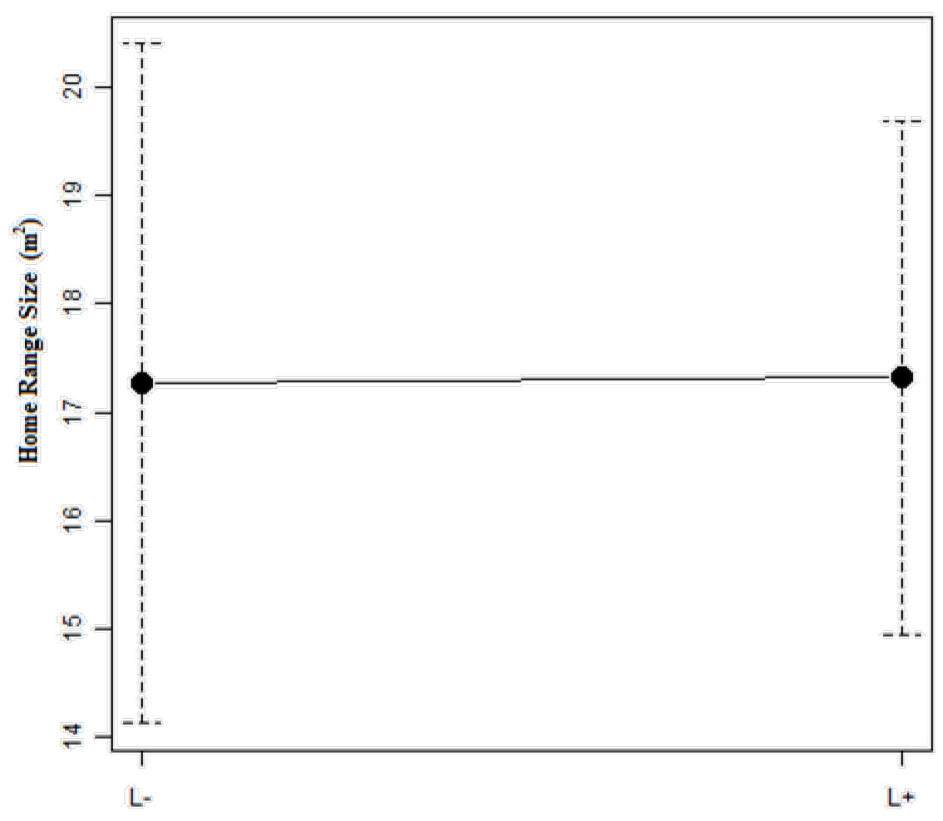

Group means of kernel estimated home range size by leaf litter treatment (bars indicate standard error). Home range size remained largely unchanged with leaf litter addition.

Figure 3.4 Home range by leaf litter treatment

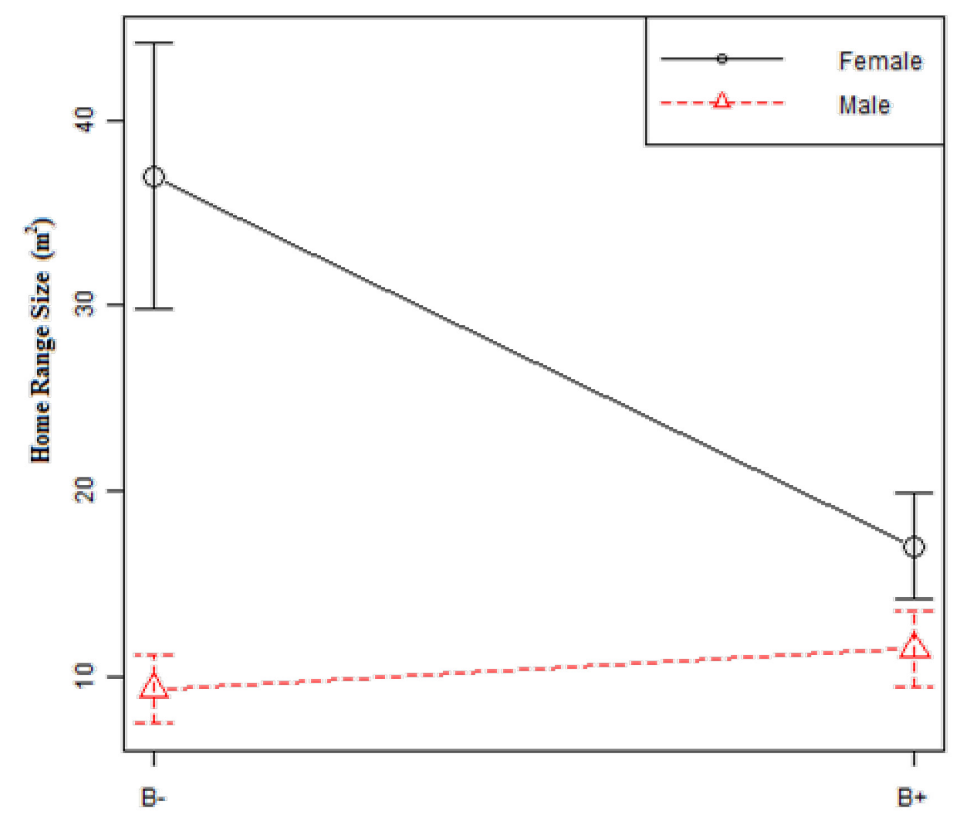

Group means of kernel estimated home range size by bromeliad treatment and sex interactions (bars indicate standard error). Home range size of female frogs decreased significantly with bromeliad addition, while home range size of male frogs increased.

Figure 3.5 Home range by bromeliad and sex interactions 


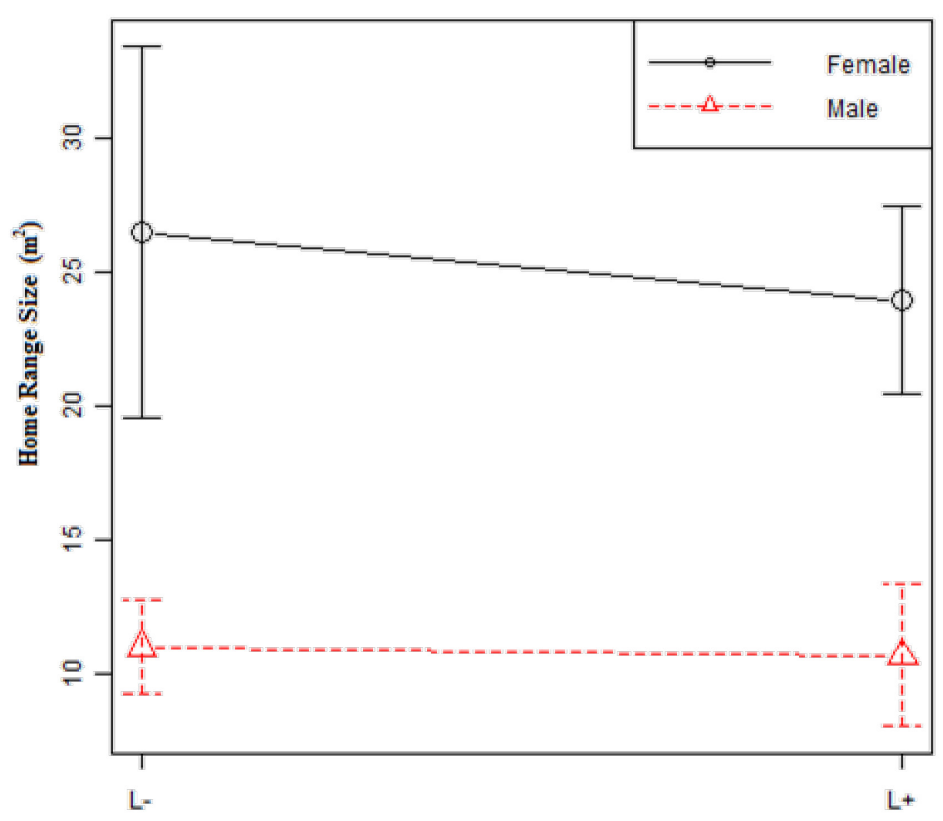

Group means of kernel estimated home range size by leaf litter treatment and sex interactions (bars indicate standard error). Home range sizes of both sexes were not affected significantly by addition of leaf litter.

Figure 3.6 Home range by leaf litter and sex interactions

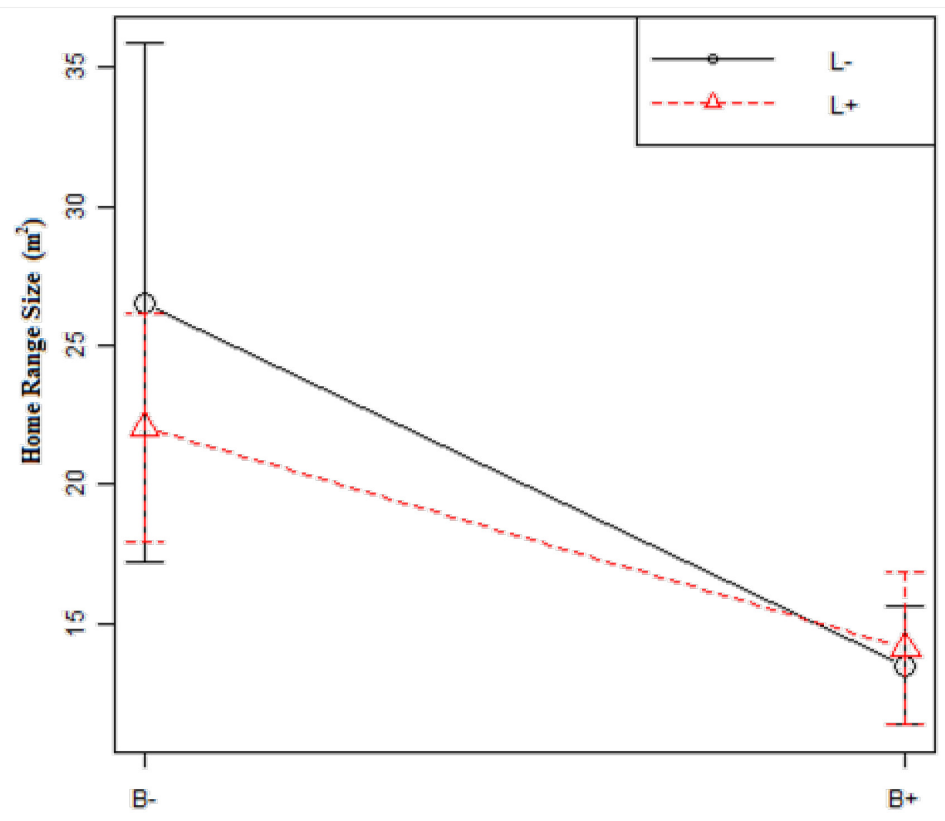

Group means of kernel estimated home range size by bromeliad and litter treatment interactions (bars indicate standard error). Home range size decreased regardless of the litter treatment when bromeliads were added.

Figure 3.7 Home range by bromeliad and leaf litter interactions 


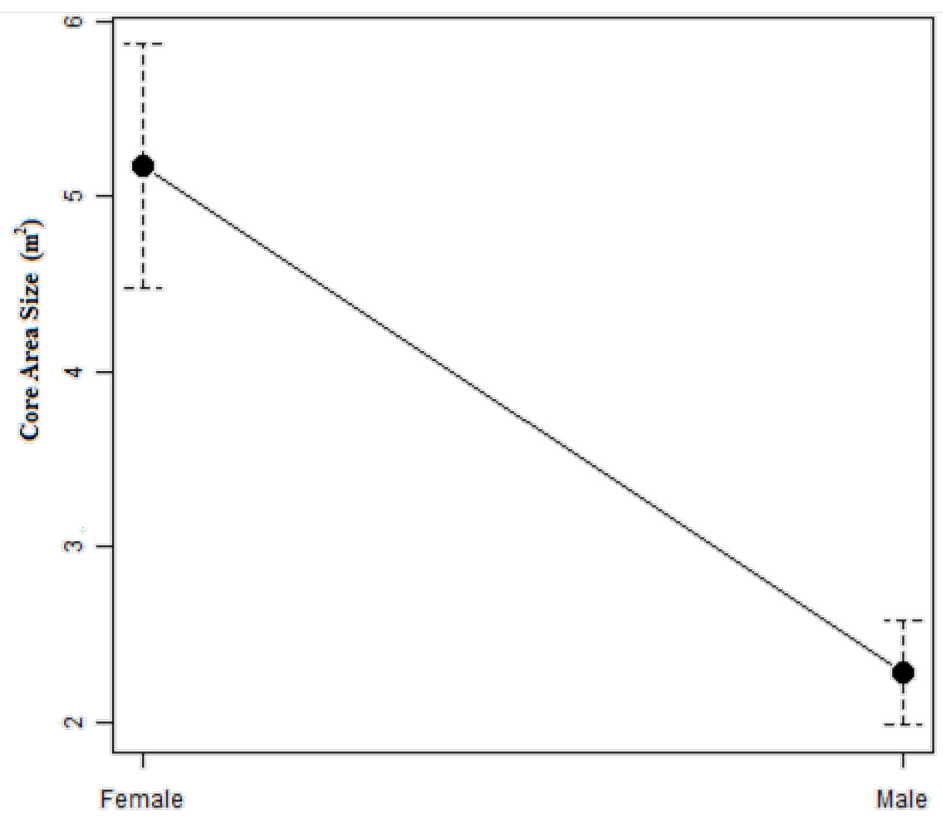

Group means of kernel estimated core area size by sex of frog (bars indicate standard error). Core area size of female frogs was significantly larger than core area size of male frogs.

Figure 3.8 Core area by sex

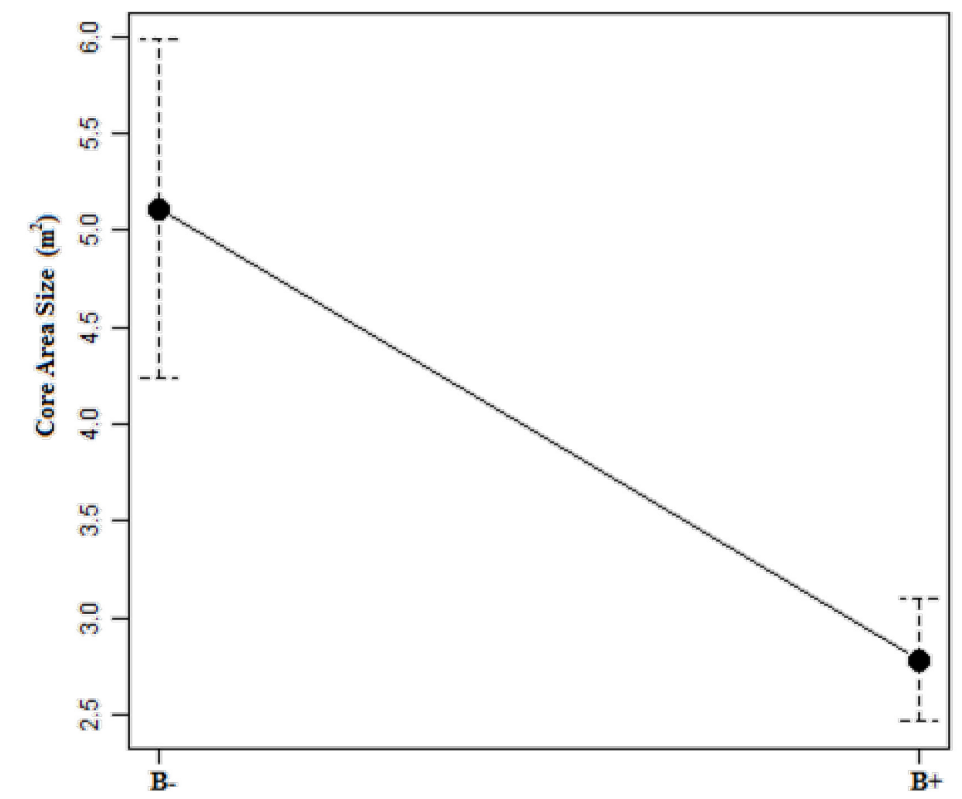

Group means of kernel estimated core area size by bromeliad treatment (bars indicate standard error). Core area size decreased significantly with bromeliad addition.

Figure 3.9 Core area by bromeliad treatment 


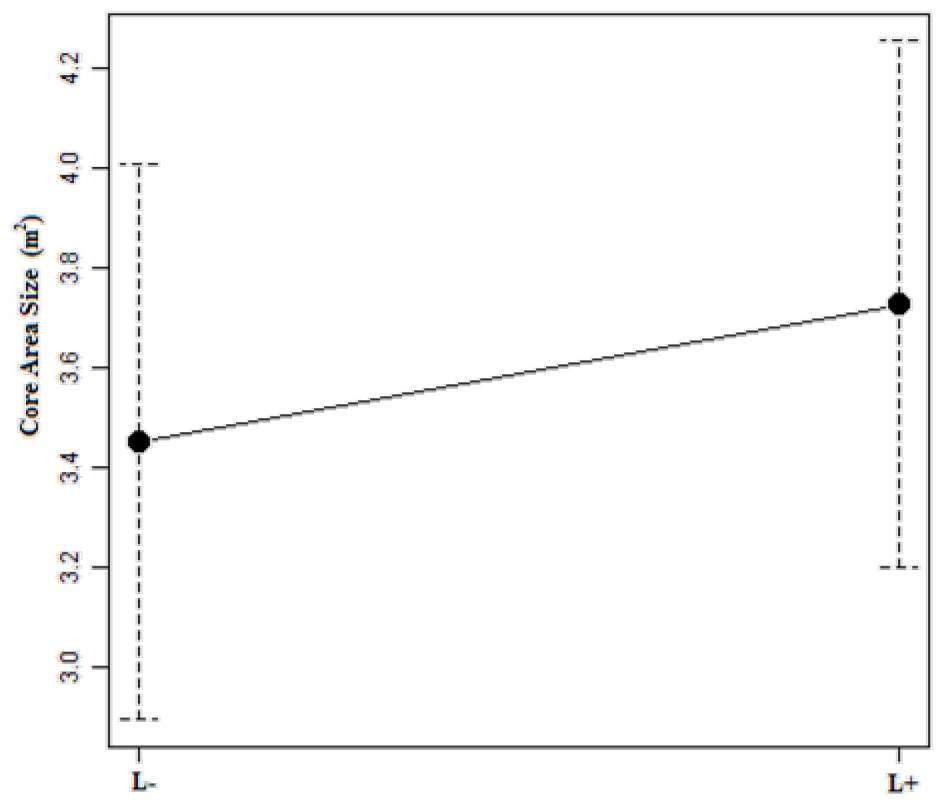

Group means of kernel estimated core area size by leaf litter treatment (bars indicate standard error). Core area size remained largely unchanged with leaf litter addition.

Figure 3.10 Core area by leaf litter treatment

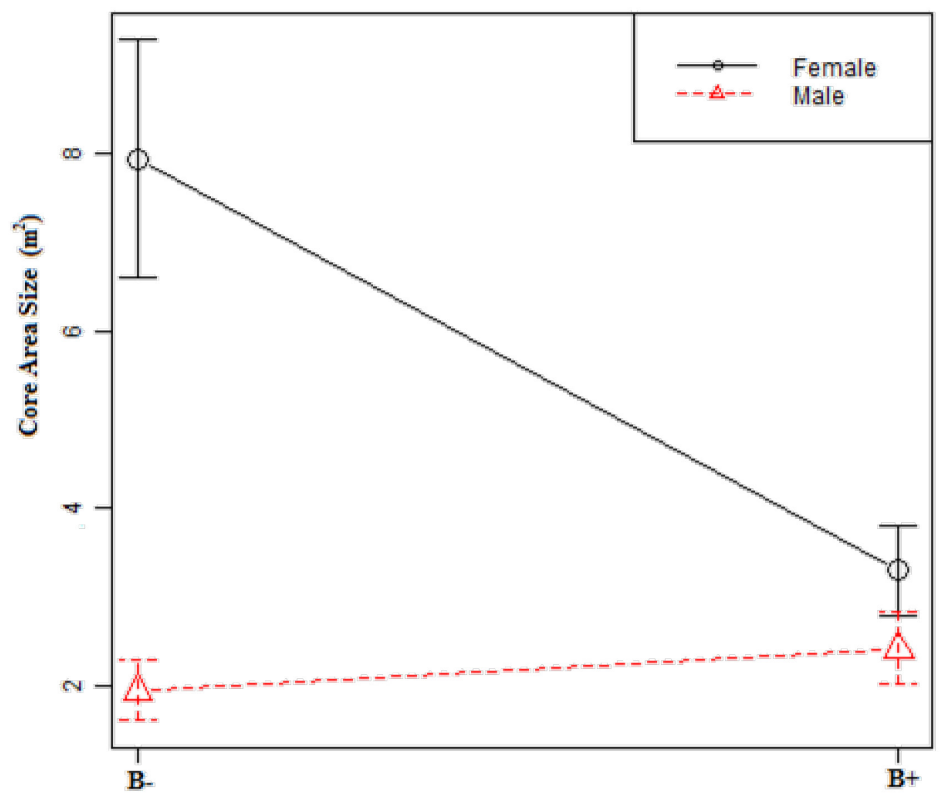

Group means of kernel estimated core area size by bromeliad treatment and sex interactions (bars indicate standard error). Core area size of female frogs decreased significantly with bromeliad addition, while core area size of male frogs increased.

Figure 3.11 Core area by bromeliad and sex interactions 


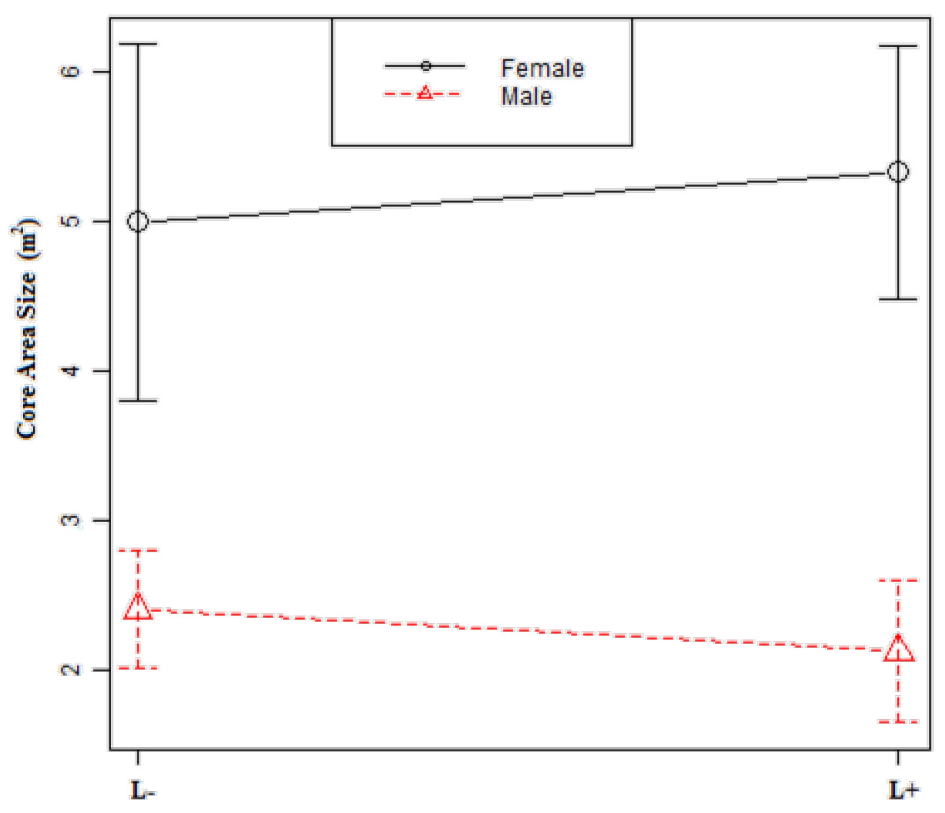

Group means of kernel estimated core area size by leaf litter treatment and sex interactions (bars indicate standard error). Core area sizes of both sexes were not affected significantly by addition of leaf litter.

Figure 3.12 Core area by leaf litter and sex interactions

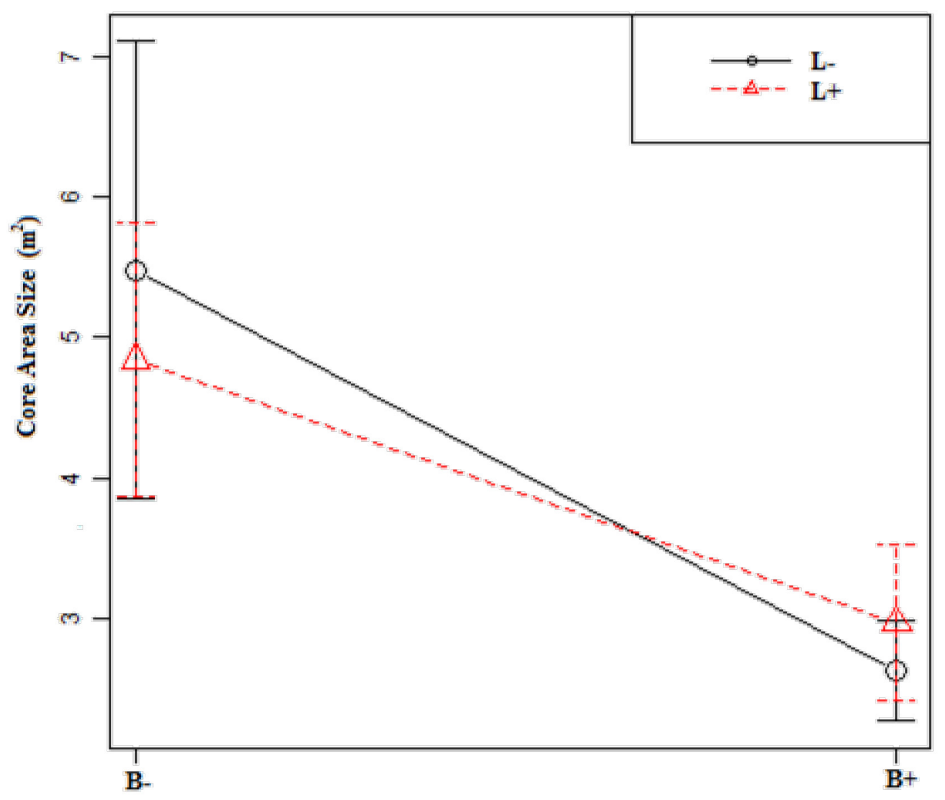

Group means of kernel estimated core area size by bromeliad and litter treatment interactions (bars indicate standard error). Core area size decreased regardless of the litter treatment when bromeliads were added.

Figure 3.13 Core area by bromeliad and leaf litter interactions 


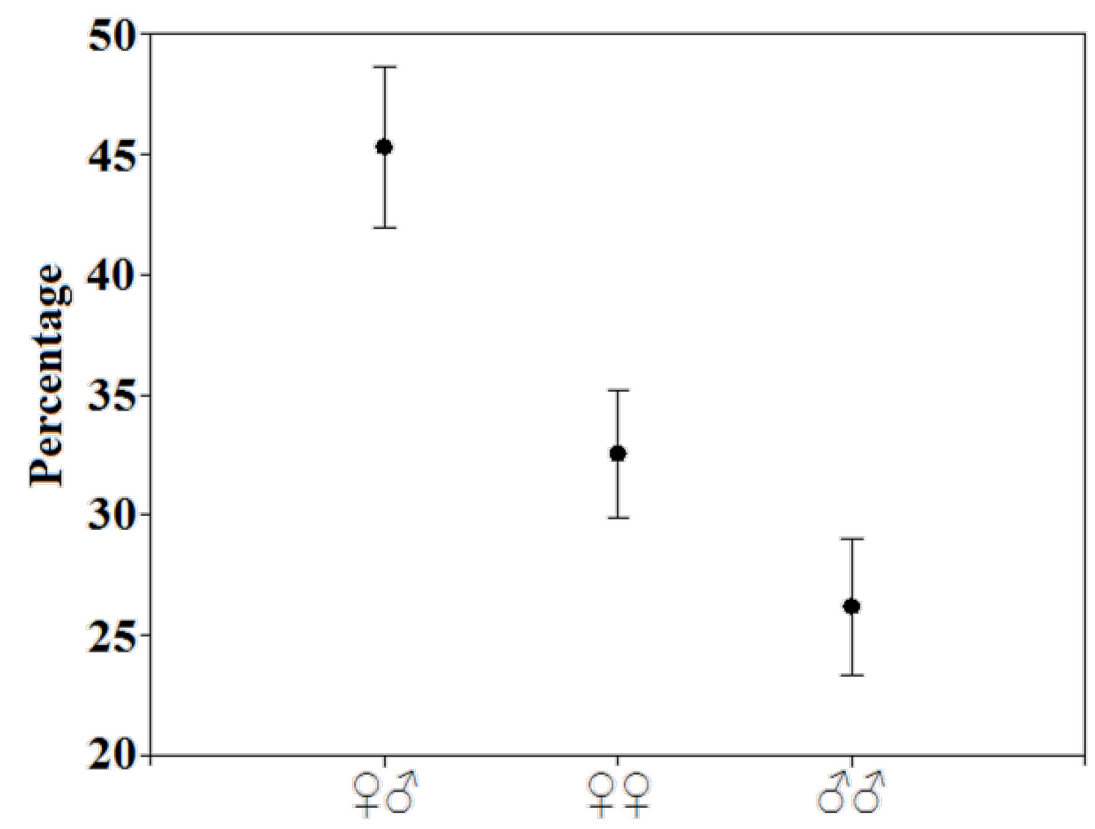

Group means of home range overlap percentage by sex interactions (bars indicate standard error). All group means were significantly different. Male-Female overlap was highest, followed by Female-Female overlap and Male-Male overlap.

Figure 3.14 Home range overlap by sex interactions

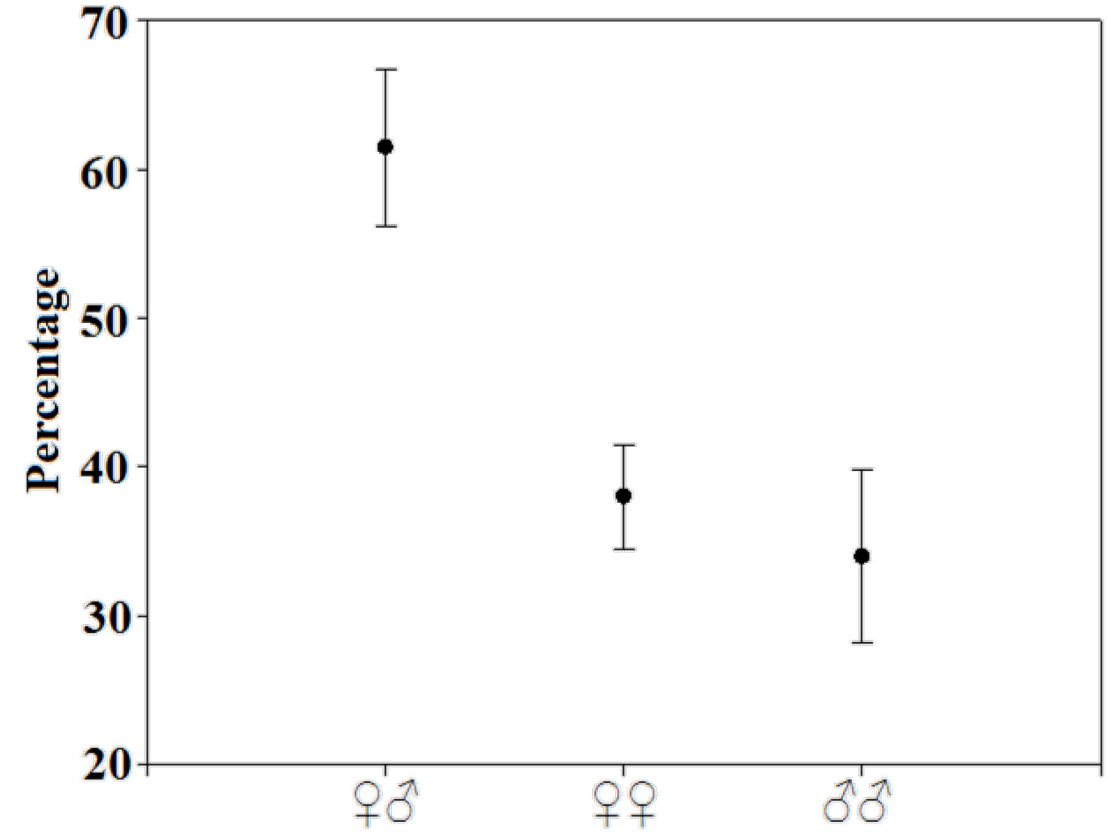

Group means of core area overlap percentage by sex interactions (bars indicate standard error). Male-Female overlap was significantly higher than both Female-Female overlap and Male-Male overlap, which were not significantly different.

Figure 3.15 Core area overlap by sex interactions 


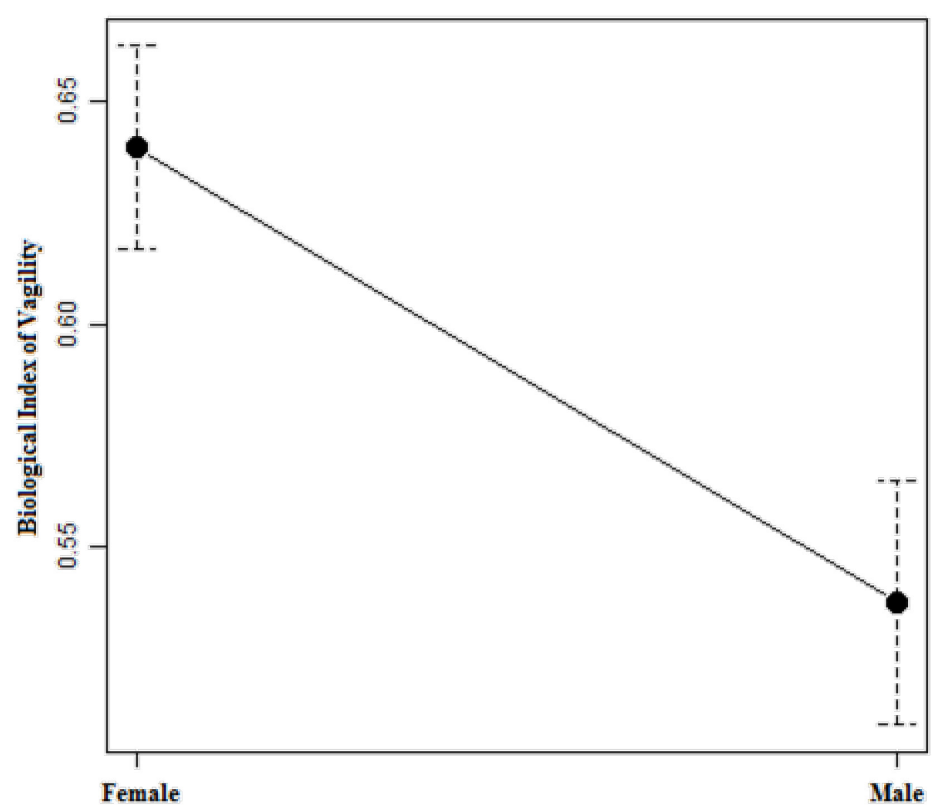

Group means of Biological Index of Vagility values by sex of frog (bars indicate standard error). Biological Index of Vagility values of female frogs were significantly larger than Biological Index of Vagility values of male frogs.

Figure 3.16 Biological Index of Vagility scores by sex

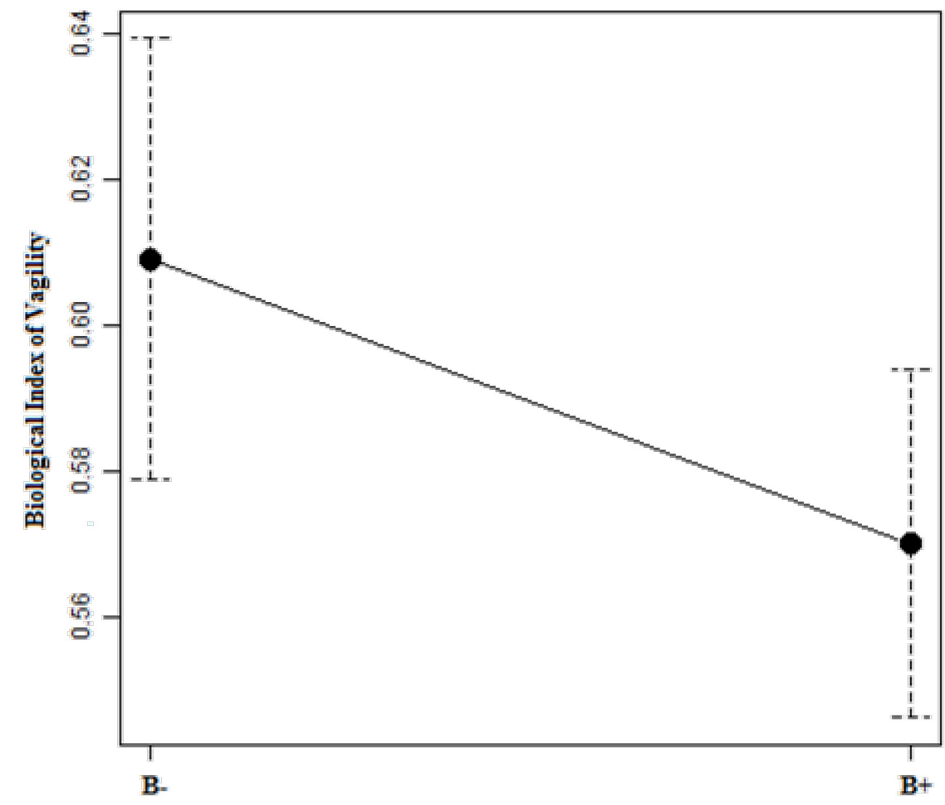

Group means of Biological Index of Vagility values by bromeliad treatment (bars indicate standard error). Biological Index of Vagility values decreased (nonsignificantly) with bromeliad addition.

Figure 3.17 Biological Index of Vagility scores by bromeliad treatment 


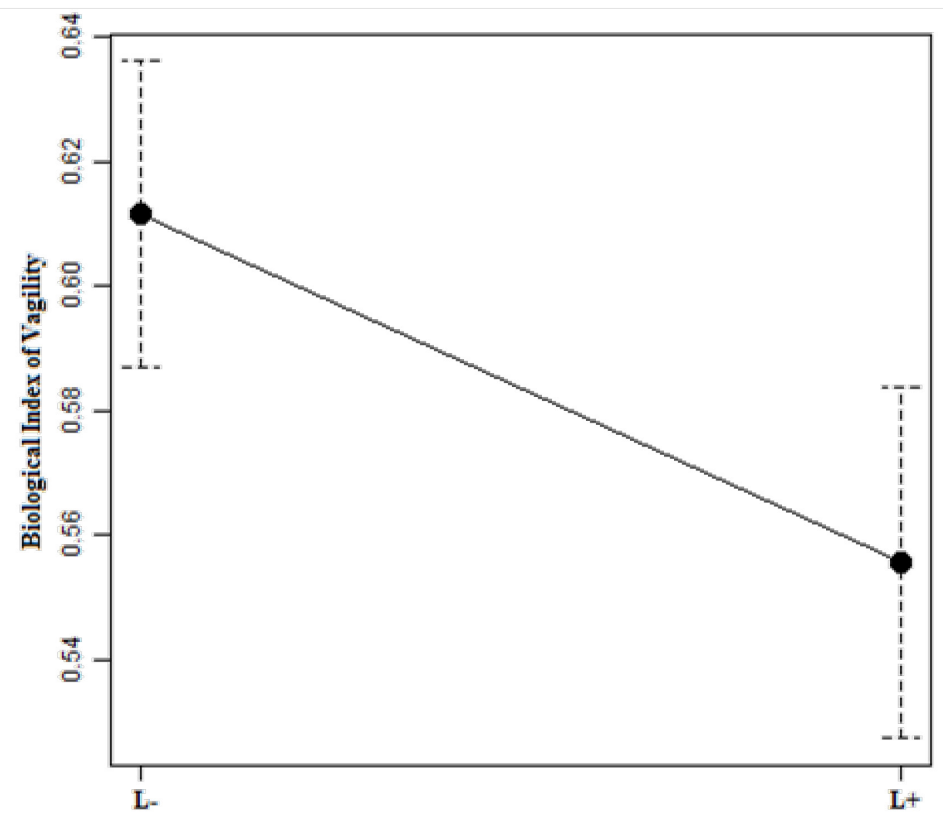

Group means of Biological Index of Vagility values by leaf litter treatment (bars indicate standard error). Biological Index of Vagility values decreased (non-significantly) with leaf litter addition.

Figure 3.18 Biological Index of Vagility scores by leaf litter treatment

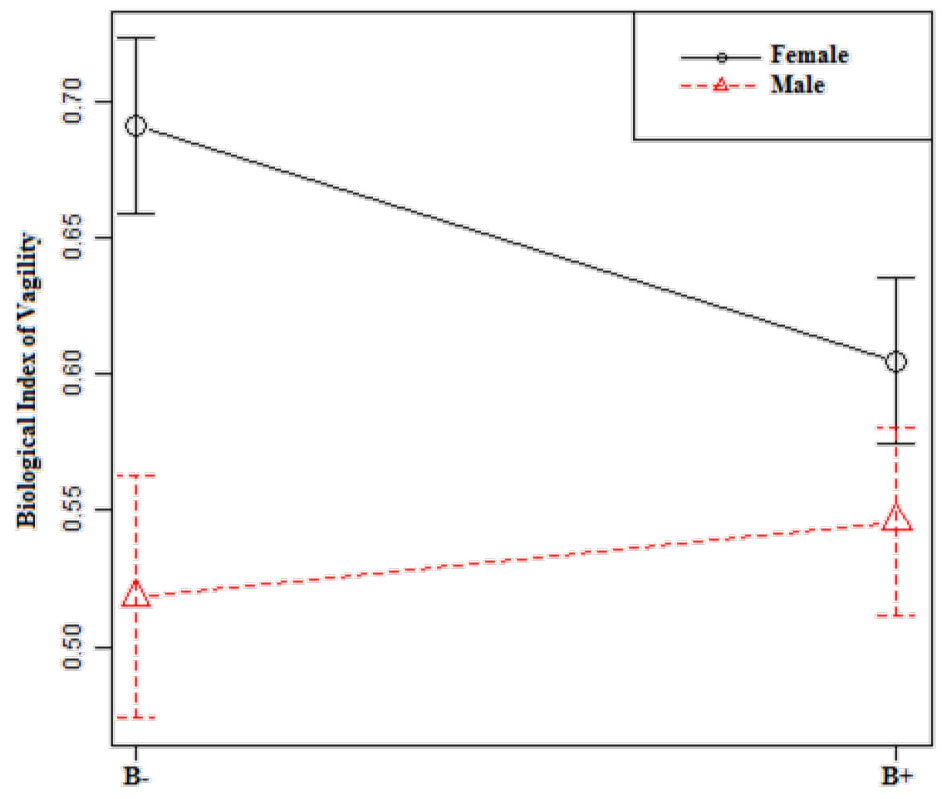

Group means of Biological Index of Vagility values by bromeliad treatment and sex interactions (bars indicate standard error). Biological Index of Vagility values of female frogs decreased (borderline non-significantly, $\mathrm{p}=0.0597$ ) with bromeliad addition, while Biological Index of Vagility values of male frogs increased.

Figure 3.19 Biological Index of Vagility scores by bromeliad and sex interactions 


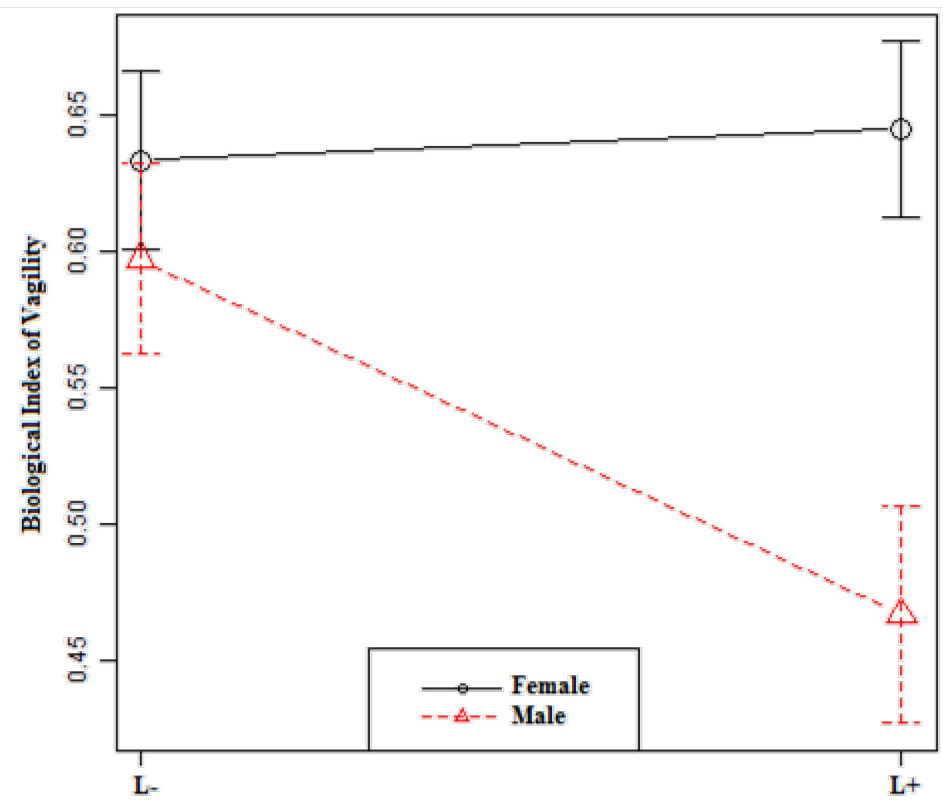

Group means of Biological Index of Vagility values by leaf litter treatment and sex interactions (bars indicate standard error). Biological Index of Vagility values of female frogs were not affected significantly by addition of leaf litter, however, Biological Index of Vagility values of male frogs decreased significantly $(p=0.0146)$.

Figure 3.20 Biological Index of Vagility scores by leaf litter and sex interactions

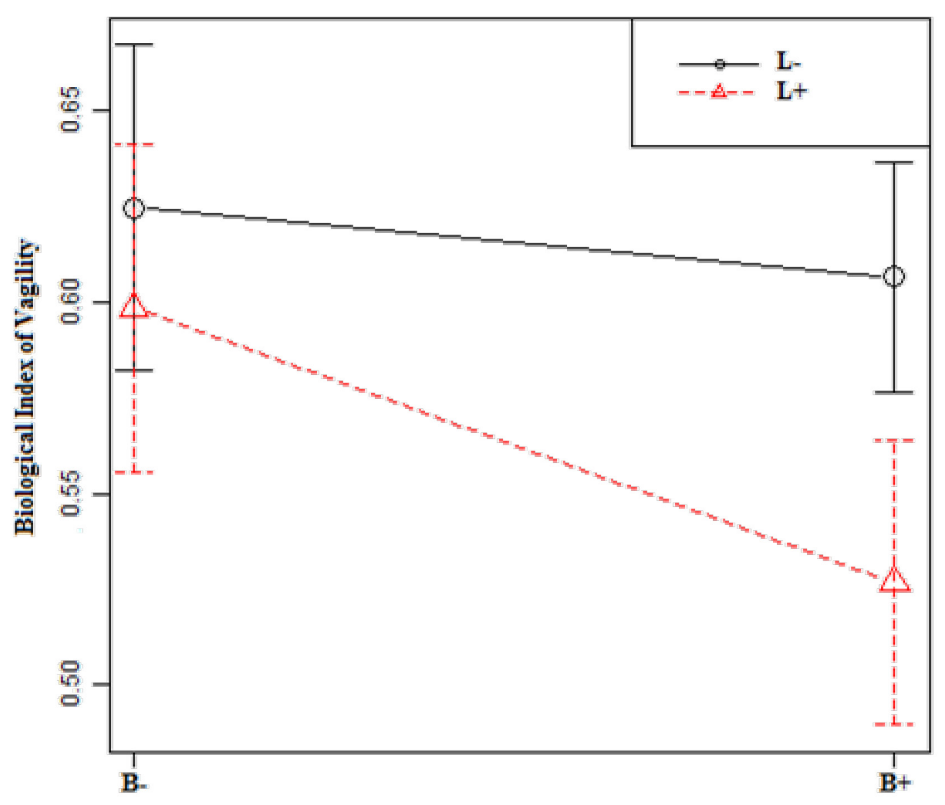

Group means of Biological Index of Vagility values by bromeliad and litter treatment interactions (bars indicate standard error). Biological Index of Vagility values decreased slightly, regardless of the litter treatment when bromeliads were added.

Figure 3.21 Biological Index of Vagility scores by bromeliad and leaf litter interactions 


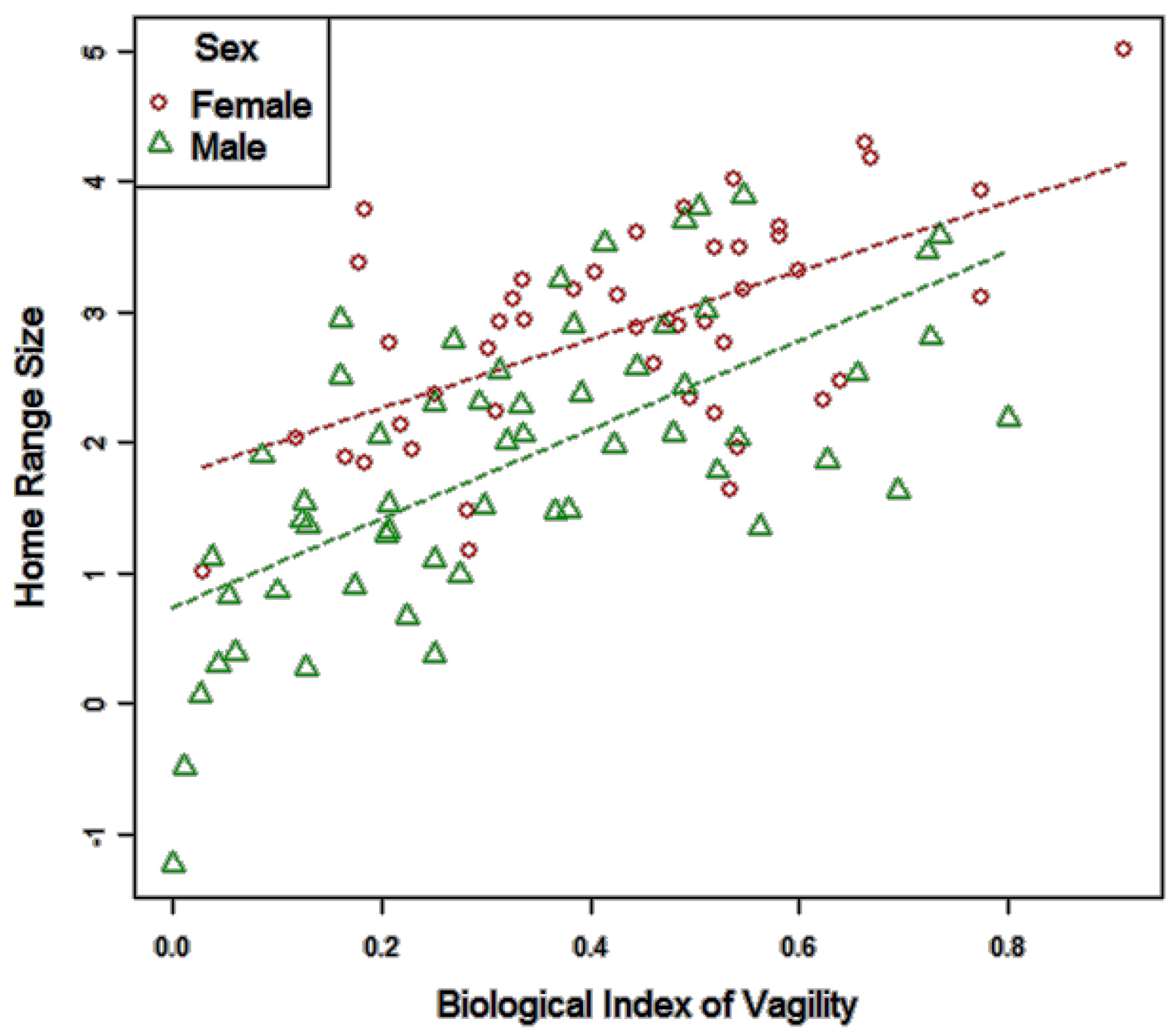

Biological Index of Vagility Scores (square-transformed) by $90 \%$ Kernel Estimated Home Range Size (natural log transformed). (Males $\mathrm{R}^{2}=0.2746, \mathrm{P}<0.001$; Females $\mathrm{R}^{2}$ $=0.3485, \mathrm{P}<0.001)$

Figure 3.22 Biological Index of Vagility scores by home range size 
CHAPTER IV

CONCLUSIONS 


\section{Home Range Size}

To understand the ecological and behavioral processes driving animal movement and space use, it is necessary to first measure the size of the home range of an animal. Determining the appropriate method to estimate this measurement can be problematic because home range features vary widely among and within taxa. In particular, the use of an unsuitable estimator may bias measurements. Unfortunately, it is impossible to truly know the exact home range size, and few studies have investigated the utility of common home range estimators at the scale of very small-bodied animals (e.g., amphibians).

Given that amphibians are globally the most threatened group of vertebrates (Houlahan et al. 2001, Stuart et al. 2004), information on the home range size is critical for making educated conservation decisions (e.g., reserve size). Because methods of estimating home ranges may perform differently for amphibians than for other vertebrate groups, one aim in the present study was to evaluate common estimators of home range size in relation to small animals with presumably small home range size. In chapter two, I tested three current home range estimation methods using simulations of small sample sizes and small spatial scales. Additionally, I used empirical field data to calculate the home ranges of 104 adult Strawberry Poison Frogs (Oophaga pumilio) in a demonstration of the area estimation trends of the tested methods.

Methods of estimating home range sizes produced significantly different values of home range size in simulations. In all simulations, all methods except for $90 \%$ kernel estimators generated home range size estimates that were significantly different from the actual home range sizes. The Minimum Convex Polygon (MCP) method underestimated, and the Bivariate Normal method overestimated, home range size in all simulations. 
Furthermore, the commonly used $95 \%$ kernel estimator always overestimated home range size by at least $10 \%$. Although Worton (1995) recommends reducing the bandwidth to between $50 \%$ and $80 \%$ to correct for the positive bias in $95 \%$ kernels, the $90 \%$ kernel estimator, using LSCV to select the smoothing parameter, is robust even at small sample sizes and generated relatively accurate home range size estimates. Low accuracy and high variance would likely make the MCP method an unsuitable method in studies with small sample sizes or at small scales.

These findings concur with some studies (e.g., Burgman \& Fox 2003, Börger et al. 2006, Nilsen et al. 2008) that MCP should be avoided because of unpredictable bias, but are in sharp contrast to several recent studies that claim the MCP method is more accurate than kernel estimators (e.g., Row \& Blouin-Demers 2006, Boyle et al. 2009) and have large implications: many studies may be irrelevant if inappropriate methods were used to estimate area required for conservation purposes, research purposes, etc. The differences between these studies and the present study are likely based on speciesspecific ecology; the frogs in the present study restrict movement to within relatively small home ranges compared to highly motile animals such as snakes and monkeys. Furthermore, location sample sizes in these studies were much larger as a result of GPS and telemetry technology, unavailable in studies of very small animals.

Kernels using the computationally less expensive ad hoc bandwidth selector produced less accurate, but similar home range estimates to kernel estimates using LSCV-selected bandwidths, indicating substitutability for rapid comparisons or when LSCV fails (i.e., when location data include many identical coordinates). 
The "ideal average individual" approach of the Population Utilization Distribution method produced significantly smaller estimates with much smaller variance than estimates in the present study. These values are based on relocation distances and may be inappropriate for use in estimating home range size but might find utility in estimating areas of concentrated activity (i.e., core areas).

The results of chapter two indicate that $90 \%$ kernels using LSCV to select bandwidth may provide the most accurate and precise estimates, whereas traditional methods of estimating home range size (e.g., Minimum Convex Polygon, Bivariate Normal, and the $95 \%$ kernel methods) may generate erroneous home range estimates for studies involving small vertebrates and/or limited location data.

\section{Intersexual Space Use and Movement Patterns}

Following home range size estimation, patterns of movement (i.e., vagility) and space use (i.e., core areas of intense use) within the home range must then be identified and analyzed to extract information such as essential resources and interactions with other animals. To avoid obscuring biologically relevant information, analyses of space use and movement patterns should be made after identifying and isolating different groups within a population. These groups may be based on such factors as: age, sex, reproductive status, etc. In chapter three, I investigated differences in rates of movement and various space use aspects between the two sexes of $O$. pumilio.

Home range size, core area size, intrasexual overlap, and movement rates among coordinates were higher in female frogs than in male frogs. Home range sizes for female frogs also had higher variance. These measures likely reflect behavioral differences; 
sexually responsive female frogs sample among territory-holding male frogs and the extensive use of space in tadpole-rearing females is linked to uneven parental care.

As with the present study, many recent studies have found that in many frog species, females use more space than males (e.g., Muths 2003, Bartelt et al. 2004, Johnson et al. 2007). Habitat (i.e., usable space) loss is directly related to the many of the threats leading to global population declines (Houlahan \& Findlay 2003). Because adequate habitat area is essential in maintaining healthy amphibian communities (Guerry \& Hunter 2002), the common practice of developing protected areas for only the most sedentary frogs (Fellers \& Kleeman 2007) may have disproportionately large negative impacts on amphibian populations unless conservation decisions include the requirements of the greatest consumers of space (e.g., females, dispersing juveniles, etc.)

Home range and core area overlap occurred most in both quantity and intensity (i.e., percent overlap) between opposite-sex pairs, and home ranges of female frogs often overlapped the core areas and home ranges of multiple male frogs. Space use overlap of opposite-sex pairs would logically result from courtship and breeding. The prevalence of female space use overlapping multiple male home ranges provides evidence that female O. pumilio demonstrate sexual selection. Overlap among males may be associated with territory disputes or takeovers.

Female and male frogs reacted differently to resource supplementation. Although leaf litter supplementation did not affect the home range or core area size of either sex, bromeliad addition had a significant effect on home range and core area size. Home ranges of female frogs decreased in size in response to bromeliad additions, whereas the home ranges of male frogs increased in size. The decrease in female frog home range 
size on bromeliad addition plots may reflect a reduction in the need to locate tadpoledeposition sites. Reduced home range size with bromeliad addition suggests that bromeliads are the limiting reproductive resource. Additionally, it supports territorial behavior in tadpole-rearing female frogs reported by Haase and Pröhl (2002). Larger home range sizes of male frogs may be associated with an adjustment of territory borders to compensate for increased benefits of defending more resources following an increase in the density of the limiting reproductive resource (Adams 2001).

The simple Biological Index of Vagility (BIV) generated movement values that scaled well with home range size while revealing more information than home range estimates alone: male frogs responded to leaf litter supplementation by reducing rates of movement. No difference in movement rates was seen in female frogs. Male O. pumilio likely demonstrate a "sit-and-eat" mode of foraging (Donnelly 1991) while female frogs, occupied with tadpole rearing, would need to forage opportunistically. The reduction in movement of male frogs was likely associated with an increase in arthropod prey item abundance with the increase of prey item habitat: leaf litter. 


\section{REFERENCES}

Adams, E.S. (2001) Approaches to the study of territory size and shape. Annual Review of Ecology and Systematics, 32, 277-303.

Bartelt, P.E., Peterson, C.R. \&Klaver, R.W. (2004) Sexual differences in the postbreeding movements and habitats selected by western toads (Bufo boreas) in southeastern Idaho. Herpetologica 60, 455-467.

Börg er, L., Franconi, N., de Michele, G., Gantz, A., Meschi, F., Manica, A., Lovari, S., \& Coulson, T. (2006) Effects of sampling regime on the mean and variance of home range size estimates. Journal of Animal Ecology, 75, 1393-1405.

Boyle, S.A., Lourenco, W.C., da Silva, L.R., \& Smith, A.T. (2009) Home range estimates vary with sample size and methods. Folia Primatologica, 80, 33-42.

Burgman, M.A. \& Fox, J.C. (2003) Bias in species range estimates from minimum convex polygons: implications for conservation and options for improved planning. Animal Conservation, 6, 19-28.

Donnelly, M.A. (1991) Feeding Patterns of the Strawberry Poison Frog, Dendrobates pumilio (Anura: Dendrobatidae). Copeia, 1991, 723-730.

Fellers, G.M. \& Kleeman, P.M. (2007) California Red-Legged Frog (Rana draytonii) movement and habitat use: implications for conservation. Journal of Herpetology, 41, 276-286.

Guerry, A.D. \& Hunter Jr., M.L. (2002) Amphibian distributions in a landscape of forests and agriculture: an examination of landscape composition and configuration. Conservation Biology, 16, 745-754.

Haase, A., \& Pröhl, H. (2002) Female activity patterns and aggressiveness in the strawberry poison frog Dendrobates pumilio (Anura: Dendrobatidae). AmphibiaReptilia, 23, 129-140.

Houlahan, J.E., Findlay, C.S., Schmidt, B.R., Meyers, A.H. \& Kuzmin, S.L. (2001) Quantitative evidence for global amphibian population declines. Nature, 404, 752-755.

Houlahan, J.E. \& Findlay, C.S. (2003) The effects of adjacent land use on wetland amphibian species richness and community composition. Canadian Journal of Fisheries and Aquatic Sciences, 60, 1078-1094.

Johnson, J.R., Knouft, J.H. \& Semlitsh, R.D. (2007) Sex and seasonal differences in the spatial terrestrial distribution of gray treefrog (Hyla versicolor) populations. Biological Conservation, 140, 250-258. 
Muths, E. (2003) Home range and movements of boreal toads in undisturbed habitat. Copeia, 2003, 160-165.

Nilsen, E.B., Pedersen, S. \& Linnell, J.D.C. (2008) Can minimum convex polygon home ranges be used to draw biologically meaningful conclusions? Ecological Research, 23, 635-639.

Row, J. \& Blouin-Demers, G. (2006) Kernels are not accurate estimators of home-range size for herpetofauna. Copeia, 2006, 797-802.

Stuart, S.N., Chanson, J.S., Cox, N.A., Young, B.E., Rodrigues, A.S.L., Fischman, D.L., $\&$ Waller, R.W. (2004) Status and trends of amphibian declines and extinctions worldwide. Science, 306, 1783-1786.

Worton, B.J. (1995) Using Monte Carlo simulation to evaluate kernel-based home range estimators. Journal of Wildlife Management, 59, 794-800. 